\title{
LA VILLA GALLO-ROMAINE DE SAINT-MICHEL À LA GARDE (VAR) UN DOMAINE OLÉICOLE AU HAUT-EMPIRE
}

Texte, plans et coupes : Jean-Pierre Brun

Direction des recherches : Marc GÉRARD $\dagger$

Équipe de fouille: Jacques et Nicole Bérato, Isabelle Béraud, Brigitte Bonavita, Michel Bonifay, Pascale Durieux, Louis Imbert, Pascal Lecacheur, Michel Pasqualini, Pierre Saliceti, Jacques Vanel

Étude des monnaies: Georges B. Rogers

Étude de la faune : Philippe Columeau, CNRS, Centre Camille Jullian

Etude des charbons: Michel Thinon, GNRS

Dessins : Isabelle Béraud, Jean-Louis Fechino

Axonométries : Jean-Marie Gassend, IRAA, CNRS (fig. 16 et 17)

7. A l'est de Toulon, la villa gallo-romaine de La Garde a été fondée dans la seconde moitié du $\mathrm{I}^{\mathrm{er}} \mathrm{s}$. avant J.-C. et 2 connu un développement progressif marqué notamment par la construction de plusieurs huileries sucorssives au $\mathrm{I}^{\text {er }} \mathrm{s}$. de notre ère. Le principal intérêt de la fouille réside dans la mise au jour d'une huilerie domaniale comprenant six pressoirs, édifiée au début du $I^{e} \mathrm{~s}$. sur les vestiges antérieurs. Cette huilerie, la plus gra hde de Gaule, a fonctionné jusqu'au milieu du III $^{\mathrm{e}} \mathrm{s}$. Elle faisait partie d'une vaste villa dont la pars urbana, relâtivement luxueuse a été reconnue partiellement. L'exploitation agricole paraît avoir périclité au ive $s$. et été abandonnée au début du $\mathbf{v}^{\mathrm{e}} \mathrm{s}$.

La publication présente l'évolution des constructions et des installations techniques et dans une seconde partie, l'étude des monnaies, des céramiques, de la faune et des charbons.

Founded in the second half of the Ist century B. C., the gallo-roman villa of La Garde, situated to the east of Toulon, underwent a period of progressive development marked in particular by the construction of several successive oil-presses during the Ist century $A$. D. The most significant result of the excavation, however, has been the uncovering of a domanial oil-mill composed of six presses built at the beginning of the IInd century on the remains of earlier constructions. This oil-mill, the largest in Gaul, was in use up until the middle of the IIIrd century. It formed a part of a vast villa the pars urbana of wich appears to have been relatively luxurious but has been only partially excavated, declined dramatically during the IVth century and ended completely at the beginning of the Vth century.

The publication presents the evolution of the buildings and technical installations, and, in the second part, a study of the coins, pottery, fauna and charcoal.

La villa gallo-romaine de Saint-Michel s'étend sur les terrasses marquant l'extrémité orientale de la colline du Thouar sur la commune de La Garde, voisine de celle de Toulon (Telo Martius) (fig. 1).

Le site était autrefois inclus dans le domaine de Saint-Michel, propriété comprenant un vignoble en plaine, des oliviers, des chênes et des garrigues sur la colline. En 1968, la majeure partie de ces terres fut acquise par l'université de Toulon tandis que le reste était légué à l'évêché de Fréjus-Toulon. Les recherches archéologiques ont été conditionnées par ces mutations foncières et leurs conséquences immobilières. 
Fig. 1 - a, situation de la villa de Saint-Michel ;

b, contexte archéologique de la villa avec les deux possibles cadastrations antiques successives.
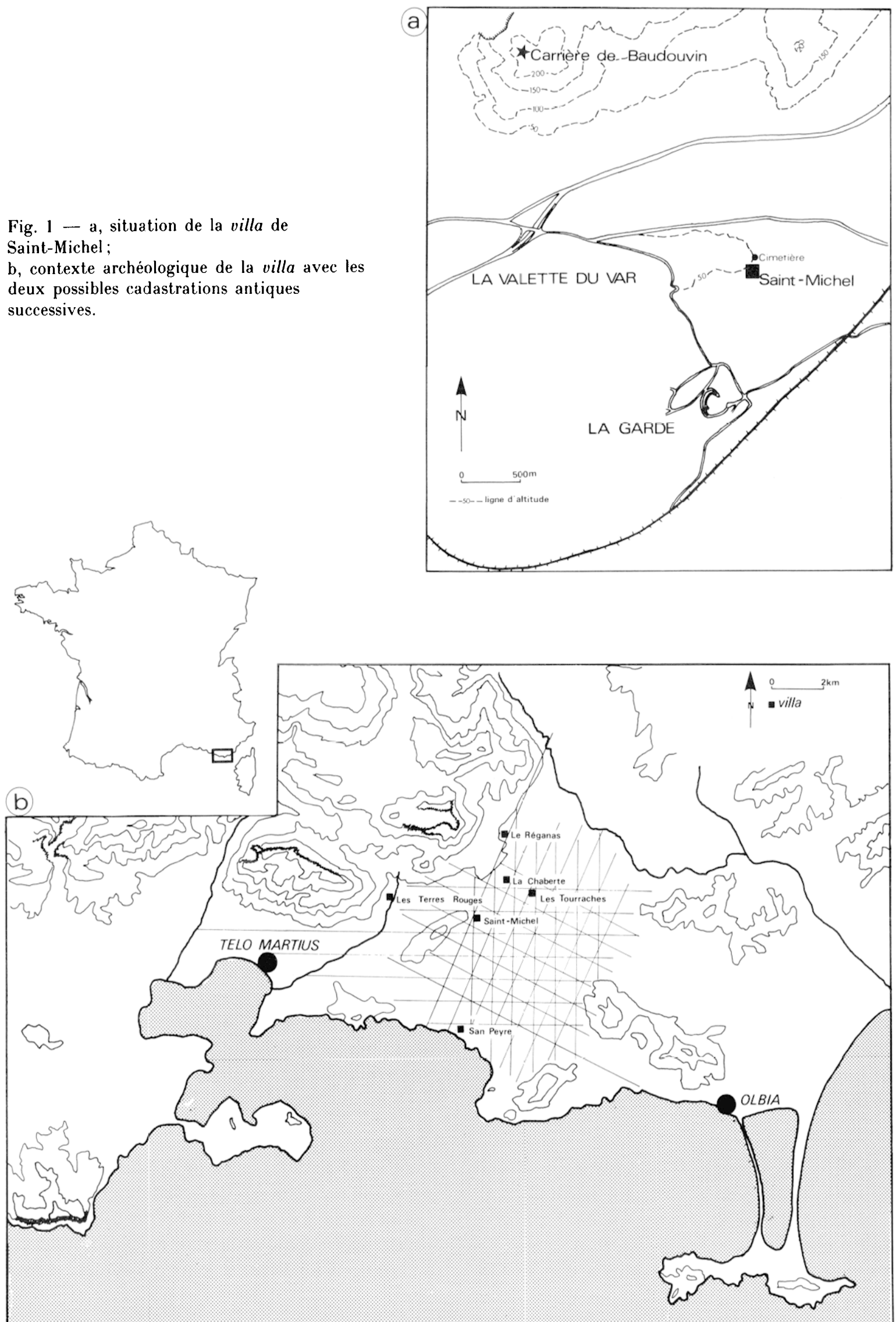


\section{Historique des fouilles}

Le site de la villa avait été signalé en 1885 par Charles Ginoux qui y voyait les ruines d'un village (Ginoux, 1885, p. 36-37). Sur ces indications, André Neyton, professeur au Collège d'enseignement général de La Garde, retrouva le site et commença des prospections et des sondages avec ses élèves. Ces travaux, supervisés par M. Marc Gérard, permirent de mesurer l'extension du site et de dégager une pièce sur hypocauste. En 1969, les premiers travaux de construction de l'IUT de Toulon occasionnèrent la destruction d'un cimetière comprenant une dizaine de tombes sous tuiles à $500 \mathrm{~m}$ au nord des vestiges repérés : seules deux tombes purent être sauvées (Gérard, 1971, p. 54 sq.).

De 1969 à 1974, les travaux, conduits par Marc Gérard, Pierre Saliceti et Jean-Pierre Brun portèrent surtout sur les parties d'habitation. Leur but était de sensibiliser l'administration à la sauvegarde des vestiges. En 1975, grâce à l'action de M. Maurice Delplace, Maire de La Garde, l'université décida d'abandonner aux recherches archéologiques une partie des terrains, sorte de "réserve" comprenant les deux terrasses méridionales et la partie sud du plateau formé par la terrasse supérieure. Il importait dès lors, d'explorer les parties du site non protégées, impératif rendu pressant par l'accélération des constructions universitaires. En 1975, l'université fit construire sans préavis un bâtiment préfabriqué en dessous de l'huilerie détruisant un vaste dépotoir et un bâtiment de forge. Les travaux archéologiques de 1975 et 1976 délimitèrent un vaste espace formé de cours et de bâtiments abritant des pressoirs et des cuves appartenant à une importante huilerie.

De 1977 à 1979, des crédits de fouilles furent octroyés sur le Fonds d'Intervention pour l'Archéologie de Sauvetage. Trois campagnes de fouilles dirigées par Michel Bonifay, Jean-Pierre Brun, Marc Gérard et Michel Pasqualini permirent de dégager l'huilerie et de comprendre son évolution et son fonctionnement. De façon annexe, la fouille des thermes fut terminée et une zone en bordure du plateau de l'huilerie au sud-est fut explorée ${ }^{1}$.

En 1984 et 1985, une équipe constituée de Jacques et Nicole Bérato, Louis Imbert et Pierre Saliceti a repris des recherches dans cette zone. Le résultat le plus notable réside dans la découverte de plusieurs petites huileries antérieures à celle dégagée en 1977-1979 (Bérato et alii, 1987).

1 Des comptes rendus sommaires de ces travaux ont paru: CDAV, 1979, p. 31-39; Brun el alii, 1981, p. 69-70; Brun, 1986a, p. 160-170.

\section{DONNÉES NaTURELLES}

Le substrat géologique est formé de grès permien, de pélites et d'argile. Le grès, relativement dur, qui affleure en de nombreux endroits du site a servi de matériau de base pour la construction des bâtiments. Sur les pentes et au pied de la colline, on trouve des éboulis et des colluvions récentes contenus par des terrasses de culture modernes.

La plaine qui s'étend au pied du site est formée d'alluvions récentes : cailloutis et limons argileux qui la rendent inondable et marécageuse. Au milieu de la plaine, un "neck" d'andésite, roche éruptive très dure, a été exploité comme carrière à l'époque moderne. Cette roche n'a cependant pas servi à la construction de la villa à la différence du calcaire hettangien de la colline de Baudouvin employé en dalles (couverture d'égout, séparation des pressoirs ... $)^{2}$.

Dans la partie ouest du site, sourdent deux sources qui alimentent le village de La Garde. Les travaux de captage du siècle dernier ont détruit toute trace d'un probable aménagement antique.

Avant les extensions urbaines et industrielles récentes, la plaine de La Garde était presque exclusivement consacrée à la viticulture. Sous l'Ancien Régime, on y cultivait de la vigne, du blé, des oignons réputés et les collines étaient couvertes d'oliviers (Fauchier, 1805, p. 30; Garcin, 1835, p. 513).

\section{Contexte aRChÉologique}

La région toulonnaise, incluse en 46 avant J.-C. dans la civilas d'Arles, paraît avoir été desservie par une voie secondaire, joignant les pistes côtières et surtout les routes maritimes à Forum Voconii et la "voie aurélienne" ${ }^{3}$. Cette voie passant dans la dépression permienne entre les Maures et les massifs calcaires, devait suivre à peu près le tracé de l'actuelle route nationale 97 . La villa de SaintMichel en est située à $1,5 \mathrm{~km}$.

Aucun site archéologique n'est connu à proximité immédiate de la villa. A quelque distance, on trouve d'autres villae dont l'importance reste à déterminer (fig. lb).

2 La colline de Baudouvin, distante de $2,5 \mathrm{~km}$ porte une enceinte occupée aux vie-ve s. avant J.-C. (Borréani, 1984 et CDAV, 1984, p.198-199).

3 Sur les limites des cités d'Arles et de Fréjus, voir Jullian, 1887, p. 5 et en dernier lieu Gascou, Janon, 1985, p. $25 s q$. Sur le réseau des voies, Boyer, Février, 1959, p. 177 et Barruol, 1969, p. 58. 
- Vers le sud, à $3,2 \mathrm{~km}$, au lieu-dit «San Peyre", sur la commune du Pradet, une villa est connue. Construite sur une colline (présence de murs de soutènement), elle possédait une citerne voûtée et devait être ornée de mosaïques (Bonstetten, 1873, p. 37; Ginoux, 1885 , p. 40 ; Lafaye, 1909, p. 5 , $\mathrm{n}^{\circ}$ 18; Blanchet et alii, 1932, p. 84, $\left.\mathrm{n}^{\circ} 65\right)$.

- Vers l'est, à $2,5 \mathrm{~km}$, au lieu-dit «Les Tourraches", des découvertes anciennes et des prospections récentes attestent l'existence d'une villa sur une légère éminence dans la plaine de La Crau. Le site a livré des fragments de béton de tuileau et d'enduits peints ainsi que des tessons de sigillées sud-gauloise, africaine $\mathrm{A}$ et $\mathrm{D}$ et paléochrétienne qui indiquent une occupation assez longue (Ginoux, 1885, p. 37; Gérard, Joubert, 1968, p. 35; CDAV, 1982, p. 41, $\left.\mathrm{n}^{\circ} 1\right)$.

- Vers le nord-est, à environ $2,5 \mathrm{~km}$, au lieudit "La Chaberte", commune de La Garde, des photographies aériennes ont révélé une villa dont les bâtiments, couvrant 1 ha environ, s'ordonnaient autour d'une vaste cour. Des prospections récentes ont recueilli des tuiles et des fragments de sigillée mais la majeure partie du site a été recouverte par l'autoroute C52 et par un dépôt de matériaux.

- Vers le nord-est, au nord du site précédent, au lieu-dit "Le Règanas», commune de La Farlède, une villa s'étendait sur les dernières pentes du Coudon. Sa pars urbana était décorée de marbres et de peintures. La pars rustica possédait un pressoir. Les céramiques indiquent une occupation aux $\mathrm{I}^{\mathrm{er}}, \mathrm{II}^{\circ}$ et IV $^{\mathrm{e}} \mathrm{s}$. après J.-G. (sigillées italiques, gauloises et claires D) (Brun, 1986a, p. 158).

- Vers le nord-ouest, à $3 \mathrm{~km}$ environ, au lieudit "Chemin des terres rouges", commune de La Valette, une villa relativement luxueuse (marbre, sculpture) était dotée d'une huilerie. Le mobilier découvert, essentiellement des amphores gauloises, ne permet pas une grande précision de datation (Brun, 1986a, p. 217; Bérato, Borréani, 1987).

L'éloignement relatif de ces villae pourrait indiquer que leurs domaines étaient assez étendus. Nous sommes trop tributaires du hasard des découvertes dans cette zone très urbanisée pour ne pas rester prudents mais cette indication sera à considérer lorsqu'on essaiera de déterminer la dimension de l'exploitation de Saint-Michel.

Les agglomérations les plus proches, Telo Marlius et Olbia étaient aux $\mathrm{I}^{\text {er }}$ et II $^{\mathrm{r}} \mathrm{s}$. des bourgades aux activités essentiellement portuaires. Les fouilles récentes du port romain de Toulon montrent que son importance a longtemps été sous-estimée : dès le $\mathrm{II}^{\mathrm{e}} \mathrm{s}$,, la ville est assez étendue, urbanisée en îlots relativement réguliers et le port, doté de quais, est bordé de boutiques ${ }^{4}$. Ces agglomérations absorbaient une part des surplus agricoles des fermes que nous venons de mentionner et offraient des débouchés maritimes plus larges qui peuvent avoir conditionné les types de production.

\section{Présentation du site}

Pour comprendre aisément les explications sur l'évolution du site, il est nécessaire de donner un bref aperçu de son état d'extension maximale au ${ }^{\circ}{ }^{\circ} \mathrm{s}$. après J.-C. (fig. 2 et 3 ). Les bâtiments s'étendaient alors sur près de 1 ha sur les dernières pentes de la colline. Le plan de la villa ne nous est pas connu avec précision puisque seulement $1 / 10^{\circ}$ du site a été exploré. La partie haute de la villa, plateau rectangulaire de $4000 \mathrm{~m}^{2}$ bordé de puissants murs de soutènement portait. l'essentiel des installations agricoles, notamment l'huilerie. La partie d'habitation et les thermes s'étageaient sur les terrasses méridionales.

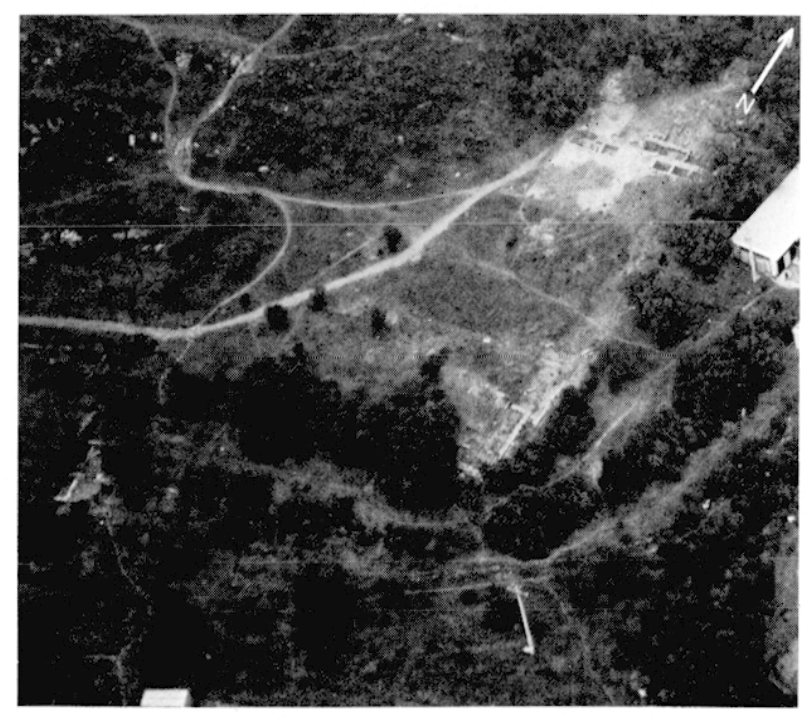

Fig. 2 - Vue générale de la villa. Au premier plan, la pars rustica et l'huilerie, à l'arrière plan, la pars urbana.

Notre étude est rendue fragile par la disproportion entre les zones connues et les parties inexplorées, disproportion aggravée par la problématique qui a animé notre travail, l'étude des vestiges agricoles. Nous avons essayé d'étendre à l'ensemble de la villa les enseignements de la fouille des huileries: ces extrapolations, commodes pour la

4 Sur Telo Martius : Boyer, Fèvrier, 1980, p. 19. Sur les fouilles récentes du port romain : (II)AV. 1987. 

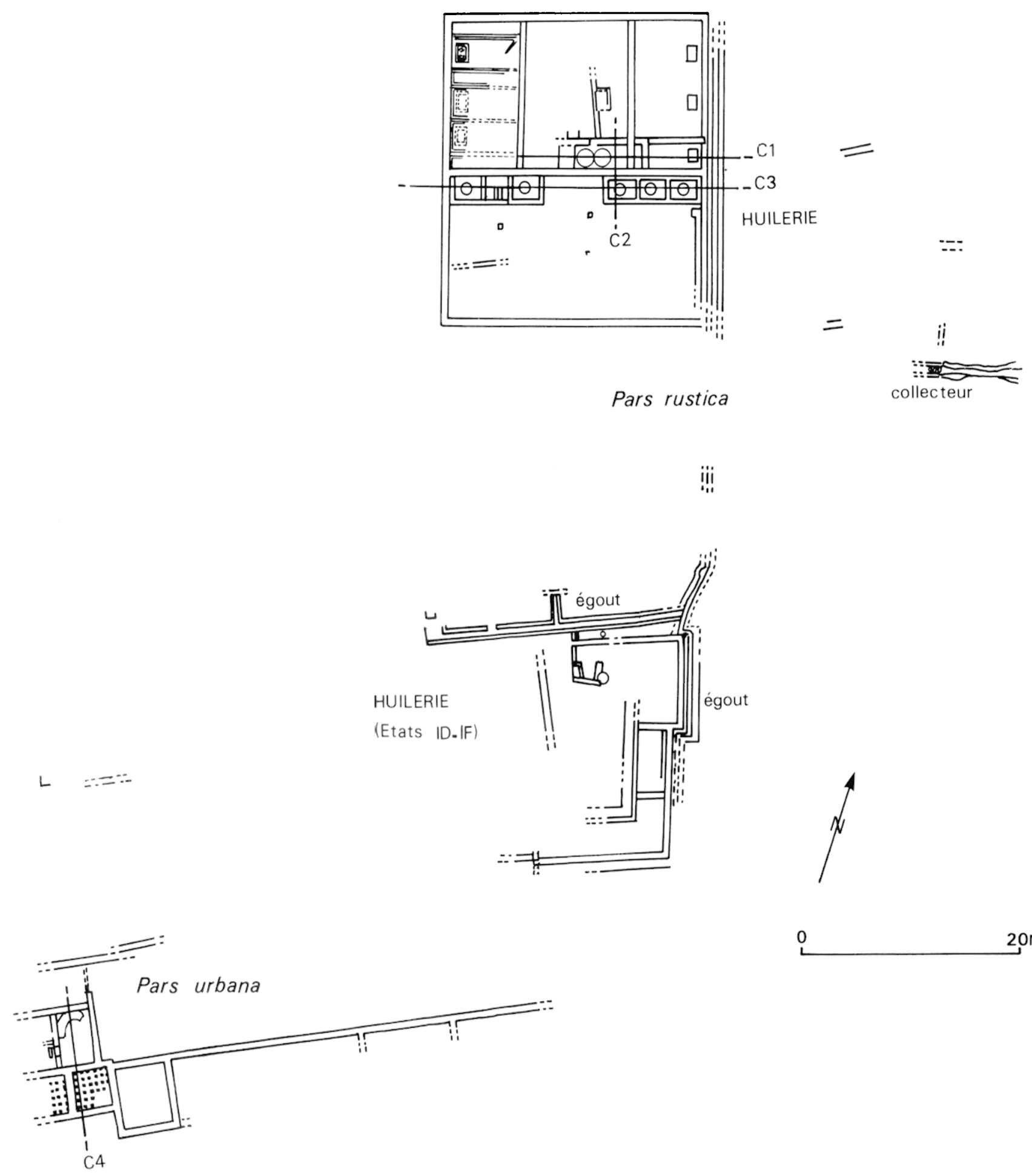

0

Fig. 3 - Plan général.

C. 1 : coupes de la cour 13 au niveau des dolia (fig. 27), du pressoir 12 et de la pièce 14 (fig. 28); C2: coupe de la cuve 19 et de la zone $C$ (fig. 29) : $C 3$ : coupe des cuves (fig. 30): $C 4$ : coupe longitudinale des pièces 205 et 202 (fig. 31 ).

compréhension, pourront ètre remises en cause par une extension des recherches. Ainsi à l'heure actuelle, nous pensons que l'habitat se développa d'abord sur le plateau à mi-pente qui portera l'huilerie et qu'il ne s'étendit qu'ultérieurement sur les pentes.
Cela vient peut-ètre tout simplement du fait que la zone de la grande huilerie a été excavée jusqu'au substrat alors qu'ailleurs ce sont surtout les vestiges des états du Haut-Empire qui ont été dégagés. 

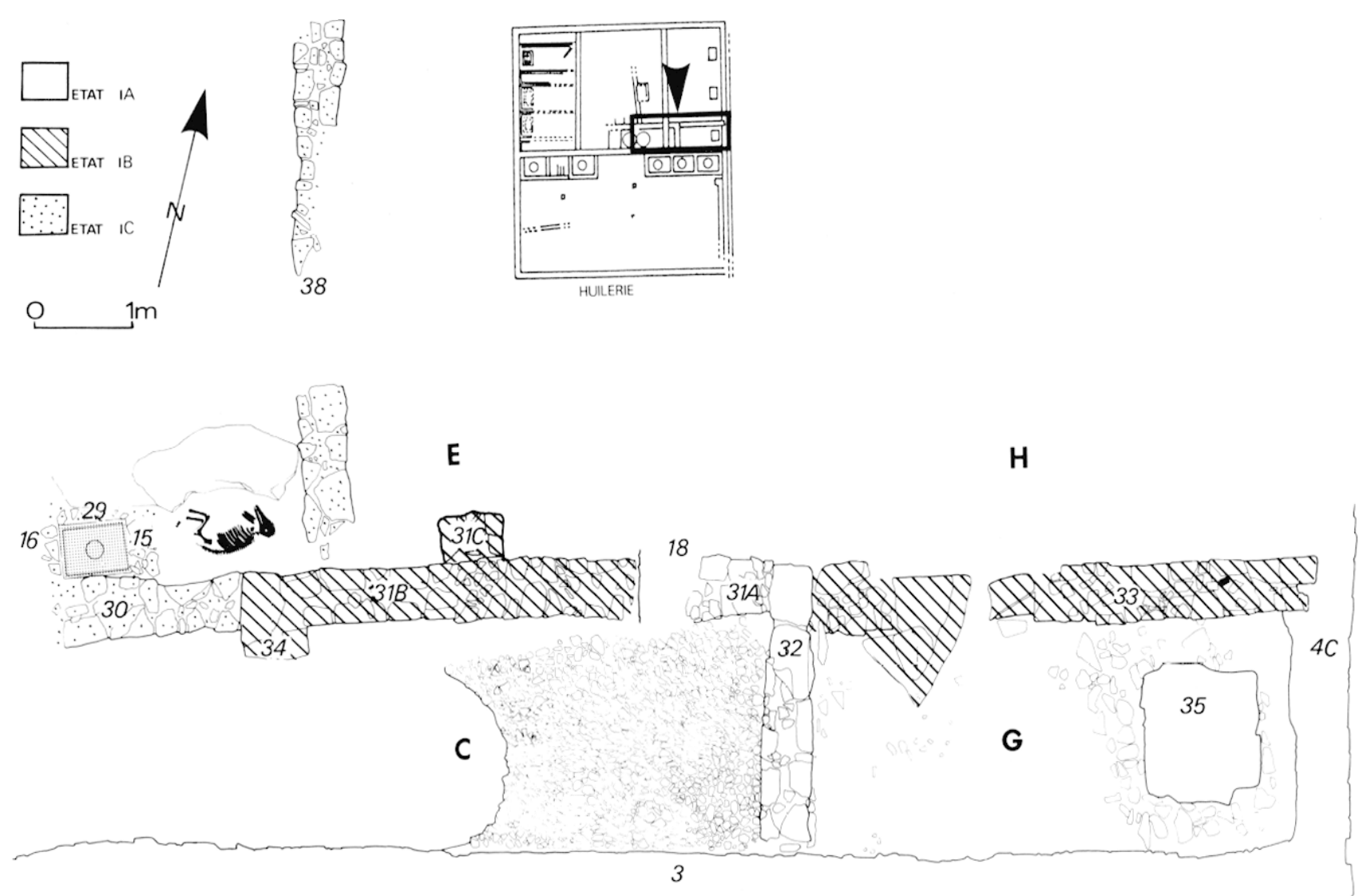

Fig. 4 - Etats IA à IC.

\section{L'ÉVOLUTION DU SITE}

\section{LES PREMIERS BÂTIMENTS AGRICOLES}

Nous regroupons sous ce titre les états antérieurs à la construction de la grande villa du $\mathrm{II}^{\mathrm{e}} \mathrm{s}$. après J.-C. Comme nous venons de l'exposer, nous ne connaissons que très partiellement les bâtiments de cette époque, souvent situés hors des zones actuellement dégagées et en grande partie détruits par les constructions ultérieures.

\section{ETat IA}

Nous désignons ainsi à la fois la construction, l'utilisation el l'abandon des structures primitives (fig. 4).

\section{Constructions}

De cet état primitif, qui repose directement sur le substrat, subsistent trois espaces $(\mathrm{C}, \mathrm{E} / \mathrm{H}$ et $\mathrm{G})$ séparés par des murs perpendiculaires. La pièce $\mathrm{C}$ a èté détruite à l'est et au sud par des aménagements postérieurs (dolia, cuves).

Les murs $31 \mathrm{~A}$ et 32 qui limitent la pièce $\mathrm{C}$ sont formés de gros blocs de grès liés à la terre. Au-dessus de la semelle de pierres encore conservée, l'élévation des murs devait être en adobe : des traces en ont été découvertes dans la couche de destruction.

L'aménagement du sol avait reçu un soin particulier. Sur le rocher aplani à l'ouest et remblayé à l'est, fut déposé un hérisson de petites pierres, de fragments de dolium et d'amphore italique; audessus, on coula une couche d'argile mêlée de chaux et de cailloux calcaires formant un opus signinum. Le sol, parfaitement lissé, paraît indiquer une pièce d'habitation.

Au cours de l'utilisation de ce sol et lors de son abandon, une fine couche de poussière se déposa (C8), bientôt suivie d'une couche d'argile verte et orange, mêlée à des cailloux de grès (C7) correspondant vraisemblablement à la ruine des parties hautes des murs en adobe (fig. 27 à 29 ).

Dans la zone G, le sol présentait une forte pente vers l'est et incite à voir dans cette pièce une sorte de remise. Sur ce sol en terre (G8) (fig. 28), se sont déposées une couche d'adobe fondu (G7) et une couche de colluvions (G6) contenant de nombreux éléments d'un four à pain. Il s'agit de barrettes d'argile séparées par de profondes stries. Ces particularités s'expliquent par le mode de construction de ces fours : sur un sol d'argile était posée une armature 
en osier dont les mailles, larges sur le pourtour étaient serrées au sommet de la coupole où elles se croisaient. Le feu carbonisait l'armature et cuisait l'argile de la coupole. Des fours identiques ont èté découverts sur les oppida des alentours de l'Étang de Berre : le Castellas de Rognac occupé de 100 à 10 avant $\mathbf{J}$.-C. et La Cloche aux Pennes, détruit en 49 avant J.-C. ${ }^{5}$.

Au-delà du mur 31 , la zone $E$ semble avoir correspondu à une cour.

\section{Datation}

Le matériel archéologique est trop rare pour assurer une datation précise de cet état. Pour la construction, seuls les fragments de campanienne forme Lamboglia A27B et de céramique modelée des ateliers marseillais peuvent donner des indications. La forme Arcelin $4 \mathrm{C}$ ne serait plus fabriquée après 49 avant J.-C. (Arcelin, 1979, p. 192). Voir infra, p. 137, tabl. I.

Les couches d'utilisation ont livré des formes de campanienne du milieu et de la fin du I $^{\text {er }} \mathrm{s}$. avant J.-C. ${ }^{6}$ et des fragments d'une assiette importée d'Italie analogue à celles de La Madrague de Giens (Tchernia et alii, 1978, p. 65). On peut rattacher à cette période une lèvre d'amphore Dressel 1A marquée au nom de Sestius ${ }^{7}$. Les autres céramiques sont courantes au cours de la seconde moitié du $\mathrm{I}^{\mathrm{er}} \mathrm{s}$. avant J.-C. L'absence de céramique arétine implique que l'occupation de cet état s'est terminée avant l'époque de grande diffusion de celle-ci vers 20/10.

La période d'abandon qui suivit est caractérisée par la formation de couches de pisé et de colluvions ${ }^{8}$. Elle semble de courte durée et n'affecte peut-être pas l'ensemble du site. Elle se termine après la diffusion de la céramique arétine dont on trouve des tessons dans les remblais de l'état IB.

\section{État IB}

\section{Constructions}

Les nouveaux aménagements portèrent sur la pièce C. Le sol fut exhaussé par un remblai de schiste. Les murs $31 \mathrm{~A}$ et 32 devaient encore émerger

5 Chabot, 1979. Les couches anciennes de la villa du Grand Loou à La Roquebrussane (rer s. avant J.-C.) ont livré des éléments d'un four à pain analogue.

6 Py, 1978, p. 233 : mobilier de . Vages III moyen; Arcelin, 1973 et 1975.

7 Dressel, 1895. Cet exemplaire, portant la marque SES et ancre, est cité dans Manacorda, 1981, p. 51 .

8 Cette couche qui présente partout le mème aspect est identique à celles qui se forment sur le site durant les orages. de la couche de colluvions 6 lors des travaux : ils furent repris avec une orientation légèrement différente. Le mur $31 \mathrm{~B}$, renforcé en son milieu par le contrefort 31C, forme un angle avec le mur 34 donnant la largeur de la pièce : $4,55 \mathrm{~m}$. Les murs sont bâtis de la même façon que ceux de l'état IA, mais on trouve des joints de chaux renforçant leur cohésion.

Les zones $\mathrm{E} / \mathrm{H}$ et $\mathrm{G}$, remblayées par une couche de schiste tassé, semblent avoir été à l'extérieur d'un bâtiment dont la pièce $\mathrm{C}$ formait l'extrémité.

\section{Datation}

Les éléments de datation sont rares. La présence de fragments d'une assiette Goudineau $17 \mathrm{c}$ dans les remblais, interdit de faire remonter la datation plus haut que 10 avant J.-C. (Goudineau, 1968, p. 202). Voir infra, p. 137, tabl. II.

\section{État IC}

\section{Constructions}

L'état IC est un agrandissement de l'état IB vers le nord, la pièce $\mathrm{C}$ restant inchangée (fig. 4).

La zone $E$ fut à nouveau remblayée afin d'exhausser le sol au niveau des affleurements de grès. A cette occasion, le contrefort $31 \mathrm{C}$ fut arasé et le mur 38, édifié en blocs de grès liés à la terre. Vers l'ouest, le mur 31B fut prolongé par le mur 30 auquel fut accolé un cuveau installé dans un creux de rocher. Ses dimensions $(61 \times 43 \times 12 \mathrm{~cm})$ indiquent une contenance faible, de l'ordre d'une cinquantaine de litres si l'on tient compte de son arasement. Ses murs sont bâtis à la chaux; fond et parois sont enduits de béton de tuileau; un petit puisard central mesure $17 \mathrm{~cm}$ de diamètre. Ce cuveau appartenait à une installation agricole : son agencement et ses dimensions évoquent un cuveau pour recueillir l'huile; les analyses chimiques confirment cette interprétation ${ }^{9}$. Il semble qu'il y ait eu dès cette époque dans ce secteur une première huilerie modeste dont toute trace de pressoir a disparu (destruction? pressoir en matériaux périssables?).

Dans un creux de rocher, clos par les murs 30 , 16,29 et 15 un jeune sanglier a été déposé lors de la construction de l'état IC. Selon Philippe Columeau, il s'agit d'un jeune suidé femelle qu'il est difficile de rattacher avec certitude aux cochons sauvages plutôt que domestiques. Il a été retrouvé couché sur le flanc droit, en connexion anatomique, les pattes

9 Analyses effectuées par $M^{\text {me }}$ Formenti dans le cadre de la RCP 403 du CNRS. 
antérieures repliées sous la tête. La tête était écrasée par une pierre plate en grès. Un enfoncement du crâne dans la partie occipitale qui ne peut avoir été causé par la pierre pourrait indiquer que la bête a été abattue à l'aide d'un objet contondant. Aucun matériel n'était associé à ce dépôt.

La manière dont cet animal a été abattu, le soin apporté à sa déposition paraissent indiquer qu'il a été sacrifié, peut-être à l'occasion de la construction du premier moulin à huile. Le porc fait traditionnellement partie des animaux de sacrifice mais les seuls vestiges de sacrifices de suidés que nous connaissons dans le Sud de la France sont d'époque tardive ${ }^{10}$.

\section{Datation}

Les remblais liés à la construction de cet état contenaient une grande part de matériel résiduel sur lequel on ne peut fonder une datation. L'absence totale de sigillée de la Gaule du Sud paraît indiquer que la construction est intervenue avant la période de grande diffusion de celle-ci dans les campagnes varoises, soit avant le milieu du ${ }^{\text {er }} \mathrm{s}$. après $\mathrm{J} .-\mathrm{C}^{11}$. Voir infra, p. 138, tabl. III.

\section{État ID}

Les états ID, IE et IF correspondent aux étapes de l'évolution de constructions situées au sud de celles des états IA-IC (fig. 3). Ces deux groupes de constructions ne sont pas reliés et l'imprécision des datations laisse la place à une certaine incertitude dans leur succession chronologique (Bérato el alii, 1987).

\section{Constructions}

Les structures rattachées à l'état ID sont très limitées : un sol de pressoir et une cuve à huile dans la pièce 108 (fig. 5 et 6 ). Le sol et la cuve 107 sont recouverts de mortier de chaux et d'argile rouge. La cuve, cylindrique, présente une margelle circulaire en légère saillie. La liaison margelle-cuve est marquée par un cavet destiné à recevoir un couvercle en bois obturant le bassin.

Les dimensions de la cuve $(60 / 70 \mathrm{~cm}$ de diamètre, $60 \mathrm{~cm}$ de profondeur) et sa contenance $(180 \mathrm{li}-$ tres) sont supérieures à celles du bassin de l'état IC.

10 Voir l'ètude de la faune infra. Sur les sacrifices de suidés, voir ceux de la Grotte de l'Hortus: de Lumley, Demians d'Archimbaud, 1972, p. 663.

11 Les fouilles des villae varoises ont montré que la céramique sigillée de la Gaule du Sud ne s'ètait répandue dans les campagnes qu'après le milieu du $\mathrm{I}^{\mathrm{er}} \mathrm{s}$. après $\mathrm{J}$.-C. La quasitotalité des fragments retrouvés se rapporte à des formes et des styles d'époques flavienne et antonine.

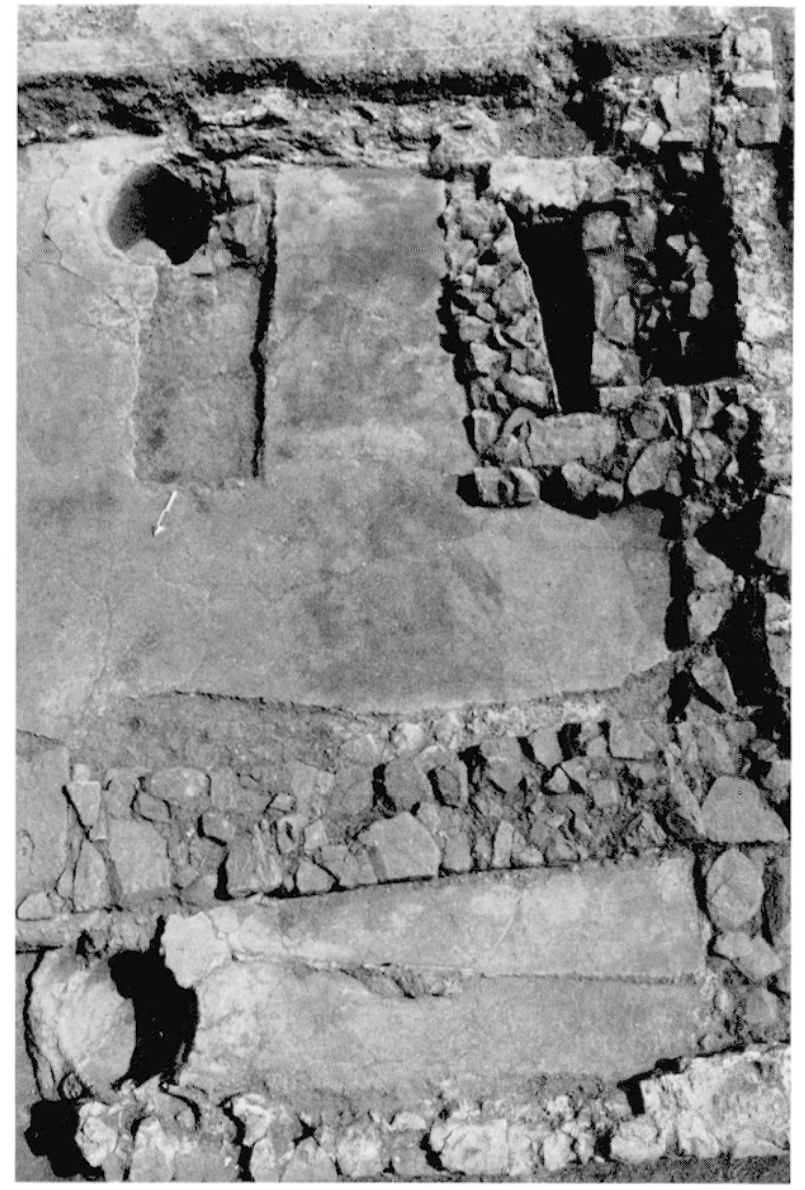

Fig. 5 - Etats ID à IF : vue d'ensemble (le nord est en bas de la photo).

Le pressoir de cette huilerie était peut-être de type A/C3 (Brun, 1986a, p. 96-102). Le contrepoids de pressoir découvert dans le mur 108 (état IF) pourrait avoir appartenu successivement aux huileries ID et IE.

\section{Datation}

Aucun élément de datation absolue n'a été découvert. De par son type et sa position stratigraphique, la cuve est immédiatement antérieure à celle de l'état IE (Bérato el alii, 1987, p. 15).

\section{Etat IE}

\section{Constructions}

Les vestiges de cette troisième huilerie sont plus étendus: la pièce 103 est bordée à l'ouest par le mur 122 bâti à l'argile et plaqué d'un enduit de chaux et d'argile jaune identique à celui du sol de la pièce (fig. 5 et 6 ).

Au ras du sol, s'ouvre la cuve cylindrique 111 de même type que la 107 mais légèrement plus grande (62 $\mathrm{cm}$ de diamètre, $61 \mathrm{~cm}$ de profondeur, contenan- 
ce : 185 litres). A son ouverture, on trouve le logement d'un couvercle de bois d'un diamètre de $84 \mathrm{~cm}$ et d'une profondeur de $4 \mathrm{~cm}$. Deux petits trous circulaires forés sur le pourtour paraissent liés au mode de fermeture (crochet en fer?).

Les dégagements ne sont pas assez étendus pour connaître les autres dispositions de cette huilerie. Toutefois, le contrepoids de grès remployé dans le mur 108 appartenait certainement à ce pressoir (fig. 7). De par son type, ses dimensions (longueur : $80 \mathrm{~cm}$, largeur : $41 \mathrm{~cm}$, épaisseur : $31 \mathrm{~cm}$ ) et sa masse $(250 \mathrm{~kg})$, il entre dans la série des contrepoids anciens, héritiers des contrepoids protohistoriques ${ }^{12}$.

\section{Datation}

Les couches attribuables à la construction de cet état n'ont livré aucun matériel datable. Les couches d'abandon ont fourni un petit bronze tardif de Marseille, un bord de coupelle sigillée sud-gauloise Dragendorff $35 \mathrm{~A}$ et un bol en paroi-fine Mayet XXXVIII. Ce matériel et la chronologie relative des structures placent cet état vers le milieu et le troisième quart du $\mathrm{i}^{\mathrm{er}} \mathrm{s}$. après J.-C. (Bérato et alii, 1987, p. 17).

\section{État IF}

\section{Constructions}

L'état IF marque des transformations importantes : destruction de l'ancienne huilerie, démantèlement du pressoir, comblement de la cuve, édification d'une nouvelle installation sur un plan modifié (fig. 5 et 6). On doit rattacher à cet état la construction des puissants murs de soutènement 109 et 110 faits de gros blocs de grès bâtis à la chaux et doublés ultérieurement par les murs 111 et 112 .

Sur la plate-forme ainsi créée, de nouveaux murs 108,118 et 119 , liés à la terre, furent édifiés sur les anciennes structures : le mur 118 chevauche le comblement de la cuve 111; les murs 108 et 119 entament le sol de l'huilerie IE; le mur 108 réutilise son contrepoids comme boutisse.

Le plan reste trop incomplet pour proposer une interprétation. On remarque que la cuve 110 , nouvellement construite sur un plan rectangulaire est sensiblement plus grande que la cuve 111. En effet, les dimensions qui subsistent $(135 \times 85 \mathrm{~cm}$ pour une profondeur de $65 \mathrm{~cm}$ ) assurent que ce bassin pouvait contenir largement plus de 900 litres de liquide. Les

12 Ce contrepoids est rattachable à notre type 13 connu à Entremont (Brun, 1987, fig. 72) et à la Courtine d'Ollioules où les masses sont du mème ordre : 250 à $350 \mathrm{~kg}$ (Brun, 1986a, p. 248-249).

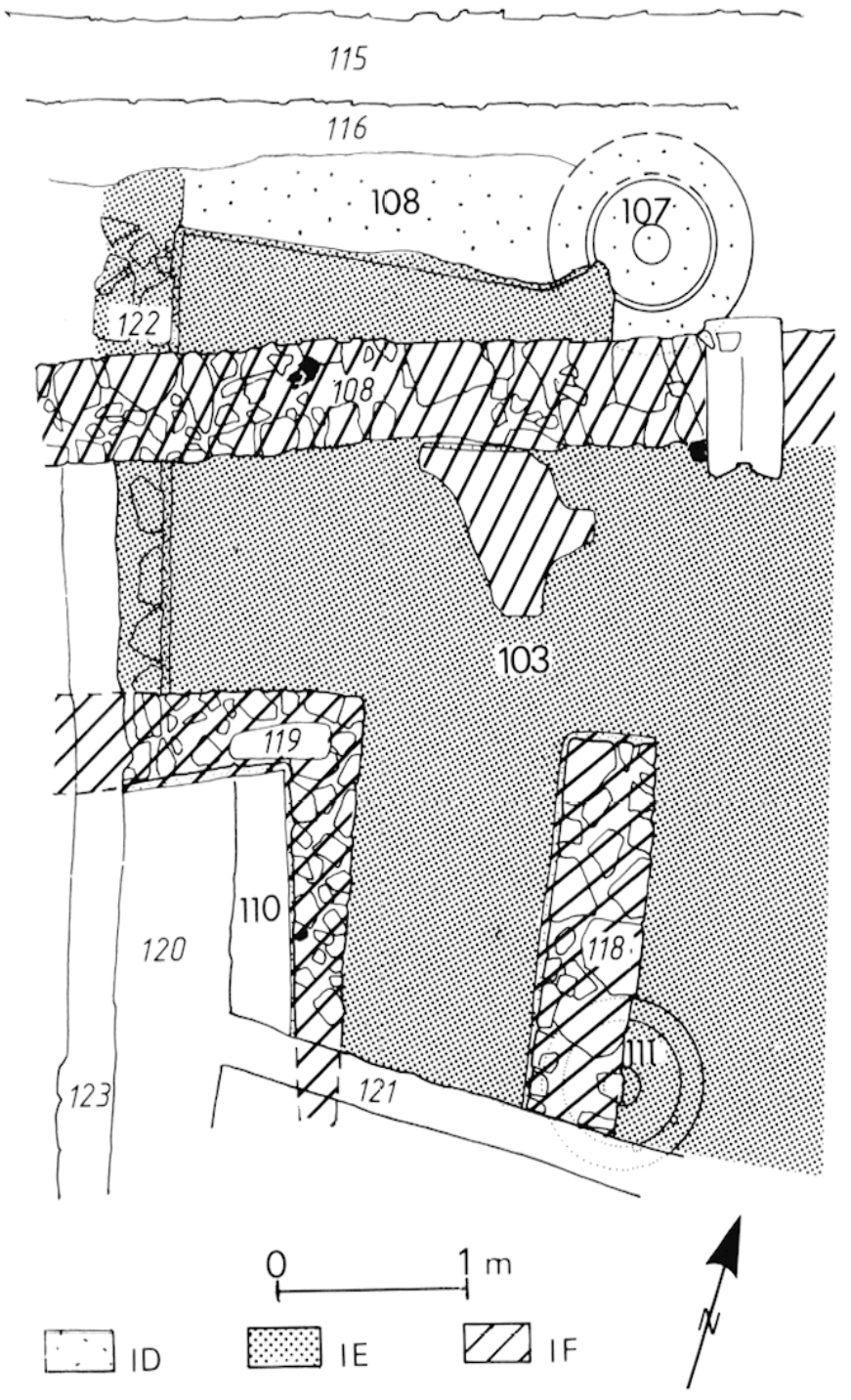

Fig. 6 - Etats ID à IF : plan détaillé de la pièce 103 .
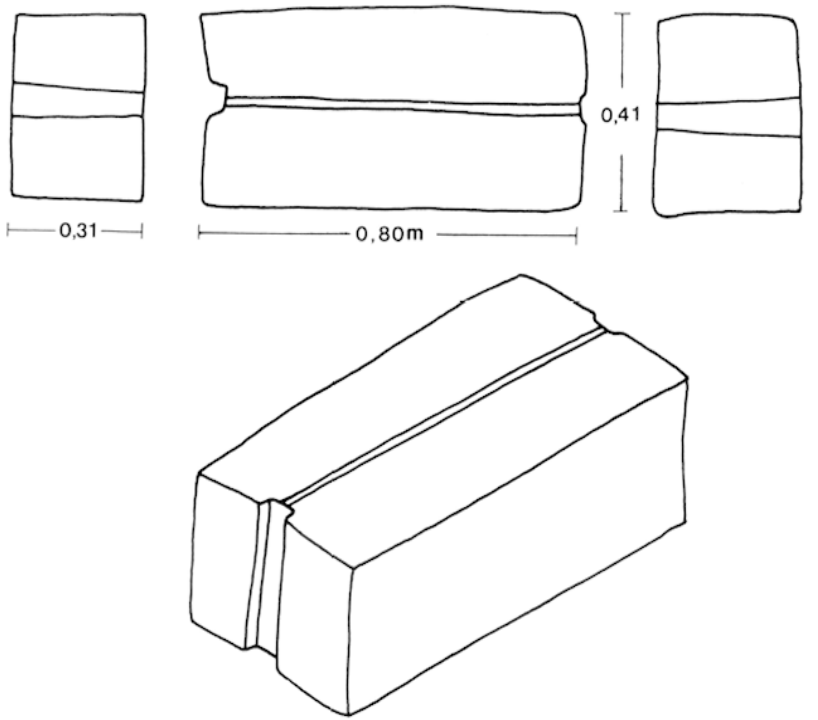

Fig. 7 - Etats IE et IF : contrepoids de pressoir. 
parois et le fond de la cuve sont enduits d'un mortier de chaux, d'argile jaune et de tuileau identique à celui d'un nouveau sol établi sur hérisson de petites pierres, mais rien n'assure que ces constructions correspondent à une huilerie; il pourrait aussi bien s'agir d'une installation vinicole.

\section{Datation}

Les remblais du sol ont livré peu de matériel datable : une pièce de Tibère a été découverte dans le blocage du mur 108 et un fragment de sigillée claire A.(Hayes 3a) dans celui du mur 118. Cet indice interdit de faire remonter la datation plus haut que l'époque de Vespasien. Il faut vraisemblablement placer l'utilisation de cette installation vers la fin du $\mathrm{I}^{\text {er }} \mathrm{s}$. (Bérato et alii, 1987, p. 15).

\section{$L A V I L L A$}

\section{PARs RUSTICA}

\section{État IIA : L'HUILERIE}

Dans la pars rustica, les transformations qui s'opérèrent lors de l'état IIA bouleversèrent complètement l'aspect de cette partie du site. A la place des anciennes constructions de l'état $\mathrm{IC}^{13}$ fut installée une vaste huilerie au plan rationnel, construite avec des matériaux et des techniques modernes pour l'époque (fig. 3). En fait, cette huilerie dont les bâtiments s'ordonnent symétriquement de part et d'autre de deux cours, paraît avoir été édifiée en deux campagnes. Certaines particularités de construction: doublement du mur 3 pour les cuves 19-21, différence de dimensions et de finition des deux séries de cuves, remaniement du sol en béton de la cour aux abords des cuves 19-21, suggèrent un décalage chronologique plutôt que des impératifs techniques.

Les murs $1,2,3,4 \mathrm{C}$ et 5 délimitent deux vastes enclos. Dans l'enclos nord, contre le mur 2, on édifia d'abord (état IIA1) une batterie de trois pressoirs (pièces 2, 4 et 5), le reste de l'enclos formant une vaste cour au sol de terre. Au sud du mur 3, s'étendait une cour bétonnée bordée de préaux abritant une série de trois cuves de décantation appuyées au mur 3 (fig. 8).

13 Au cours des ètats ID à IF, la zone C-E-G-H occupée au $\mathrm{II}^{\mathrm{e}} \mathrm{s}$. par la grande huilerie semble rester à l'abandon. Tout au plus constate-t-on quelques aménagements, notamment un caniveau est-ouest fait de tuiles marquées $M A R I$ et $H E R E N N$.
L'état IIA2 est caractérisé par la construction d'une seconde batterie de pressoirs et de cuves dans la partie est de la cour, faisant l'exact pendant de la première.

Ces deux étapes participent d'une volonté définie, d'un véritable projet et durent se succéder rapidement (voir infra, p. 139 et fig. 8).

Les vestiges nous sont parvenus dans un état de conservation très inégal : le pressoir 2 et les aires 1 et 3 sont arasés au niveau du sol; les pressoirs 4 et 5 sont détruits jusqu'au niveau de béton intermédiaire et les blocs d'assise des jumelles ont disparu (fig. 9). Des pressoirs 8,10 et 12, ne subsiste que le premier lit de fondation des sols.

\section{Constructions (fig. 9)}

\section{Cour 13}

La cour 13, bordée par les ailes des pressoirs, était au centre de l'huilerie : on y réceptionnait les olives, on les y broyait, on s'y affairait autour des pressoirs et on y chauffait l'eau et la nourriture sur des foyers alimentés avec des tourteaux d'olives que l'on appelle grignons.

Le sol était formé soit du substrat rocheux aplani, soit de remblais. Dans l'angle sud-ouest, des fragments de marbre mis au rebut avaient été déposés pour niveler le sol, comblant la tranchée de fondation du mur $6{ }^{14}$. La cour ne reçut son aspect définitif qu'après la construction de l'aile est. Contre le mur 18, le sol fut exhaussé ennoyant les anciens murs. Sur les remblais, entre le mur 18 et le foyer A fut déposé un mince lit de chaux qui s'éroda en plusieurs endroits.

L'espace compris entre les murs $3,18,31$ et 34 (pièce 14) fut recouvert d'un sol de béton de tuileau posé sur un hérisson de galets. Ce sol fut établi à un niveau inférieur à celui du pressoir 12 en même temps que celui-ci. Il est vraisemblable que ces lits de béton furent déposés le long du mur 18 afin d'affermir les sols supportant les contrepoids et d'éviter que ce point bas de la cour ne se transformât en bourbier lors des pluies.

Le centre de la cour était dégagé de toute construction pour laisser la place à des charettes pénétrant certainement par une porte ouverte dans le mur 1. Les olives devaient être déposées en tas sur le sol de la cour, comme le montre une peinture de la nécropole d'Hadrumète (Reinach, 1892, pl. XXXI, p. 460$)$.

14 La casse se produisait surtout lors du forage des trous de fixation dans les moulures (marbres inachevés ou défectueux : $11 \%$, brisés : $82 \%$, en bon état : $7 \%$ ). 


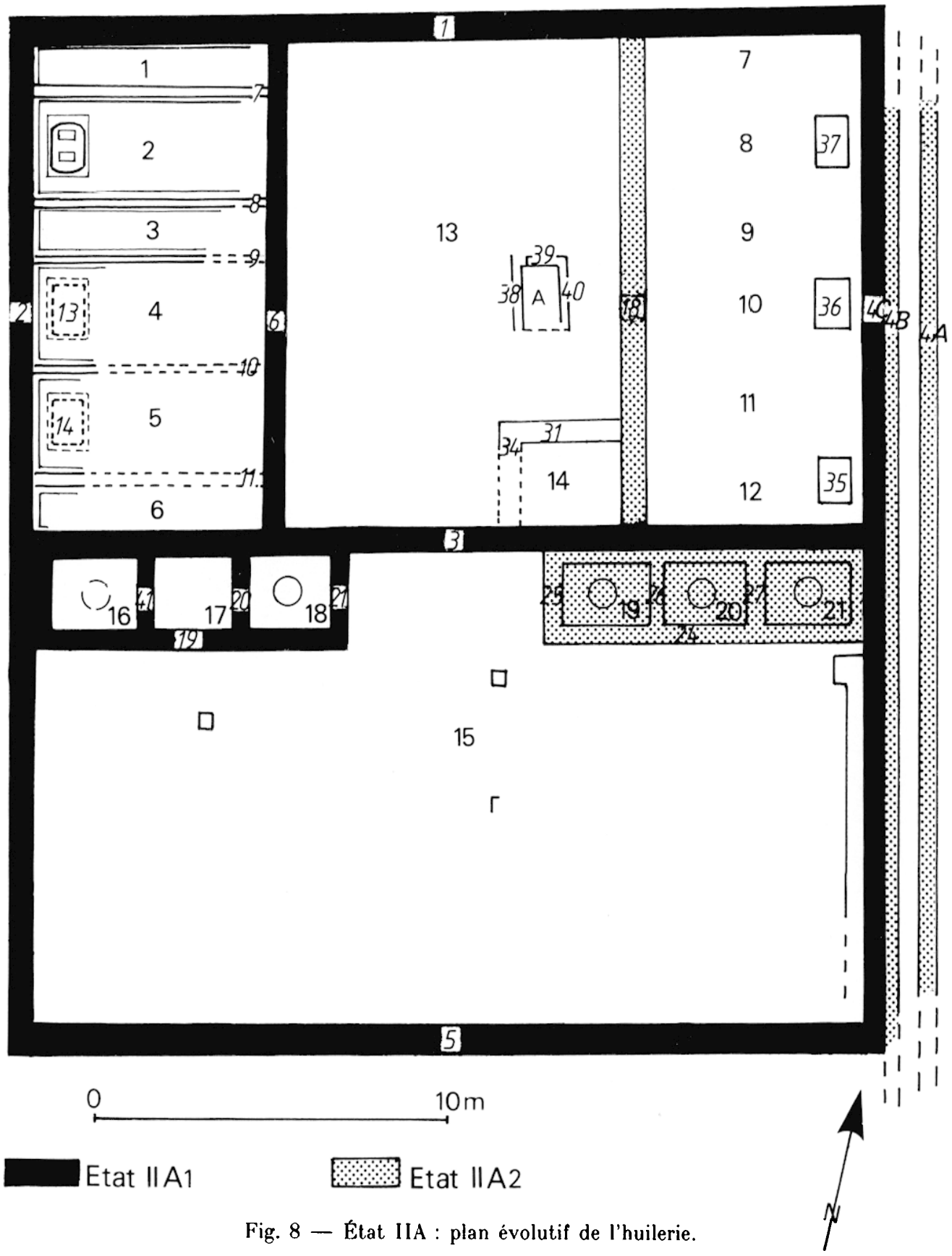

Un foyer A fut aménagé lors de l'établissement du sol E3 dans les ruines du mur 38. Des pierres posées de chant délimitent une fosse approximativement carrée (de $1,50 \mathrm{~m}$ de côté). Elle servit longtemps : on y brûlait, outre du bois, les grignons d'olives comme le préconise Pline (N.H., XV, 22) et comme on le fait encore dans les huileries traditionnelles contemporaines. Ce foyer était utilisé pour la cuisine : des ossements carbonisés de suidés, d'ovicapridés et de bovidés y ont été trouvés mêlés à de la vaisselle (céramique modelée, sigillée sud-gauloise et claire A, voir infra, p. 139, tabl. V). On utilisait également ce foyer pour chauffer l'eau nécessaire aux opérations de pressurage et de décantation. L'importance du foyer se justifiait donc s'il était destiné à supporter des chaudrons ou une véritable chaudière, comme on en connaît aujourd'hui et comme Caton en mentionne dans ses inventaires ${ }^{15}$.

15 Caton (Agr., 10,1) mentionne dans l'équipement d'une huilerie d'un domaine de 240 jugères $(60 \mathrm{ha})$, deux chaudières de bronze, une de 30 quadrantals ( 782 litres) et l'autre de 5 quadrantals (130 litres). 


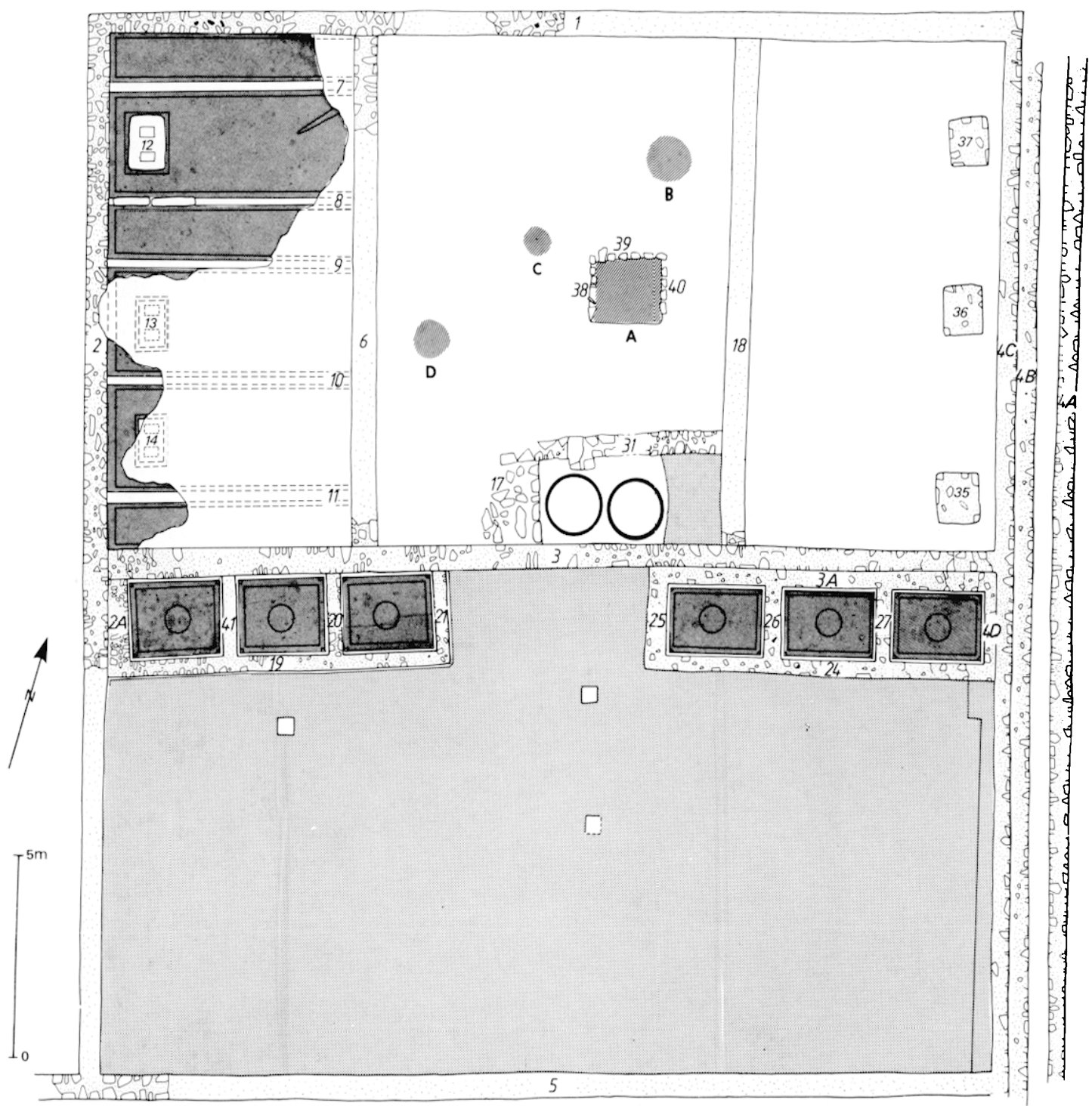

Fig. 9 - Etat IIA : plan détaillé de l'huilerie.

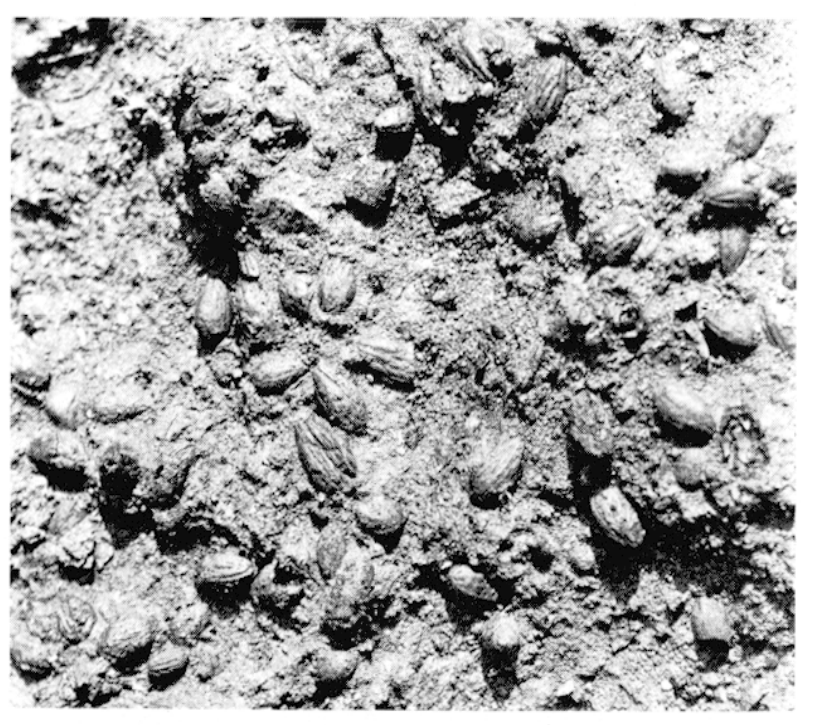

Fig. 10 - Etat II : olives carbonisées dans le foyer D.
D'autres foyers plus petits ont été découverts sur le sol de la cour. Le foyer B était matérialisé par une lentille de cendres, de charbons de bois et de grignons carbonisés mêlés à de la faune et des tessons se recollant avec ceux du foyer $\mathrm{A}$. Le foyer $\mathrm{C}$, très petit, était installé dans un creux de rocher en avant du pressoir 2. Il a également livré des noyaux d'olives. Le foyer $D$, plus étendu $\left(1 \mathrm{~m}^{2}\right)$ était formé d'une lentille de cendres, de charbons de bois et de grignons en très grande quantité (fig. 10). La présence d'un fragment de plat en sigillée claire A, forme Hayes 31 , semble dater l'utilisation de ce foyer d'une période postérieure à celle des foyers $\mathrm{A}, \mathrm{B}$ et C. Voir infra, p. 139, tabl. V.

Les olives étaient certainement broyées dans cette cour : les broyeurs sont utilisés en début de travail avant les pressoirs, donc plutôt dans la cour de réception des olives que dans celle où l'on 

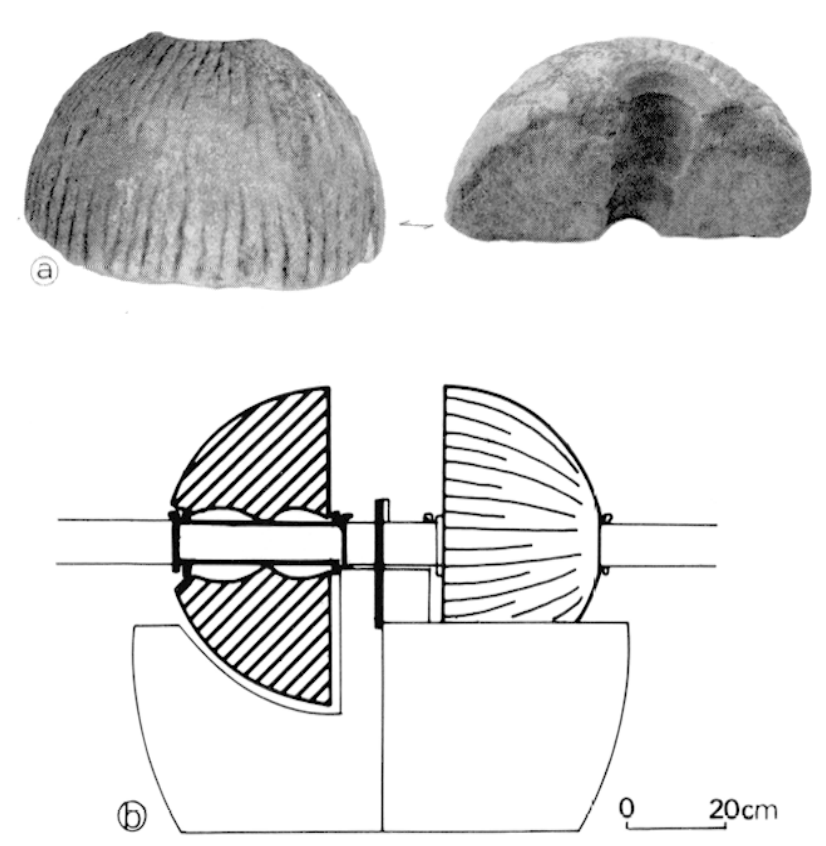

Fig. II - Etat II : a, orbis de trapelum; b, restitution du trapelum.

décantait l'huile. Par ailleurs, c'est dans la couche de destruction de la cour 13/14 qu'on a trouvé l'unique vestige de broyeur. II s'agit d'un orbis de trapetum, en grès local, brisé en deux (fig. 11). Son diamètre est de $59, \overline{5} \mathrm{~cm}$ et son épaisseur de $31 \mathrm{~cm}$. La face hémisphérique est creusée de stries pour entraîner les olives. La meule est percée d'un logement cylindrique permettant le passage d'un axe en bois, toumant directement dans la pierre ${ }^{16}$.

Les installations connues par l'archéologie et l'ethnologie comportent en général un moulin pour deux pressoirs ${ }^{17}$. Il devait donc y avoir trois moulins dans la cour mais on ne peut en préciser l'emplacement. Les autres éléments de moulins ont dû être récupérés dans l'Antiquité ou lors de la mise en culture $^{18}$.

16 Sur cette particularité des Irapela antiques de Provence, voir Brun, 1986a, p. 232. Aux exemples cités, on ajoutera ceux du Collet de Bras à Tourves, du Fort à Six-Fours dans le Var et de Saint-Julien de Martigues dans les Bouchesdu-Rhône (Communication Lucien Rivet).

17 Pour la période antique : Madaure, Christofle, 1930; Taqle, Callot, 1984, pl. 36-37; Granaraccio, Faccena, 1957, p. 149. Pour la période moderne : Bernard. 1788 (in Casanova, 1978, p. 143). Caton, par contre, prévoit un broyeur par pressoir (Agr., 12).

18 Lors de la mise en culture, les sols des pressoirs ont été détruits, les pierres arrachées. La couche de destruction a été enlevée; il n'en subsistait plus qu'un lambeau. Les meules avaient d'ailleurs peut-être été récupérées dès l'Antiquité.

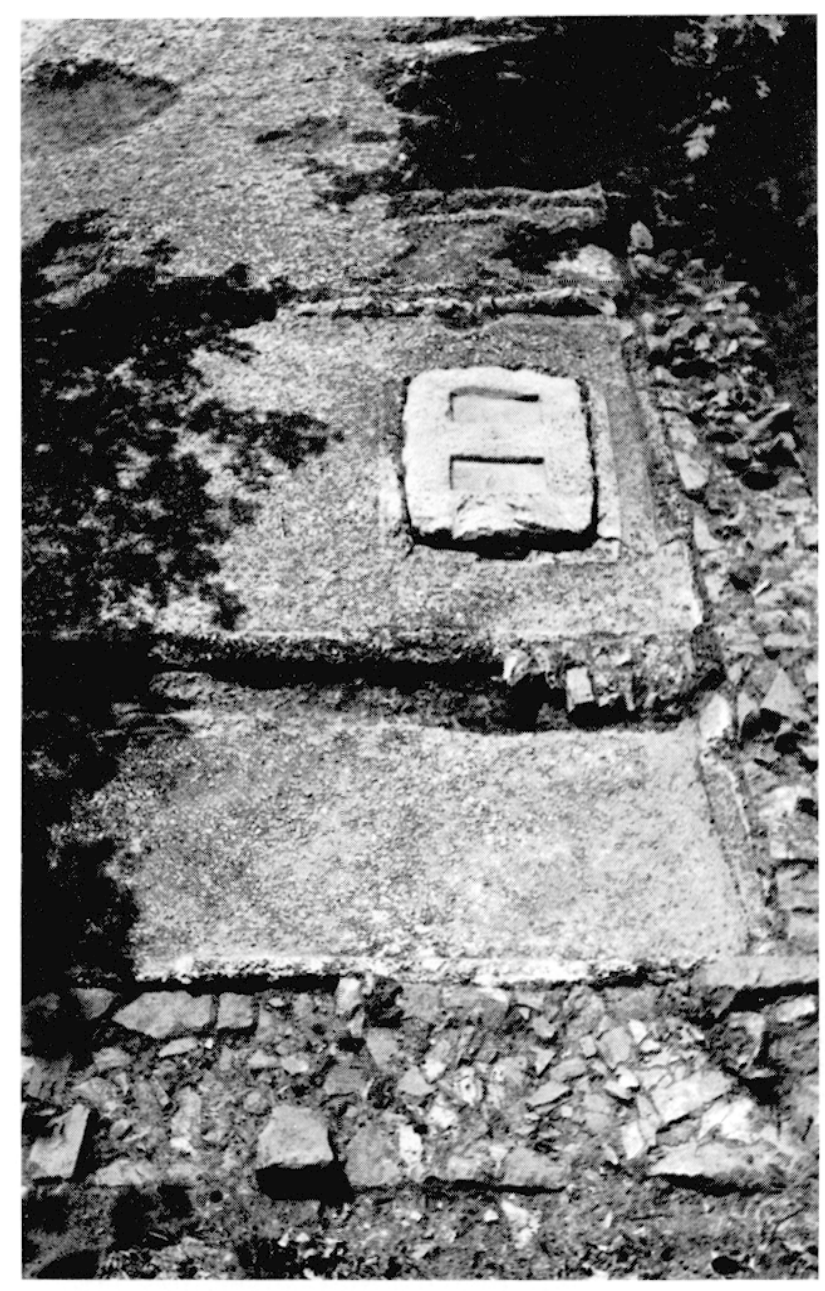

Fig. 12 - Etat IIAl : batterie occidentale de pressoirs : le pressuir 2.

\section{Aile des pressoirs 2,4 et 5}

A l'ouest de la cour 13 s'élevait une aile de trois pressoirs bordés d'aires de manipulation. La description du pressoir 2 et des aires 1 et 3 vaut pour les autres pièces (fig. 12).

Pressoir 2. - La pièce longue de 6,60 $\mathrm{m}$ et large de 2,68 m est limitée à l'ouest et à l'est par des murs en opus caementicium à appareil irrégulier et sur ses longs côtćs par des murettes constituées de dalles hautes d'une vingtaine de centimètres, posées de chant. Ces dalles, extraites d'une carrière de calcaire hettangien à Baudouvin, ont été retaillées sur place.

Le sol est formé d'une dalle de béton très soigneusement construite. Sur le rocher aplani, un premier hérisson de gros blocs de grès posés de chant, puis une couche de mortier de chaux et tuileau sur laquelle on posa une seconde couche de pierres de grès plus petites recouverte d'une nouvelle couche de mortier et d'un pavé en éclats de tuiles et pierres 
calcaires. L'étanchéité entre le sol et les murs était assurée par des solins en quart-de-rond.

A $37 \mathrm{~cm}$ du mur 2, au milieu de la pièce émerge la partie supérieure du bloc d'assise des jumelles servant d'ancrage au levier du pressoir (fig. 12). Le forum est en grès local et mesure $140 \mathrm{~cm}$ de long pour $95 \mathrm{~cm}$ de large. La face supérieure est creusée de deux mortaises profondes de $2 \mathrm{~cm}$.

A l'autre extrémité de la pièce, une rigole oblique servait à l'écoulement des liquides vers les cuves : il faut restituer un petit canal collecteur courant le long de la face interne du mur $6^{19}$.

Ces procédés de constructions sont conformes à ceux préconisés par les auteurs antiques ${ }^{20}$ et, de fait, la solidité initiale du sol lui a permis de résister aux pressions sans qu'aucune fissure ne se produise. Dans d'autres installations moins bien construites, les dalles se sont fendues et ont nécessité des réfections ${ }^{21}$.

Aires 1 et 3. - Ces pièces étroites, sortes de couloirs de 1,25 m de large, encadrent le pressoir 2 . A chaque pressoir correspondait une aire de ce type même si la symétrie n'est pas respectée : au pressoir 2 correspondait l'aire 1, au 4 l'aire 3 et au 5 l'aire 6. Elles paraissent avoir rempli deux fonctions complémentaires : couloir d'entrée et aire de dégagement.

Le bâtiment était clos; les pressoirs ne donnaient sur la cour que par des ouvertures étroites servant de guide au levier. On ne pouvait pénétrer que par ces couloirs pour apporter la pâte d'olive triturée dans les broyeurs de la cour. Ces couloirs servaient également d'aire de dégagement permettant entre autres d'entreposer de la pâte d'olive

19 Une installation analogue est connue (pour le vin ?) à Cosa, Via della Fattoria (Carandini, Settis, 1979, p. 76).

20 Cáton $(A g r ., 18,7)$ donne les indications suivantes : fondations : couche de pierre $(1 / 2$ pied + couche de mortier de chaux et sable (1/2 pied); - dalle : deux couches de mortier de chaux, sable et gravier (1 pied, 3 palmes, 2 doigts); pavement : chaux, sable, tessons de tuiles : 2 doigts.

Vitruve (Arch., VII, 1) : fondations : couche de cailloux (stalumen); - dalle : couche de mortier et gravier (rudus) (3/4 de pied) + couche de mortier de tuileau (6 doigts); pavement : carrelage.

Pressoir 2: fondalions: couche de blocs de grès (20/30 $\mathrm{cm})+$ couche de mortier de chaux, tuileau, sable et gravier $(5 / 10 \mathrm{~cm})+$ couche de pierres $(15 \mathrm{~cm}) ;-$ dalle : couche de mortier de chaux, gravier et sable $(10 / 15 \mathrm{~cm})$; - pavement : couche de mortier de chaux, sable, gravier et tuileau $(7 \mathrm{~cm})$.

21 Construite moins solidement, la dalle du pressoir 2 de L'Ormeau à Taradeau s'est largement fissurée (Brun, 1986a, fig. 190), celles des pressoirs de Peymeinade ont subi plusieurs réfections (Vindry, 1981). entre deux pressurages et de nettoyer individuellement chaque pressoir à grande eau.

Ce système de murettes et d'aires de dégagement est relativement fréquent dans les grandes installations de pressurage. Nous avons émis l'hypothèse que les Anciens les appelaient, canales (Caton, Agr. 18) ${ }^{22}$.

\section{Aile des pressoirs 8,10 et 12}

Les pressoirs de cette aile sont très ruinés : il ne subsistait plus, lors de la fouille que le hérisson et un lambeau du sol du pressoir 12 et les trois socles de maçonnerie des blocs d'assise 35,36 et 37 .

L'emplacement de ces socles permet de restituer avec certitude trois pressoirs $8,10,12$ séparés par des couloirs 7, 9 et 11 (fig. 8). Ce nouvel ensemble n'est pas l'exact symétrique du premier puisqu'il n'y a pas deux pressoirs accolés : il est possible que cette disposilion ait paru plus judicieuse.

Les pressoirs de l'aile est présentent les mêmes caractėristiques que ceux de l'aile ouest. Le bâtiment, fermé des quatre côtés, devait posséder une toiture dont la pente, déterminée par les contraintes des machineries, allait du mur 4 vers le mur 18.

Les constructeurs ont dû faire face à des problèmes nouveaux liés à la nature du substrat. Les pressoirs de l'aile est sont fondés sur les anciennes structures des états IA à IC dont les couches d'occupation forment une assise bien moins ferme que le rocher des pressoirs ouest. Aussi le sol reçut une fondation extrêmement solide et le mur $4 \mathrm{C}$ fut renforcé par la construction du mur 4B.

Pour la construction du pressoir 12 , les murs 32 et 33 furent arasés (fig. 28); une fosse rectangulaire fut creusée à une trentaine de centimètres du mur 4C et remplie d'un blocage maçonné et damé afin d'offrir une base solide au bloc d'assise des jumelles ${ }^{23}$ (fig. 13). Une couche de blocs de grès, parfois énormes $(60 \times 50 \mathrm{~cm})$, fut déposée sur toute la superficie du pressoir (fig. 13 et 14). Au-dessus, on coula un lit de mortier, puis un hérisson de galets et

22 Les huileries de Volubilis possèdent des aires de travail séparées par des murettes de pierres; elles servaient au stockage de la pâte avant le pressurage (Akerraz, Lenoir, 19811982 , p. 76). Sur le sens de canalis chez Caton, voir Brun, 1986 a, p. 239.

23 Ce massif est conservé sur $0,80 \mathrm{~m}$ de haut. Si l'on restitue les couches de mortier de la dalle du pressoir, on obtient une hauteur totale pour le massif et le bloc de l'ordre de $1,50 \mathrm{~m}$. Caton $(\Lambda g r ., 18,3)$ précise qu'il est nécessaire de fonder profondement le forum (arbores ubi statues, fondamenta bona facito alta $p$. $V$, inibi lapides silices). 


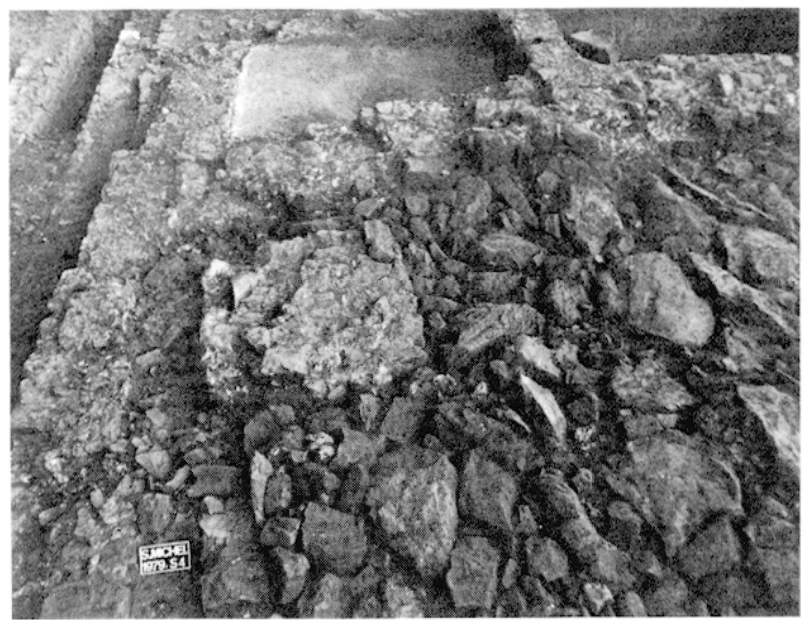

Fig. 13 - État IIA2 : socle du bloc d'assise et hérisson du pressoir 12 vus du nord.

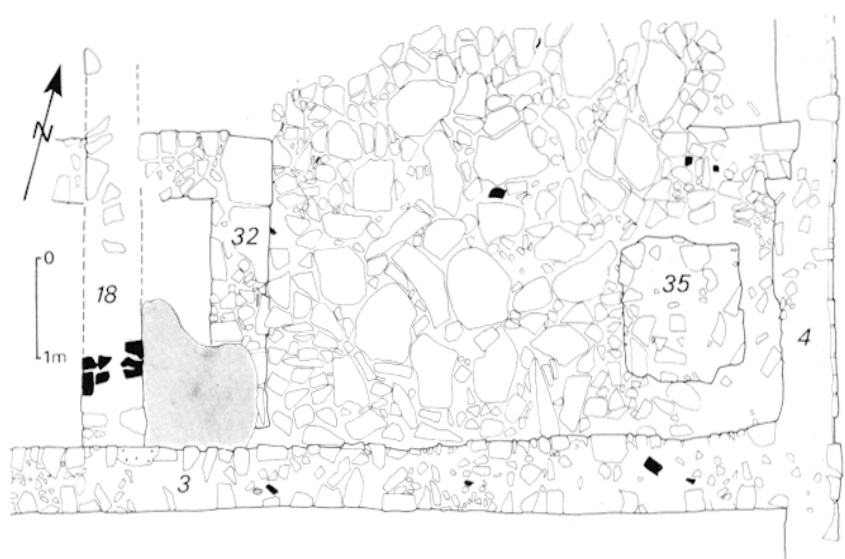

deux couches de béton de tuileau, la seconde formant le sol d'opus signinum.

\section{Cour 15 el cuves 16,17 et 18}

La superficie de la cour est de $280 \mathrm{~m}^{2}$. Son sol est formé d'une couche de béton de tuileau reposant sur un hérisson. Elle communiquait avec la cour 13 par une ouverture située entre les deux séries de cuves. Contre le mur 3 et probablement le mur 2, courait un préau dont les murs portaient un enduit peint en rouge. Sa charpente était supportée par des piliers de bois reposant sur des socles de pierre rectangulaires en grès et calcaire. Les cuves et leurs zones de travail étaient couvertes mais il semble qu'un espace à l'air libre ait subsisté entre les deux séries de cuves.

L'angle ouest de la cour ètait occupé par une batterie de trois cuves construites en même temps. Les trois cuves s'appuient directement contre le mur 3 : leurs constructions sont contemporaines. Par contre le mur 2 est doublé par le mur $2 \mathrm{~A}$ (fig. 9),

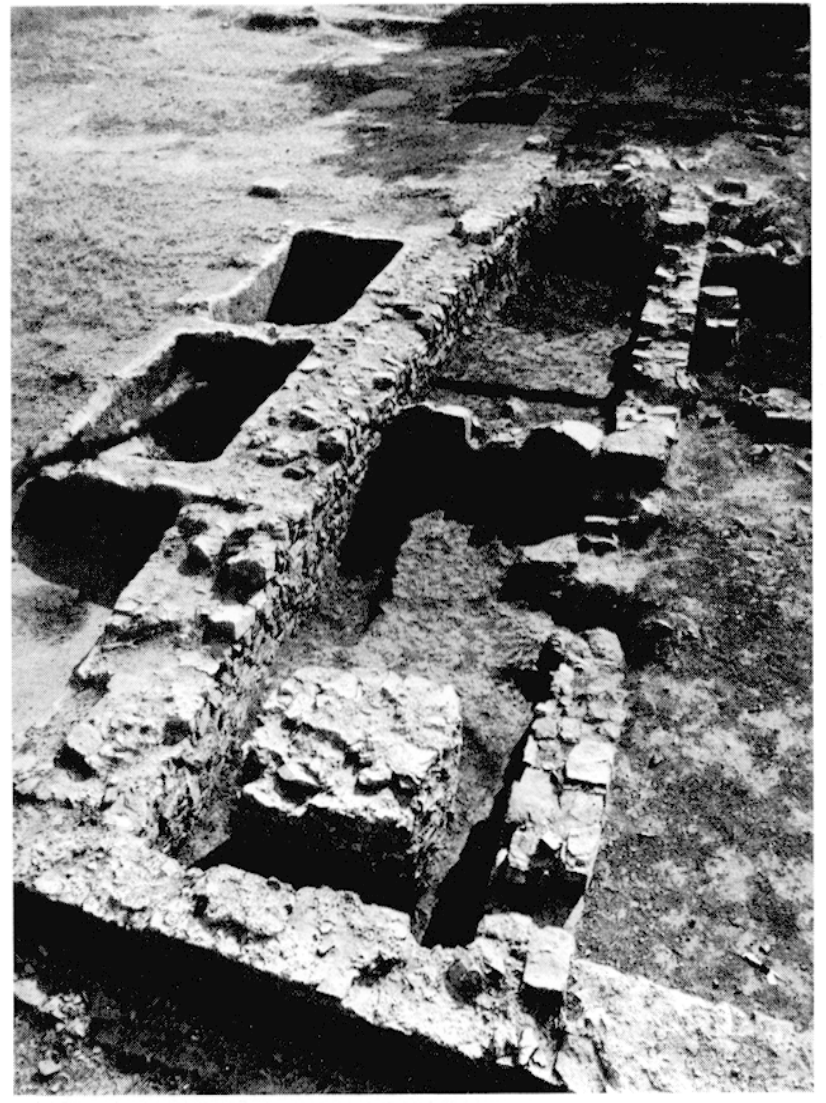

Fig. 15 - État IIA : pressoir 12 et batterie orientale de cuves.

Fig. 14 - Etat IIA2 : relevé du hérisson du pressoir 12.

probablement pour l'aider à supporter la pression des terres qu'il soutient. Les murs sont faits de pierres de grès et de tuiles lièes au mortier de tuileau; leurs faces internes sont enduites de béton de tuileau sur 3 à $5 \mathrm{~cm}$. Les angles sont étanchés par des solins verticaux carrés et horizontaux en quartde-rond. Chaque cuve présente un puisard circulaire central de $75 \mathrm{~cm}$ de diamètre et $15 \mathrm{~cm}$ de profondeur.

La profondeur de ces cuves était de l'ordre de $1,20 \mathrm{~m}$ : le sommet des murets du cuveau 17A, installé postérieurement dans la cuve 17, est situé à $1,10 \mathrm{~m}$ au-dessus du fond de la cuve. Cette profondeur, compatible avec une pente de $2 \%$ du canal drainant les pressoirs, implique des contenances de l'ordre de 5000 litres.

\section{Cuves 19, 20 el 21}

L'angle est de la cour est occupé par une autre série de trois cuves correspondant aux trois pressoirs orientaux (fig. 15). Leurs murs ont èté bàtis en une 
seule fois: aucune reprise n'est décelable. Les murs $3 \mathrm{~A}$ et $4 \mathrm{D}$ ont été construits après les murs 3 et $4 \mathrm{C}$ auxquels ils sont accolés. L'intérieur des cuves est enduit de béton de tuileau et les angles sont marqués par des solins d'étanchéité à pans coupés. Un peu moins larges mais légèrement plus longues que les cuves $16 / 18$, elles ont une capacité sensiblement égale.

Comme les cuves $16 / 18$, les bassins $19 / 21$ étaient couverts de préaux : le sol de la cour présente une forte pente d'ouest en est permettant aux eaux de pluie de s'écouler. Un caniveau bétonné les drainait au bas de la cour et les rejetait dans le grand collecteur situé entre les murs $4 \mathrm{~A}$ et $4 \mathrm{~B}$, la liaison étant marquée par un regard.

\section{Fonctionnement de l'huilerie dans son état IIA}

\section{Nature de la production}

La première question à examiner est celle de la nature de la production. Nous avons jusqu'à présent admis qu'il s'agissait d'une huilerie et non d'une installation vinicole; il convient maintenant de le prouver.

Une meule de trapelum a été découverte. Cet indice peut paraître faible: on s'attendrait à trouver des vestiges plus abondants du broyage des olives. La disproportion entre les vestiges conservés des pressoirs et des moulins est constante dans la documentation : les moulins ont été fréquemment récupérés dans l'Antiquité et les destructions modernes les ont touchés plus complètement que les pressoirs ${ }^{24}$.

Les foyers ont livré une abondante quantité de noyaux calcinés, mais aussi des charbons issus de ceps de vignes et quelques pépins de raisin : n'a-t-on pas aussi traité du raisin?

Les cuves paraissent très vastes pour des cuves de décantation d'huile. Leurs contenances moyennes semblent disproportionnées au volume habituellement traité dans les huileries. Un moulin contemporain à La Farlède (Var) comporte trois petites cuves de décantation d'une contenance totale de 600 litres pour quatre pressoirs hydrauliques. Une huilerie du xvir" s. a Gordes (Vaucluse) comptait deux cuves de 800 litres pour deux pressoirs à levier. Les huileries antiques fouillées en Italie: Settefinestre, Boscoreale, San Rocco ont livré de petits bassins souvent reliés par une surverse dont la contenance varie de 30 à 800 litres (Carandini et alii, 1986, II, p. 29-30; Pasqui, 1897, plan; Blanckenhagen el alii, 1965,

24 Sur le faible nombre des moulins conservés dans les huileries antiques, aussi bien en Provence qu'en Espagne, en Maurétanie ou en Afrique, voir Brun, 1986a, p. 223 sq. fig. 10). En revanche, la capacité de nos cuves avoisine celles de certaines cuves à vin : à Boscoreale, la cuve souterraine contenait 7000 litres, à Allasles-Mines, la cuve de recueil du moût 2000 litres (Héron de Villefosse, 1899, p. 27-28; Maurin, 1964, fig. 1). Dans la région même, les cuves à vin des villae de La Roquebrussanne et de Cavalaire sont aussi grandes que celles de Saint-Michel.

Cependant, certaines installations oléicoles possèdent des cuves analogues aux nôtres : en Italie, les huileries de Posta Crusta à Ordona, de Posto à Francolise, de Cesana di Senigallia (Mercando, 1979, p. 112); en Afrique du Nord surtout à Volubilis, à Kherbet Agoub, à Bir Sgaoun, à Thuburbo Majus ${ }^{25}$.

Le type des cuves n'est pas caractéristique du produit traité. Dans une même huilerie on peut rencontrer les deux : à Madaure, trois petits bassins accolés pour l'huile de première pression étaient employés conjointement à deux grandes cuves pour l'huile de seconde pression. Il semble que le premier type ait surtout servi pour traiter des quantités limitées: huile de première pression (exemple: Madaure) ou production domestique (exemple : Settefinestre dont l'huile n'était pas commercialisée). Le second type, une grande cuve par pressoir, était destiné aux huiles de seconde pression, celles qui se font avec beaucoup d'eau (exemple: Madaure) et aux grosses productions (exemples : Kherbet Agoub, Bir Sgaoun).

On ne peut donc pas tirer argument du type des cuves. Par contre, les analyses chimiques apportent une indication décisive: les parois contiennent encore des traces d'huile très nettes ${ }^{26}$.

\section{Restitulion des machineries des pressoirs}

Un constat s'impose dès l'abord: l'extrême dégradation des vestiges. Des six pressoirs que comptait l'huilerie, un seul conserve encore son sol, des six blocs d'assise, un seul subsiste, des machineries de manceuvre, rien. L'état des vestiges autorise plusieurs hypothèses de restitution : pressoir à levier et treuil fixe (type C2), à levier et treuil sur contrepoids (type (B)), à levier et vis sur contrepoids (type C4) ${ }^{27}$.

25 Sur Volubilis, en dernier lieu, Akerraz, Lenoir, 19811982, p. 88 : de nombreuses cuves ont des contenances de l'ordre de 3000 a 4500 litres. Pour Madaure, Christofle, 1930, p. 63-64 mentionne des cuves de 25(0) litres. A Bir Syaoun, des travaux récents ont dégagé des cuves de 5000 litres : Brun, 1986a, p. 134 et fig. 47.

26 Etude de $\mathbf{M}^{\text {me }}$ Formenti.

27 Sur la typologie des pressoirs que nous employons et sur les exemples provençaux, voir Brun, 1986a, p. $84 \mathrm{~s} q$. 
Nous pensons pouvoir éliminer la dernière hypothèse pour des raisons de chronologie. Certes l'emploi de la vis était déjà connu au moment où l'on construisit l'huilerie. Pline (N.H., XVIII, 317), Héron (Mécanique, III) avaient déjà décrit des pressoirs à levier et vis. Mais l'usage de la vis en Provence ne semble pas s'être répandu dans les pressoirs avant le $\mathrm{III}^{\circ} \mathrm{s}$. au moins. Les huileries des $\mathrm{I}^{\mathrm{er}}$ et $\mathrm{II}^{\mathrm{r}} \mathrm{s}$. : Le Candéou à Peymeinade (AlpesMaritimes), le Grand Verger à Lambesc (Bouches-duRhône), Valrose à La Londe, Roussivau à SaintRaphaël, L'Ormeau à Taradeau (Var) utilisent des treuils.

Contre l'hypothèse d'un pressoir C2, on mentionnera l'absence de toute trace d'arrachage des blocs d'assise des montants du treuil et la rareté de ce système dans les grandes installations provençales.

Le plus probable est que l'on a affaire ici à des pressoirs C3, au demeurant les plus répandus en Provence au Haut-Empire. L'existence de pressoirs de ce type dans les huileries antérieures des états ID et IE est un indice en faveur de cette hypothèse.

Pour les jumelles, le seul point sur lequel on puisse se fonder est leur section $(48,5 \times 27 \mathrm{~cm})$ et leur écartement $(29 \mathrm{~cm})$. Il est probable que les mortaises de la pierre correspondent à la section des pedicini; les jumelles pouvaient donc avoir une section de 60 sur $45 \mathrm{~cm}$. Leur hauteur devaient être de l'ordre de $2,70 \mathrm{~m}$ si l'on suit les chiffres avancés par Caton (Agr., 18) et les données ethnologiques. Elles ètaient creusées de mortaises longitudinales servant à placer des cales qui permettaient de régler la hauteur de la tête du levier en fonction de la masse à presser ${ }^{28}$.

Les jumelles étaient coiffées d'une traverse les solidarisant. L'assemblage était surmonté par une poutre large de deux pieds supportant et répartissant la charge d'une maçonnerie suffisamment lourde pour résister aux poussées ascendantes transmises par le levier ${ }^{29}$. La restitution d'une telle poutre présente quelques difficultés du fait de la longueur de la chambre de presse $(12,80 \mathrm{~m})$. Une seule poutre ne pouvait suffire, plusieurs mises bout à bout sans liaison organique auraient rendu l'édifice trop fragi-

28 Ces mortaises se retrouvent dans les pressoirs à montants de pierre d'Afrique et dans les pressoirs modernes (Spinola, pl. 10; Humbel, 1976, pl. XVII, XVIII; Bernard, 1788, pl. 2, 2a).

29 Caton (Agr., 18) l'exprime en ces termes "in iis tignis parieles extruito iungiloque materiae uti oneris satis habeant . le. Il faut donc restituer deux séries de longrines jumelées ancrées dans les murs 1 et 3 et supportées par les jumelles des pressoirs. Pour le pressoir 2 , on comptera deux poutres jumelées larges de deux pieds, hautes d'un pied et longues de $5,30 \mathrm{~m}$ (du mur 1 au milieu de l'aire 3). Le volume du bâti de bois formant la tête du pressoir pourrait ètre estimé à $2,5 \mathrm{~m}^{3}$ et son poids à 2 tonnes environ ${ }^{30}$.

Le terme technique désignant le levier du pressoir est "mouton». Sa longueur était égale à la distance bloc d'assise-mur 6 accrue de la longueur nécessaire à l'accrochage du câble du treuil. On l'estimera à $7,50 \mathrm{~m}$ environ, soit la valeur de 25 pieds donné par Caton. Une ouverture haute et étroite devait ètre ménagée dans le mur 6 pour laisser passer et guider le mouton. Les pressoirs à levier modernes montrent des moutons de forte section, gros tronc mal équarri afin de conserver le plus de poids possible et de résister à la flexion ${ }^{31}$. Pour la commodité des calculs, nous pensons qu'un mouton en chêne d'une section moyenne de $0,60 \mathrm{~m}$ offre une approximation suffisante. Un tel levier, d'un volume de $2,5 \mathrm{~m}^{3}$ pèserait environ 2,3 tonnes ${ }^{32}$.

Pour le treuil et le contrepoids, nous prendrons la moyenne des contrepoids de treuil connus dans le Var, soit 1,3 tonne.

Ces données de départ estimées, on peut tenter de déduire la puissance optimale du pressoir et la masse de maçonnerie nécessaire au maintien des jumelles au sol.

Le réglage de la tête du levier permettait de rapprocher les couffins (scouffins) remplis de pâte d'olive du bloc d'assise jusqu'à une distance de $1,20 \mathrm{~m}$. La force qui pouvait être appliquée en ce point était de 13,5 tonnes $^{33}$. Cela donnerait une pression de $4,7 \mathrm{~kg} / \mathrm{cm}^{2}$ pour des scouffins circulaires

30 Jumelles : $\lceil(\mathrm{h}=2,60 \mathrm{~m}) \times(l=0,60 \mathrm{~m}) \times(\dot{\mathrm{e}} \mathrm{p} .=$ $\left.0,4 \mathrm{~m})=0,7 \mathrm{~m}^{3}\right] \times 2=1,4 \mathrm{~m}^{3}$.

Chapeau : $1,20 \mathrm{~m} \times 0,60 \mathrm{~m} \times 0,30 \mathrm{~m}=0,2 \mathrm{~m}^{3}$.

Poutres : $5,30 \mathrm{~m} \times 0,60 \mathrm{~m} \times 0,30 \mathrm{~m}=0,9 \mathrm{~m}^{3}$.

Masse pour du chène : $2,5 \mathrm{~m}^{3} \times 0,9$ (densité) $=2,2 \mathrm{t}$.

31 Voir les exemples modernes de Val Benoit (Humbel, 1976, pl. XLIII), du Musée Martini (Spinola, pl. 10), de Boscotrecase (Drachmann, 1932, p. 122), etc.

32 Levier: $[(\mathrm{L}=7,50 \mathrm{~m}) \times($ section $=0,60 \times 0,60 \mathrm{~m})]$ $-[(\mathrm{L}$ de la lingula $=0,75 \mathrm{~m}) \times(0,60 \times 0,25 \mathrm{~m})]=2,5 \mathrm{~m}^{3}$ soit 2,3 tonnes.

Par comparaison, le mouton de l'huilerie d'Idanha Velha au Portugal pèse 2.25 tonnes (Amouretti et alii, 1984, p. 394).

33 Le mode de calcul est exposé dans Brun, 1986a, p. 244-246. Dans le cas présent, on a :

$\mathrm{F}=\frac{\mathrm{PI}+\mathrm{TL}}{\mathrm{d}}=\frac{(2300 \times 3,25)+(1300 \times 6,75)}{1,2}=13500 \mathrm{~kg}$. 


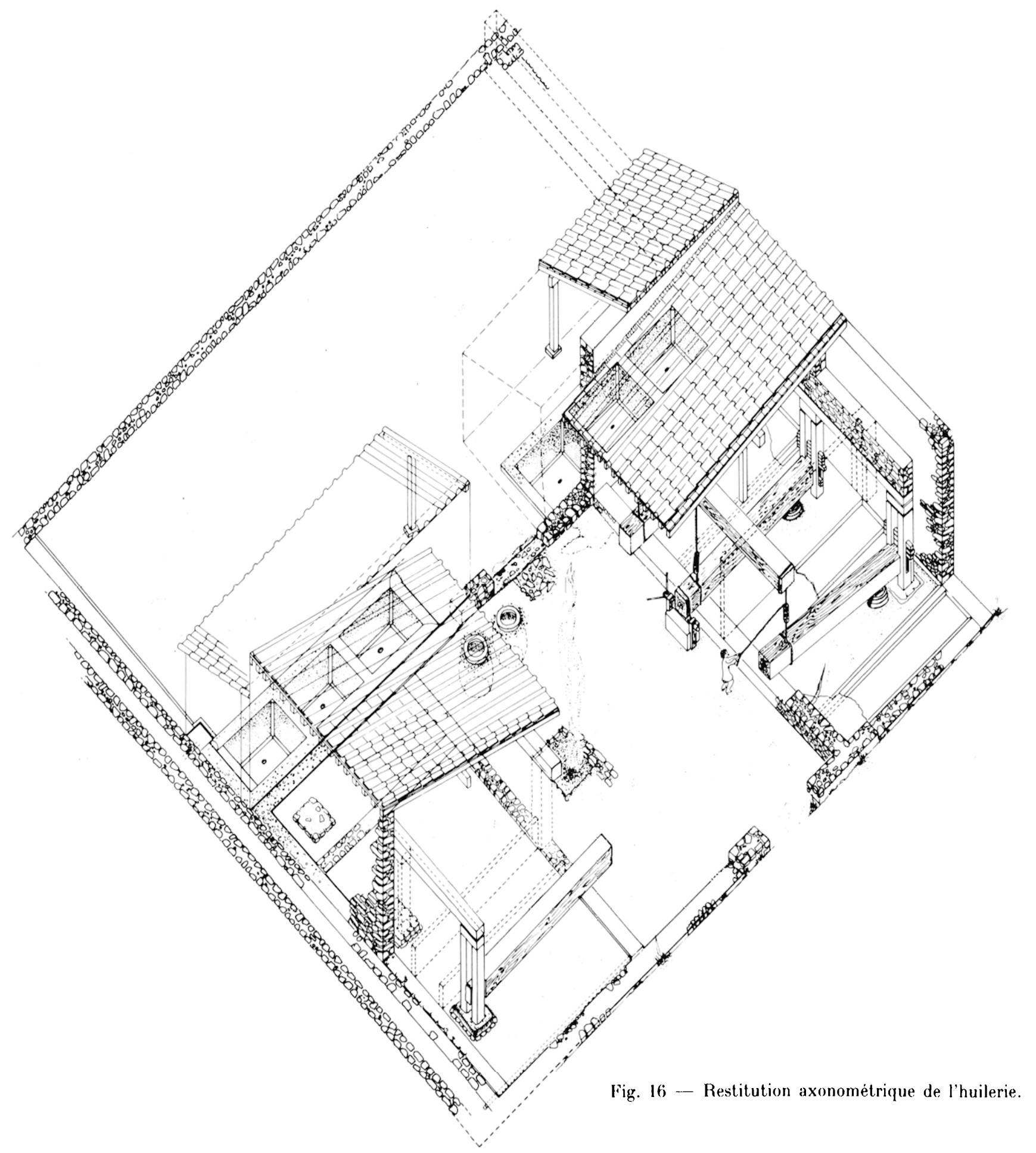

de 2 pieds de diamètre. En réalité, compte-tenu des frottements, la pression moyenne devait s'établir autour de 3 à $4 \mathrm{~kg} / \mathrm{cm}^{2} 34$.

On peut dès lors estimer la masse qui devait charger les poutres supportées par les jumelles : elle devait être égale à la force exercée par le levier sur les jumelles, soit environ 10 tonnes ${ }^{35}$. Compte-tenu

34 Soit environ 20 à 40 fois moins qu'un pressoir hydraulique actuel dont les pressions spécifiques oscillent entre 70 et $140 \mathrm{~kg} / \mathrm{cm}^{2}$ (Loussert, Brousse, 1978, p. 366 , note 2).

35 La force exercée par le levier sur les jumelles est égale à celle exercée sur les scouffins diminuée de la tension du du poids du bâti des poutres $(2,25 \mathrm{t})$, la maçonnerie devait peser environ 8 tonnes et représenter un mur de $1 \mathrm{~m}$ de haut sur $0,60 \mathrm{~m}$ de large ${ }^{36}$. Étant donné la hauteur minimale du mur 2 , plus de $4 \mathrm{~m}$, il est évident que la pente du toit allait de l'extérieur vers la cour 13. Ces estimations fondent la restitution des pressoirs que nous donnons (fig. 16 et 17).

contrepoids et de la masse du mouton : $13500-(1300+2300)=9900 \mathrm{~kg}$.

36 La prise en compte du poids de la charpente el de la toiture permettrait d'abaisser la hauteur de la maçonnerie d'une vingtaine de centimètres mais en aucun cas de l'éliminer. 


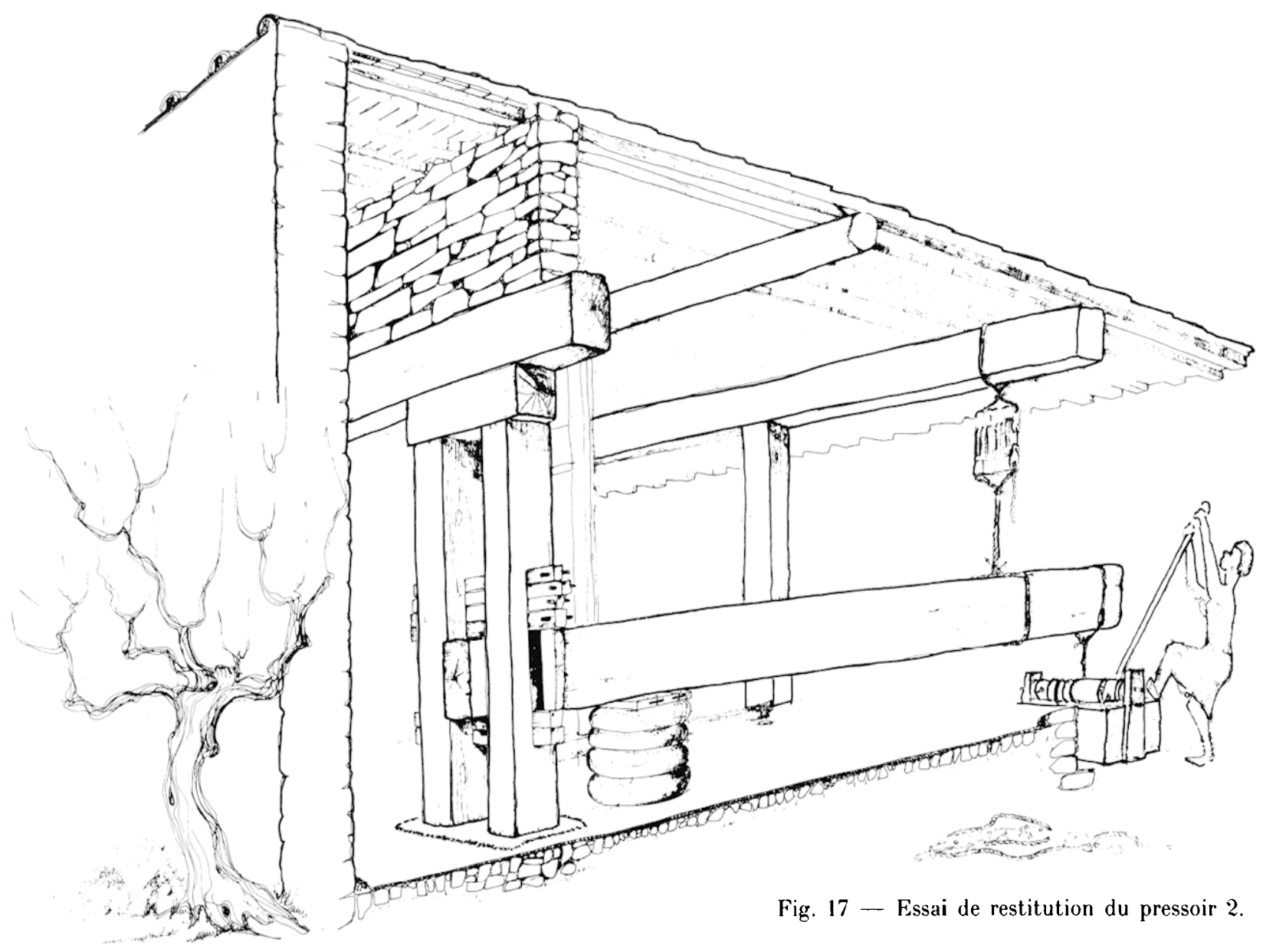

Déroulement des opérations d'extraction de l'huile

Les olives devaient arriver par charettes ou à dos d'âne dans la cour 13 pour être déposées en tas. Après un temps d'attente plus ou moins long, elles étaient ensuite broyées au moyen de trapela probablement au nombre de trois.

Après le broyage, la pâte d'olives était transportée dans les pressoirs où elle était mise en scouffins. On y accédait par des ouvertures situées en bout des couloirs de séparation. Le bâtiment était vraisemblablement fermé. Le pressurage se faisant au cours des mois de novembre à février, il est inconcevable de procéder à l'air libre : l'extraction serait rendue difficile par le froid. Les auteurs antiques insistent d'ailleurs sur la nécessité de maintenir les pressoirs clos et bien chauds. Palladius (I, 20) pour une époque postérieure à notre huilerie précise même que le moulin à huile "doit être exposé au midi et protégé contre le froid; ainsi la lumière ne doit y pénétrer qu'à travers des vitres". Les vitres retrouvées au fond de la cuve 16/17, dernière restée en usage, pourraient provenir des vitrages de la chambre de presse. S'ils préconisaient d'exposer les pressoirs au sud, les agronomes déconseillaient de faire du feu dans le pressoir même car les fumées auraient risqué de gâter le goût de l'huile. Ces conseils paraissent avoir été suivis ici : tous les foyers sont dans la cour.

Les scouffins remplis étaient empilés un peu en avant du bloc d'assise des jumelles, puis on abaissait le mouton à l'aide d'un câble tiré par un treuil fixé au contrepoids. Lorsque le tas de scouffins s'était un peu écrasé, il fallait descendre quelque peu la tête du levier pour continuer la pression. Pour ce faire, on remontait l'extrémité libre du mouton à l'aide d'un câble passant dans une mouffle ou un palan pour démultiplier l'effort. La tête du levier s'abaissait alors et on pouvait ajouter de nouvelles aiguilles dans la mortaise taillée dans les jumelles. On recommençait l'opération plusieurs fois jusqu'à ce que la première pression soit terminée.

Pour continuer les opérations, il fallait ensuite remonter le levier afin de libérer la pile des scouffins. La galette noire de pâte d'olives contenue dans les scouffins était brisée et abondamment arrosée d'eau chaude. Les scouffins, à nouveau remplis étaient portés sous un pressoir voisin dans l'ordre inverse de 
celui adopté pour la première pression. Deux pressées au moins étaient nécessaires à une bonne extraction de l'huile ${ }^{37}$.

L'huile, les margines, les boues, l'eau ajoutée s'écoulaient par un caniveau jusqu'aux cuves de décantation. Le grignon devait être entassé dans un coin de la cour en attendant d'ètre brùlè dans les foyers. Le liquide extrait lors de la première pression est formé d'huile $(25 / 30 \%)$ et d'eau de végétation $(70 / 75 \%$ ). Lors des pressées ultérieures, la proportion d'eau croît considérablement. Pour séparer les éléments, il suffit de laisser s'opérer une décantation par gravité ; l'huile surnageant est recueillie à l'aide d'une "casse». La décantation s'opérait dans les cuves 16 à 21 que leurs grandes dimensions rendaient a priori moins pratiques que des cuveaux jumelés reliés par des surverses. Il est toutefois vraisemblable que ces vastes bassins présentaient des aménagements internes, tels que des cuveaux de plomb mobiles qui recueillaient par surverse l'huile lorsqu'elle avait atteint le niveau de leur embouchure. Caton (Agr., 66, 1) dit très clairement "que le moulinier mette dans la cuve un chaudron de plomb pour que l'huile coule dedans". Columelle (XII, $52,10)$ indique également que l'on employait des récipients carrés ou des bassins jumelés en plomb ${ }^{38}$.

La première décantation effectuée, il fallait purifier l'huile plusieurs fois afin d'éliminer toute trace de margine. Ces opérations se faisaient dans le cellier où l'huile était entreposée. Ce bâtiment n'a pas èté retrouvé, mais pourrait se trouver au sud-est de la cour 15 , zone encore inexplorée.

\section{Datation de la construction de l'huilerie}

Les remblais de la cour 13 contemporains de l'édification de l'ètat IIA se sont révélés très pauvres en matériel datable, pour l'essentiel attribuable à la seconde moitié du $\mathrm{I}^{\text {er }} \mathrm{s}$. après J.-C. Si, comme nous le pensons, la grande huilerie a pris la succession de l'état IF daté de la fin du $\mathrm{I}^{\mathrm{er}} \mathrm{s}$., sa construction est à placer au plus tôt à l'extrême fin du $\mathrm{I}^{\mathrm{er}} \mathrm{s}$. et plus probablement au début du $I^{\circ}$ s.

C'est surtout le début de l'utilisation des foyers, d'un dépotoir en contrebas de l'huileric (voir infra,

37 C'resswell, 1965 , p. $46-48$ a montré qu'il existe un palier de rendement optimum pour les presses traditionnelles obtenu avec des pressions faibles en augmentant le facteur temps. Ces presses permettent d'extraire environ les deux tiers de l'huile qu'il est théoriquement possible d'obtenir.

38 L'utilisation de plomb est nécessaire pour que le récipient se maintienne au fond de la cuve. La disparition totale de ces ustensiles ne doit pas étonner : on sait combien, tout métal, le plomb particulièrement, était récupéré. p. 124) et des égouts $98 / 99$ et $115 / 116$ qui nous renseigne sur l'époque de construction de la grande huilerie. En effet, mis à part le matériel résiduel, rare d'ailleurs, ces dépôts commencèrent tous à se constituer avec des objets d'époque flavienne en asse $z$ grand nombre probablement encore en usage à la fin du $\mathrm{I}^{\mathrm{er}} \mathrm{s}$. et au début du $\mathrm{II}^{\mathrm{e}} \mathrm{s}$. Ces divers endroits continuèrent à recevoir du matériel durant tout le II $\mathrm{s}$. et au cours de la première moitié du II ${ }^{*} \mathrm{~s}$. Après 250 , il semble qu'ils n'aient plus beaucoup été alimentés : c'est que leur fonction de décharge cessa alors au profit des cuves de décantation d'huile plus proches et inutilisées au cours de l'état III (voir infra, p. 128 et p. 139 , tabl. VI et VII).

\section{Etat IIB : LES TRANSFormations de L'HUilerie}

L'état IIB regroupe des transformations mineures, normales dans la vie de l'huilerie. Ces remaniements sont difficiles à dater, même relativement les uns par rapport aux autres (fig. 18).

\section{État IIBI}

Cet état est marqué par la mise en place de deux dolia dans la cour 13 contre le mur 3 . Le béton de tuileau de la pièce 14 et le mur 34 furent détruits et un mur de soutènement 17 édifié. Les dolia étaient enterrés jusqu'au col dans une fosse longue de $3,20 \mathrm{~m}$ et profonde de $1,60 \mathrm{~m}$. Ils étaient calès par des pierres et des fragments d'un autre dolium brisé lors de la mise en place (fig. 27). Leur contenance était de l'ordre de 1600 litres $^{39}$.

Leur rôle n'est pas très clair : il ne peut s'agir de dolia de stockage de toute l'huile produite dans l'huilerie; leur capacité était insuffisante. A Peymeinade, la salle de stockage du pressoir de l'îlot 1 comprenait 14 dolia, certes plus petits, mais dont la capacité totale avoisinait 7000 litres (Goudineau, 1973, p. 567-568 et fig. 36 , pièce XVI). Doit-on y voir deux unités de stockage provisoire et de raffinage pour les décantations secondaires? Cela paraît plausible encore que les analyses chimiques n'aient pas trouvé de traces d'huile dans leurs parois. Peut-ètre étaient-ce des récipients pour l'eau nécessaire aux opérations de pressurage ou pour les margines, l'amurca dont les anciens faisaient un grand usage ${ }^{40}$ ?

39 Sur les ralculs de contenance des dolia, voir Lecacheur, 1985.

40 l'amurca des anciens correspond aux margines, résidu de la décantation fait d'eau de végétation, d'eau ajoutée et de boues huileuses. Sur les usages multiples de l'amurca, voir Brun, 1986a, p. 56 sq. 


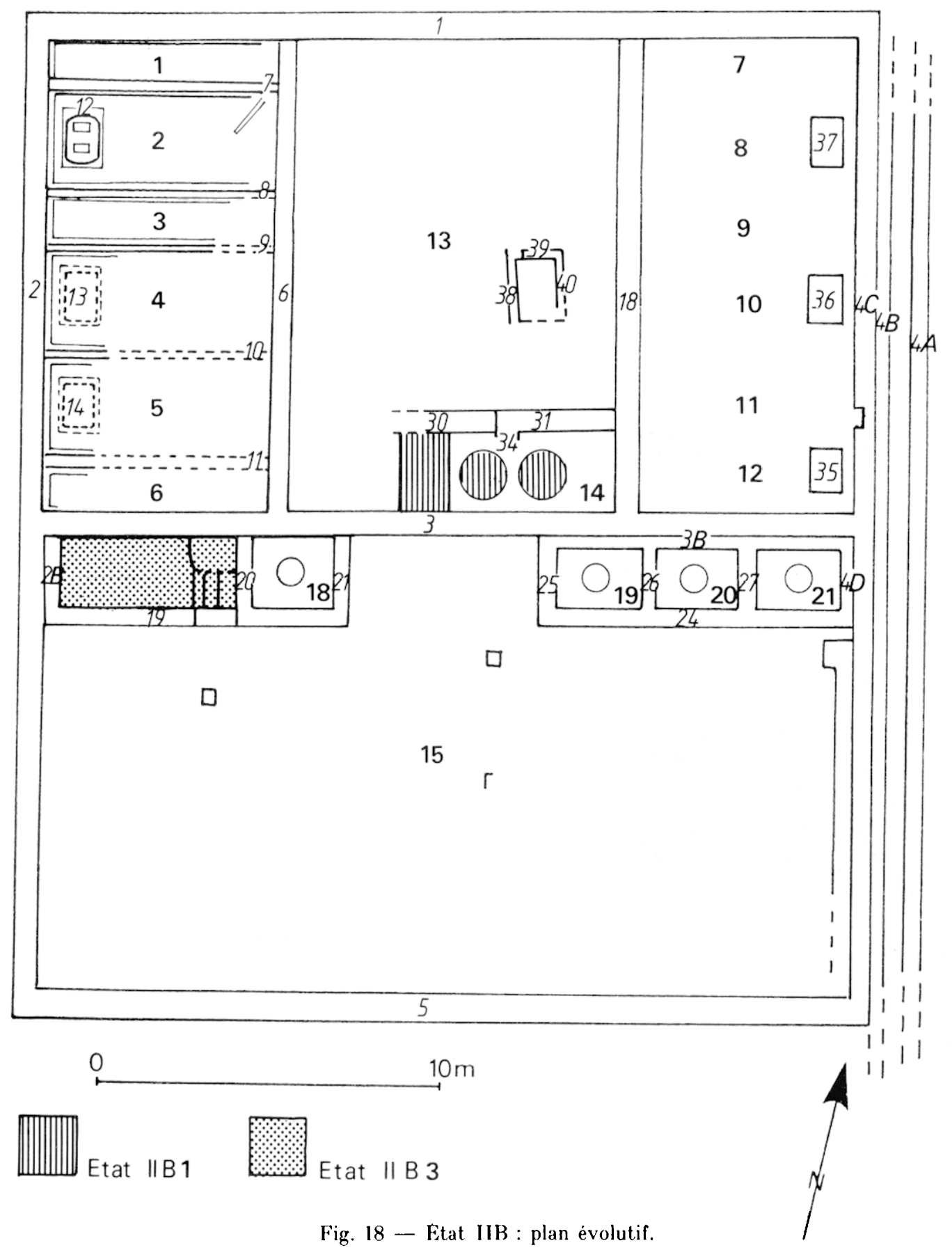

Les remblais de calage des dolia ont livré très peu de matériel. On ne sait donc précisément quand ils furent mis en place, peut-être peu de temps après la construction de l'huilerie dont ils complètent l'aménagement.

\section{État IIB2}

Les états IIB2 et 3 intéressent les cuves 16 et 17 , seules à avoir subi des remaniements. L'état IIB2 est caractérisé par la destruction complète du mur 41 séparant les cuves 16 et 17 et par l'édification de murets ou socles bâtis à la chaux contre le mur 3 à l'intérieur de la grande cuve formée et extérieurement enduits de morticr de tuileau (fig. 19).

La destination de cette installation très arasée reste indéterminée : il pourrait s'agir d'un soubassement de cuveaux. Cette modification qui rend inutilisables les cuves 16 et 17 est indatable.

\section{État IIB3}

L'état IIB3 correspond à une nouvelle transformation changeant l'aspect et la destination des cuves 16 et 17. Les aménagements de l'état IIB2 furent alors arasés à $15 \mathrm{~cm}$ du sol, ennoyés dans un 


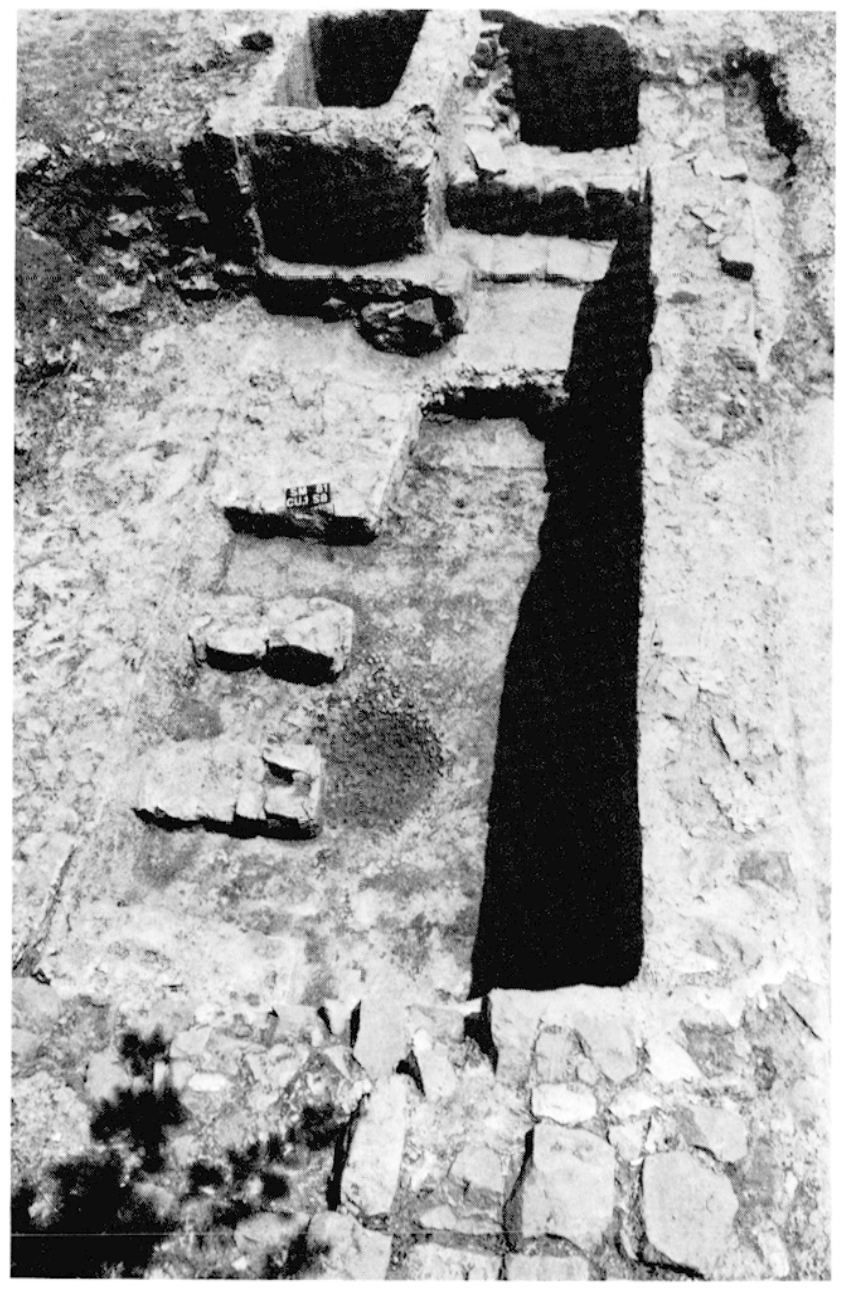

Fig. 19 - Etat IIB2: socles de maçonnerie dans la cuve 16/17. État IIB3 : escalier et puisard à l'extrémité est de la cuve. Etat III : cuveau dans l'angle nord-est de la cuve.

hérisson. Le tout fut recouvert d'une dalle de béton de tuileau en pente vers un puisard circulaire ménagé au pied d'un escalier à trois degrés installé dans la partie nord-est de la cuve 17 (fig. 19).

L'utilisation de cette vaste cuve de $5,25 \mathrm{~m}$ de long par 1,90 m de large et d'une contenance utile de 7500 litres n'apparaît pas clairement. La présence d'un escalier dans les grandes cuves est relativement fréquente mais la nouvelle cuve est trop vaste et trop peu profonde pour servir à la décantation ou au stockage de l'huile ${ }^{41}$. Il reste deux possibilités : les cuves 16 et 17 furent réunies et remodelées soit pour créer une cuve à vin, soit pour aménager un bassin de récupération de l'huile d'enfer c'est à dire de l'huile de mauvaise qualité que renferment les

41 Cuves avec escaliers à Guidonia (Caprino, 1944-1945, fig. 2), à Posta Crusta, Ordona (De Boe, 1975, fig. 29), au Petit Bois, Maroc (Ponsich, 1964, fig. 4), etc. Une vaste surface à l'air libre occasionne le rancissement par oxydation. margines. La première hypothèse suppose une reconversion partielle des installations de pressurage ${ }^{42}$. La seconde parait s'inscrire plus aisément dans la logique de l'installation ${ }^{43}$.

Les remblais et les sols de béton s'étant révélés stériles, il est impossible de préciser la datation de cet état.

\section{État II : Aménagements annexes}

\section{Zone sud-est (fig. 3)}

Il convient de rattacher à l'état IIA les structures dégagées dans la partie sud-est du plateau : les murs 104 présentent le même mode de construction, le même système d'évacuation d'eau et prolongent les murs 4 . Entre les murs $104 \mathrm{~A}$ et $104 \mathrm{~B}$ court un caniveau qui forme un coude vers le nord pour rattraper l'alignement du canal placé entre les murs $4 \mathrm{~A}$ et $4 \mathrm{~B}$.

Le plateau est bordé au sud par un puissant soutènement large de $1,40 \mathrm{~m}$ et formé de deux murs accolés. La zone située au sud-est de ces murs, très en contrebas du plateau, semble appartenir à la pars urbana.

Le plateau est traversé d'ouest en est par un égout 115/116 long de $24 \mathrm{~m}$. Il drainait les eaux usées des bâtiments de cette partie du plateau : son comblement, contemporain de l'utilisation de l'état II, contenait essentiellement des résidus alimentaires et de la céramique. Cet égout se jetait certainement dans le collecteur 98/99: la topographie et la similitude du matériel l'indiquent.

\section{Terrasses orientales}

Cette zone est mal connue : la mise en culture avait occasionné d'importantes destructions aggravées par l'édification de deux baraquements préfabriqués en 1975 et 1979 . Les terrassements de 1975 ont mis au jour un vaste dépotoir et les vestiges d'un bâtiment qui parait désaxé par rapport aux autres constructions de la villa. A l'intérieur, se trouvait une couche de tuiles brisées mêlées à des cendres et d'abondantes scories de fer : il pourrait donc s'agir d'une forge. Le matériel de la tranchée de fondation du mur 93 permet de dater la construction de ce bâtiment de la fin du ier $s$.

42 Une telle reconversion ne pose pas de problèmes techniques (les machineries sont identiques à peu de choses près), mais présente des difficultés de nettoyage. L'huile laisse une odeur et des traces très difficiles à éliminer. Un tel exemple de reconversion existe peut-être à la villa Prato en Italie (communication d'Henri Broise et Xavier Lafon).

43 Un caquier de grandes dimensions $(4,50 \mathrm{~m} \times 2,90 \mathrm{~m})$ a été mis au jour dans l'huilerie de L'Ormeau B à Taradeau. 
La zone d'épandage écornée en 1975 a été partiellement fouillée en 1978: son matériel est contemporain de l'état II : il s'agit du dépotoir de la grande huilerie ${ }^{44}$.

La terrasse inférieure devait être située en dehors des bâtiments et cultivée en jardins. Le collecteur 98/99 débouchait à son niveau. Sa construction nécessita le creusement d'une profonde tranchée dans le substrat. Un voutain de pierres plates et de tuiles devait le couvrir. Ses parois sont tapissées de tuf descendant jusqu'à une couche horizontale de tuf (couche 5). Cet égout, très grand, situé au point le plus bas des vestiges était probablement le collecteur des eaux usées et pluviales de la villa. Au-delà de la partie couverte, les eaux usées s'écoulaient dans une tranchée et se perdaient dans une zone d'épandage en contrebas.

\section{PARS URBANA}

La pars urbana était implantée sur les terrasses méridionales du site. La terrasse supérieure n'a pas été fouillée. Les bâtiments de la terrasse inférieure ont été complètement détruits par les cultivateurs. On ne connaît pas la limite orientale des bâtiments qui disparaissent au niveau de l'alignement du mur 104. Vers le sud-ouest, l'aile thermale est détruite au ras d'une limite de propriété (fig. 20 et 21). Les découvertes de surface indiquent que les structures devaient se prolonger vers l'ouest, probablement par une cour, sur une vingtaine de mètres ${ }^{45}$.

La construction de cette partie est approximativement contemporaine de celle de la grande huilerie : les techniques de construction sont identiques et les datations fournies par le matériel archéologique concordent. Ces deux ensembles font partie d'une même phase d'expansion. Il est cependant impossible de faire coincider les évolutions de chacun d'eux car les modifications sont apportées aux constructions en fonction de motivations et de contraintes indépendantes ${ }^{46}$.

44 Il convient de signaler que parmi le matériel céramique retrouvé, deux vases portaient des graffites de propriété : Valeria et nemo tangit me[... On peut se demander si les humbles vases en question n'appartenaient pas à des esclaves comme le suggère l'éditeur des graffites de Peyrestortes (Claustres, 1958, p. 46).

45 Étant donné la disposition des pièces thermales et l'abondance du matériel découvert en surface, il est vraisemblable que la zone détruite correspondait en partie à une cour de service des praefurnia.

46 Les périodes $\mathrm{A}$ et $\mathrm{B}$ de l'état II de la pars agraria sont sans rapport avec celles de la pars urbana.

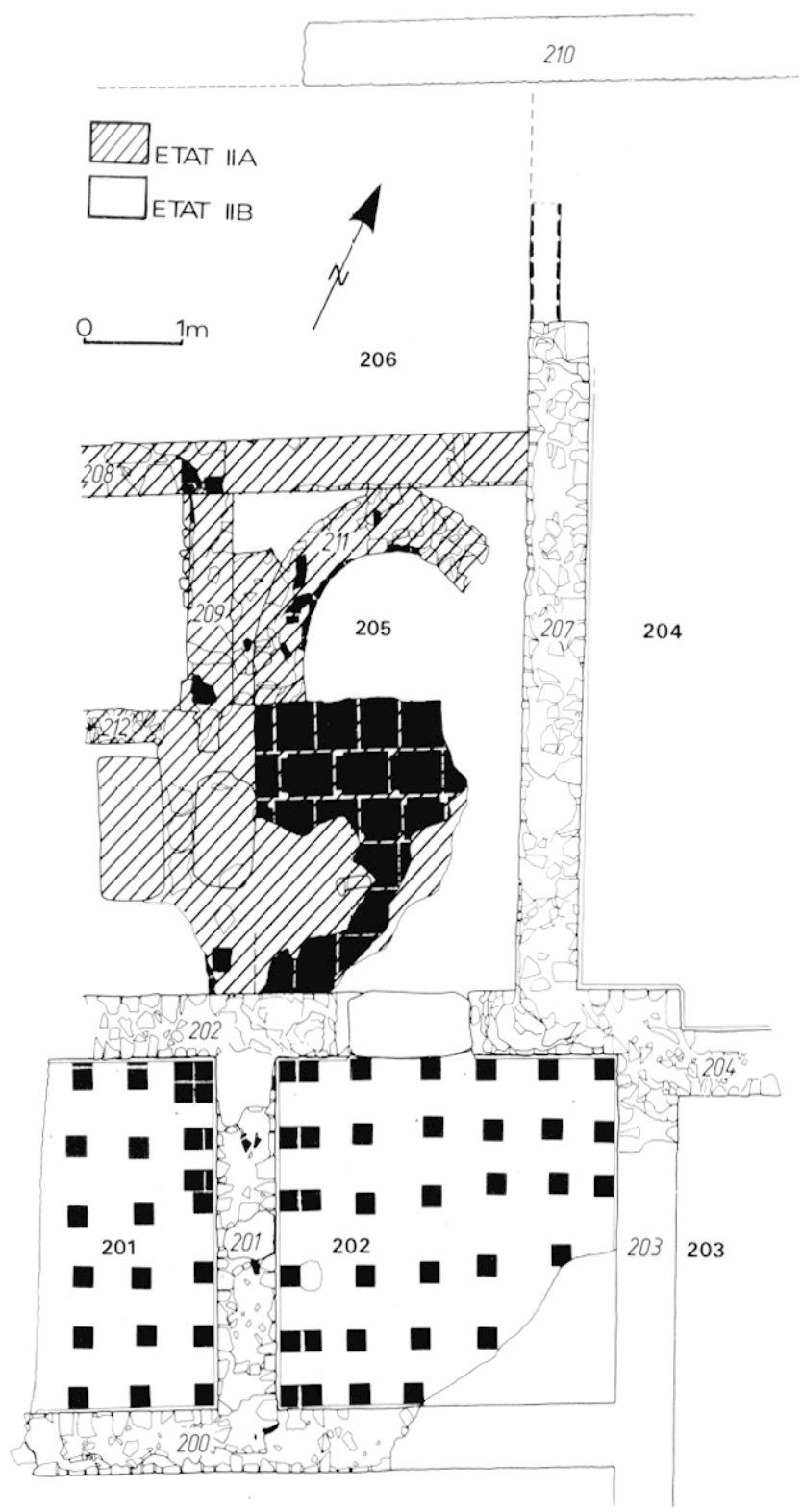

Fig. 20 - Pars urbana : état II.

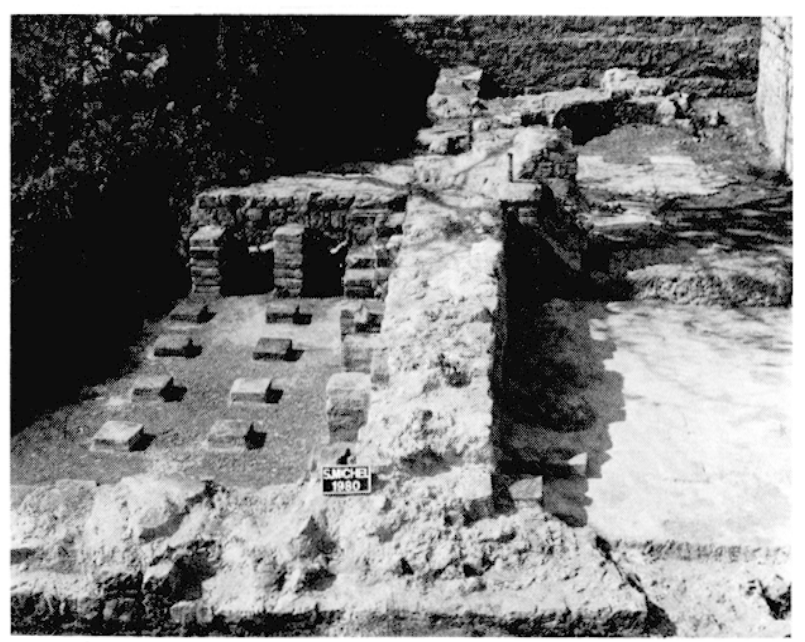

Fig. 21 - État II : vue générale de la zone thermale. 


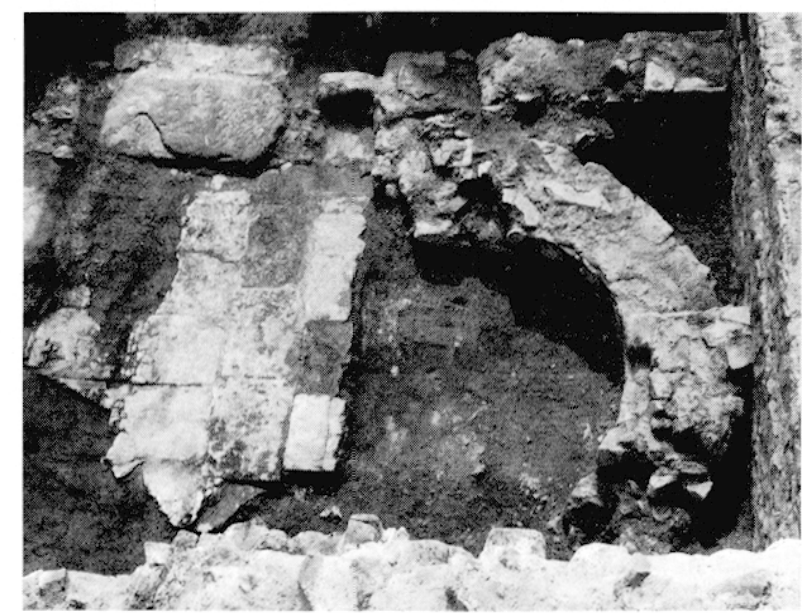

Fig. 22 - Etat IIA : pièce 205, abside et praefurnium.

\section{État IIA}

La fouille est trop partielle pour comprendre l'organisation des structures de l'état IIA : il n'en subsiste que la pièce 205. Il s'agit d'une pièce thermale à abside limitée au nord-ouest par un mur en opus caementicium, avec un appareil assez irrégulier mais soigneusement repris au fer. Le mur $209 \mathrm{de}$ même facture, est percé par une ouverture marquée par un bloc de grès. Ce bloc est doublé par un autre plus long situé à l'ouest et bordé par un muret : ce sont évidemment les restes d'un praefurnium (fig. 22). On brûlait dans ce foyer, outre du bois, des grignons d'olives résidus du pressurage.

Le sol de la pièce est formé d'un dallage de legulae retournées. Des éléments d'un pilier de grès approximativement carré ont été découverts dans les décombres de l'abside : ils pourraient provenir d'un pilier central de suspensura ou de support d'une baignoire. Cette pièce constituait donc un caldarium. Sans doute relativement longue, elle a été raccourcie lors des transformations de l'état IIB.

Les décombres accumulés dans l'abside contenaient des fragments d'enduits peints et d'opus sectile. Certains enduits, très fragmentés, paraissent avoir été décorés de panneaux ocre rouge encadrés de bandes jaunes et vertes et séparés par des champs noirs à filets ornés de candélabres ${ }^{47}$. Des corniches en marbre rouge de Mani pourraient avoir fait partie de cette décoration. L'une d'elles porte encore la peinture noire qui la recouvrait. De nombreux fragments provenant d'un pavement en opus sectile ont été également découverts. Des plaquettes de $113 s q$. marbre blanc de l'Apennin, gris du Cap de Garde, jaune de Chemtou, rouge de Mani, et de porphyre vert de Laconie sont taillés en forme de losanges, de trapèzes, de triangles, de baguettes. Le décor reconstituable à partir de ces éléments est relativement banal et peu caractéristique d'une époque particuliè$\mathrm{re}^{48}$.

Les remblais remontant à la construction de l'état IIA ont livré de la céramique sigillée sudgauloise et des fragments d'amphores gauloises. Les couches d'utilisation ont fourni un matériel similaire mais très pauvre. Malgré tout, on peut assurer que la construction est postérieure au troisième quart du $\mathrm{r}^{\text {rr }}$ s. Voir infra, p. 145, tabl. VIII.

\section{État IIB}

Lors des aménagements de l'état IIB, on transforma la pièce 205 en remise et on construisit de nouvelles pièces 201, 202, 203 et 204. L'ensemble des murs édifiés alors sont en opus caementicium à petit appareil repris au fer. Le mur 202 est percé d'une bouche de chaleur marquée par un bloc de basalte : il s'agit du praefurnium chauffant un nouveau caldarium 202. La pièce 205 perdit sa suspensura et fut transformée en remise ou courette de service.

Les pièces 201 et 202 montrent des hypocaustes au sol en béton de tuileau et à pilettes de briques. La pièce 201 était chauffée par un praefurnium indépendant, détruit, situé à l'ouest. L'angle nord de la pièce présente des doublements de pilettes liés à l'évacuation des fumées : de nombreux tubuli rectangulaires y ont été retrouvés (fig. 21).

Les couches de destruction de ces pièces ont livré des éléments provenant de leur décoration. Le sol, au-dessus du béton de la suspensura, était pavé de mosaïque blanche semée par endroits de cubes de calcaire gris. Les murs devaient être recouverts jusqu'à une certaine hauteur de plaques de marbre blanc de l'Apennin et gris du Cap de Garde, fixées par des crochets de fer et terminées en boudin. Audessus de cette plinthe, on trouvait des enduits peints à décor de bandes et d'imitation de marbre.

Lors de la construction et des transformations de la pars urbana, on a donc employé des marbres provenant de l'ensemble du bassin méditerranéen (fig. 23). Cette richesse d'approvisionnement atteste certainement l'aisance des propriétaires, mais aussi

48 Par exemple Balland et alii, 1966, fig. 17 pour l'époque républicaine et Becatti, 1971, nos 49, 189, 343 et 402 pour le IV $\mathrm{s}$. La détermination des marbres a été effectuée à partir de Gnoli, 1971 et avec l'aide de M. F. Braemer (voir Braemer, 1982). 


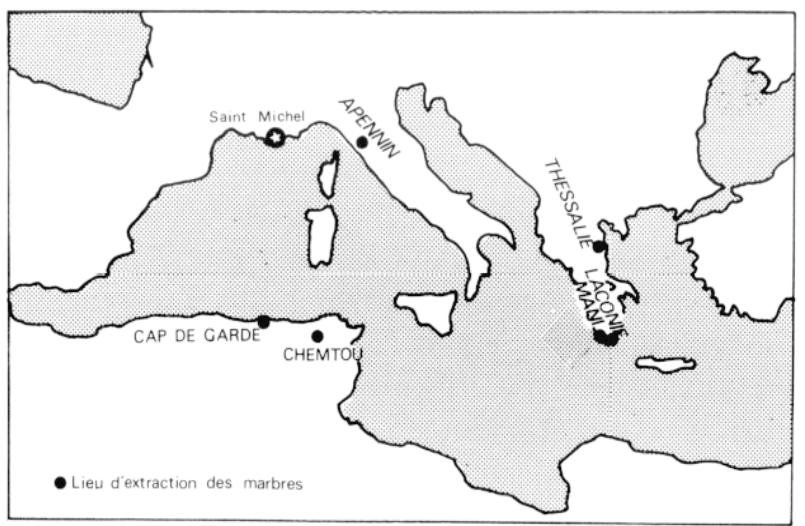

Fig. 23 - Provenance des marbres utilisés dans la décoration de la pars urbana.

la proximité de la mer. On trouve en effet une grande diversité de marbres dans les villae côtières, comme celles de La Madrague de Saint-Cyr et de Pardigon 2 à La Croix-Valmer. A l'inverse, comme il est logique, les villae de l'intérieur présentent une moins grande variété d'approvisionnement : à La Roquebrussanne, la villa du Grand Loou était seulement décorée de marbres du Cap de Garde, de l'Apennin et de brèche de Syros.

L'état IIB doit être placé dans le courant du $I^{\circ} \mathrm{s}$. Les couches liées à sa construction ont cependant fourni trop peu de matériel pour qu'on puisse être plus précis. Ces bâtiments furent utilisés jusqu'au milieu du IV ${ }^{e}$ s., époque où un incendie ravagea la remise 205 et peut-être l'ensemble des pièces thermales. Voir infra, fig. 31 et p. 145 , tabl. VIII.

\section{LES ÉVOLUTIONS TARDIVES}

Le déclin de la production oléicole, peut-être perceptible dans les transformations de la fin de l'état II, s'accentua vers le milieu du III $^{*} \mathrm{~s}$. Les installations de production furent en grande partie abandonnées et se dégradèrent. L'occupation du site continua sans connaître ni l'intensité, ni le luxe relatif de l'époque précédente. Pour finir, après l'abandon du site, les ruines, longtemps visibles furent utilisées comme cimetière rural.

\section{État III}

L'état III prend la suite de l'état IIB dans l'huilerie. Un changement important marque ce passage: la fin de la grande production oléicole. Certes, on continua à faire de l'huile mais sur une

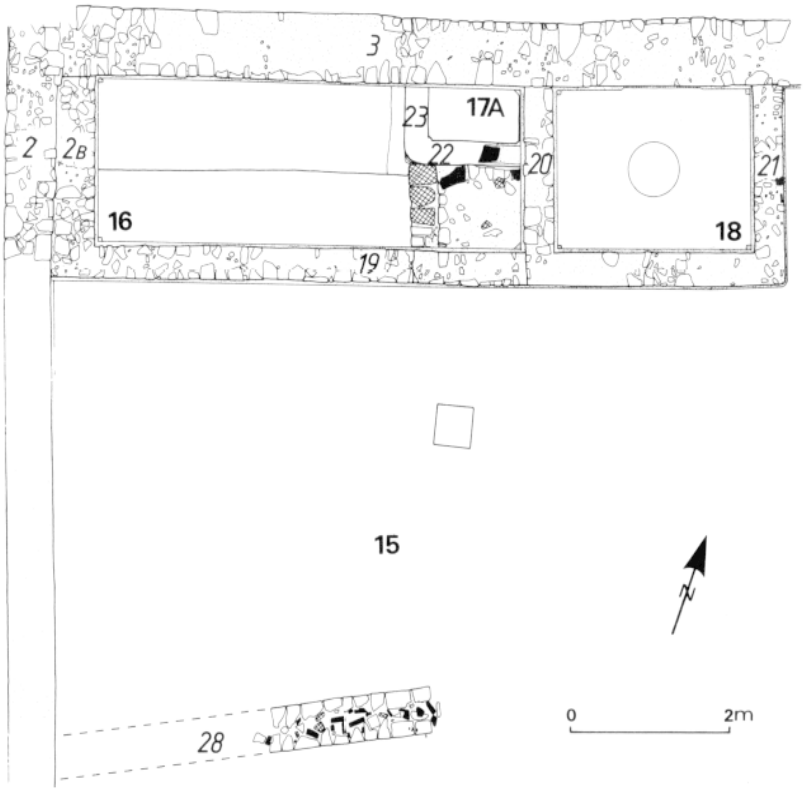

Fig. 24 - Plan détaillé des transformations de l'état III.

moindre échelle, les installations inutilisées étant transformées en dépotoirs.

\section{Constructions}

Les modifications de l'état III furent limitées au coin de la cour (fig. 24). Les cuves 16/17 furent réaménagées : l'escalier fut diminué de moitié par la construction d'un cuveau enduit de béton de tuileau, d'une contenance de 460 litres environ (fig. 19). Il servait certainement à la décantation de petites quantités d'huile. En même temps, la grande cuve créée lors de l'état IIB3 reçut un massif maçonné accolé au mur $3^{\mathbf{4 9}}$.

Parallèlement, la construction du mur 28 transforma le préau appuyé contre le mur 2 en pièce habitable. Ce mur fut édifié avec des matériaux de récupération liés à l'argile. A l'intérieur de la pièce, le sol était formé soit des affleurements de l'ancien sol, soit d'un sol en terre sur lequel étaient rejetés tessons et déchets alimentaires. Un petit foyer était posé à même le sol, vers le centre de la pièce.

L'occupation de cette pièce et des pièces voisines dura suffisamment longtemps pour que les anciennes cuves de décantation 18 à 21 et les dolia, inutilisés fussent comblés de détritus et gravats divers. La stratigraphie du remplissage des cuves, complexe, a permis de mettre en évidence plusieurs stades de comblement (fig. 30).

49 Ce massif a été détruit au xvin s. lors de l'arrachage des pierres du mur 3 . 
Un premier stade marque une période d'abandon entre la fin de la grosse production oléicole et le début du rejet des détritus (fins dépôts alluvionnaires, fragments d'enduits, lentilles de tuileau). Durant le stade 2 , des balayures, des cendres et des détritus furent jetés au fond de toutes les cuves. Au stade 3 , les cuves 18 et 19 reçurent un épais dépôt d'ossements comprenant essentiellement des os de bovins (plus de $40 \%$ des individus), suidés (35\% des individus), d'ovi-capridés ( $14 \%$ des individus) et de cervidés ( $8 \%$ des individus). Le reste se compose d'ânes, de chiens, de lapins, de fouines, de surmulots, de volaille et de coquillages (voir infra, p. 155). Le stade 4 marque une volonté d'assainissement matérialisée par d'épais remblais de tuiles et fragments de dolia, déposés dans les cuves 18 à 21 . Au cours du stade 5 , de nouvelles couches d'ordures et de balayures furent déposées dans les cuves 19 à 21 . Après ces dépôts, le stade 6 paraît marquer la destruction des structures environnantes.

Le comblement des dolia a été effectué au cours de la même période sans que l'on puisse le rattacher à un stade précis. Le dolium 1 a été arasé et comblé volontairement avant le dolium 2.

La chute de la production oléicole ne dut pas être brutale. Il est probable que les quantités traitées diminuèrent progressivement, entraînant un délabrement des installations puis leur abandon partiel. De cette progressivité, nous avons quelques indices: stade 1 du remplissage des cuves, construction du cuveau 17, arasement du dolium 1 avant le comblement de son voisin. Au cours de l'état III, alors même que les cuves 18 à 21 étaient utilisées comme dépotoir, la production d'huile continuait. Les occupants de l'état III devaient ramasser les olives des arbres laissés à l'abandon mais continuant à produire. Ils devaient se servir des pressoirs encore en état pour extraire l'huile nécessaire à la consommation domaniale ${ }^{50}$. Il est significatif à cet égard, que le cuveau $17 \mathrm{~A}$ et la remise $16 / 17$ n'aient pas été comblés par des détritus au cours de l'état III : après l'abandon total de cette zone, ils se dégradèrent et se comblèrent seulement de terre et de gravats.

Il semble donc que la cour 15 , tout en continuant à servir occasionnellement à l'extraction de l'huile ait été utilisée comme abattoir domestique,

50 Le phénomène est mutatis mutandis le mème que connait la production provençale actuelle dans les secteurs où la culture régresse : c'est "l'oléiculture de cueillette" (Maillard, 1981 , p. 11), oủ l'on se contente de nettoyer sommairement les oliviers et de récupérer les olives tombées, parfois gaulées (Amouretti, Comet, 1979, p. 72-73). les cuves servant à jeter les déchets de boucherie. Le cheptel comprenait des espèces variées mais parmi elles, le bœuf dominait largement (plus de $75 \%$ de la viande). Les bêtes abattues se répartissent à peu près également entre bouvillons et adultes : cela indiquerait un élevage d'animaux de trait sur lequel était prélevée la consommation domaniale. L'élevage de ces bovins, appartenant d̀ une race de grands animaux, signe de richesse et de productivité, pourrait avoir été favorisée par la proximité des terres lourdes de la plaine tandis que la pratique de la chasse pourrait s'être légèrement accrue avec l'extension des friches dans les collines au détriment des olivaies. Le cerf représente $5 \%$ de la viande et l'analyse des charbons de bois montre, à cette époque, un environnement en cours de reboisement où l'emprise de l'homme est moins nette qu'auparavant, voir infra, p. 158.

\section{Tombes}

Lors de la construction de l'IUT au printemps 1969, un petit cimetière rural comptant au moins une dizaine de tombes a été détruit par les terrassements (fig. 2). Seules deux tombes sous tuiles ont pu être fouillées (Gérard, 1971, p. $54 s q$ ).

- Tombe 1 : inhumation sous tuiles en caisson rectangulaire, orientée ouest-est. Le corps reposait sur le dos, bras croisés sur la poitrine. Deux cruches étaient déposées au niveau des pieds, une demimonnaie à la tête.

- Tombe 2 : inhumation sous tuiles en batière, orientée est-ouest. Le corps d'un homme d'une quarantaine d'années, mesurant $1,80 \mathrm{~m}$ environ reposait sur le dos bras droit replié sur la poitrine, le gauche sur le pubis. Deux cruches et un anneau en bronze étaient déposés aux pieds, une demi-monnaie à la tête (fig. 25). Voir infra, p. 151, tabl. X.

Le type des tombes et surtout le matériel associé permettent de rattacher ce petit cimetière à l'état III. Les deux pièces de monnaies pourraient être des antoniniani et les cruches sont de même type que celles des cuves. Elles doivent être rapprochées des cruches découvertes dans le cimetière rural du Grand Loou à La Roquebrussanne et datées de la fin du III" s. et du début du IV s. après J.-C. (CDAV, 1981, p. $43 s q$. .).

\section{Datation}

Les éléments de datation de l'état III sont relativement nombreux et précis (voir infra, tabl. IX et $\mathrm{X})$ :

- antoniniani de Salonine (1 exemplaire), Gallien ( 2 exemplaires) et Claude II ( 2 exemplaires) frappés entre 260 et 270 après J.-C.; 


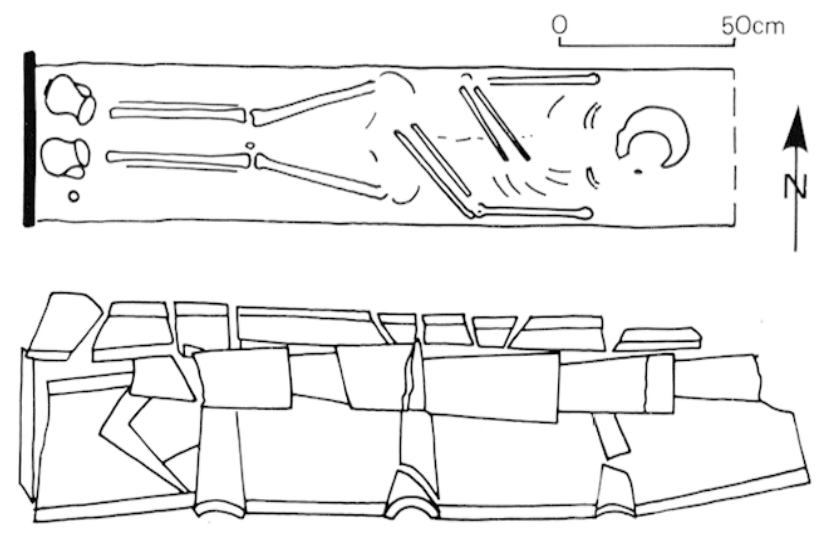

Fig. 25 - Etat 111 : relevé de la tombe 2.

- lampes : 4 exemplaires appartenant au type VIIIB de Deneauve (1969) daté de la fin du II et du III $^{\text {e }}$ s.;

- céramique sigillée claire $\mathrm{A}$, formes Hayes 14B, 17A (2 exemplaires) et 27/31 datées de la fin du $I^{\mathrm{e}}$ s. - première moitié du III $\mathrm{s}$; ;

- céramique sigillée claire $\mathrm{C}$, formes Hayes 44 et $50 \mathrm{~A}$ (6 exemplaires) datées des trois derniers quarts du $\mathrm{III}^{\mathrm{e}}$ s. et du début du IV $\mathrm{s}$;

- céramique commune africaine, formes Hayes 182 (2 exemplaires) et 196 ( 2 exemplaires) datées des années $150-250$ après $\mathrm{J} .-\mathrm{C}$.;

- céramique sigillée luisante, forme Lamboglia 1/3 datée de la fin du II ${ }^{\mathrm{e}}$ et du IV $\mathrm{s}$. après J.-C.

L'état III paraît donc avoir commencé après le milieu du II $^{e}$ s. et avoir duré jusqu'à la fin de ce même siècle ou au début du suivant.

\section{État IV}

L'état IV correspond à la réoccupation des thermes après que les bâtiments de l'huilerie encore utilisés à l'état III eurent été totalement désertés. Nous ne connaissons cette réoccupation qu'au travers d'une couche d'habitat découverte dans un sondage, au contact du sol de béton de tuileau de la pièce 204 et de couches de cendres et de détritus rejetés dans la pièce 205 en contrebas des pièces environnantes (fig. 31). La couche de cendres 4 de la pièce 205, très épaisse et uniforme semble s'être constituée à la suite d'un incendie ayant ravagé cette remise: on en trouve des traces sous forme de poutres et d'assemblages de poutrelles carbonisés, de plomb fondu, de céramiques et de plaques de marbre noircies.

Les charbons découverts dans ces niveaux montrent un paysage environnant très diversifié, formé peut-être de zones en friche voisinant avec,

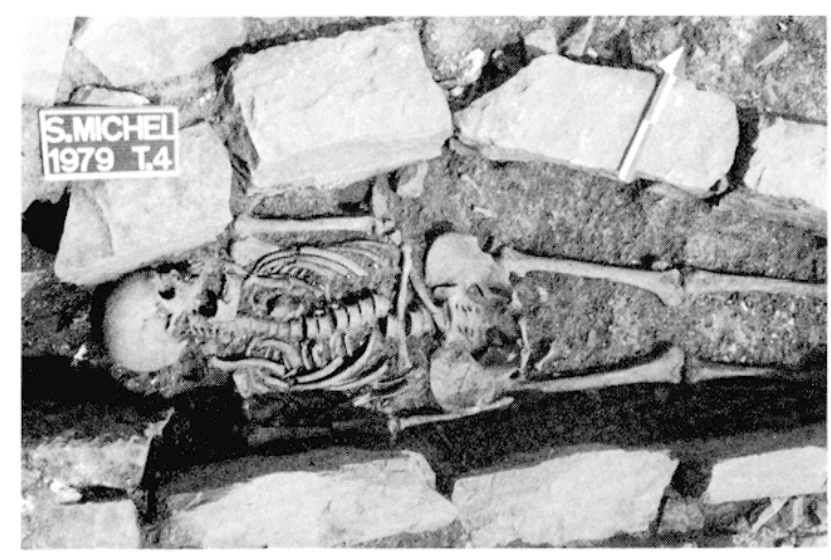

Fig. 26 - État V : tombe 4.

des parties cultivées. Les oliviers restent encore présents dans le paysage. Les couches d'occupation ont par ailleurs livré une faune relativement abondante où la proportion du bœuf baisse $(26 \%$ des individus) au profit du porc, du cerf et du cheval qui fait son apparition. Voir infra, p. 155.

Pour une bonne part le matériel de ces couches est résiduel, mais les éléments les plus tardifs (sigillée claire D, luisante, commune et amphores africaines, rares fragments de dérivées des sigillées paléochrétiennes) datent cet état du Iv ${ }^{e}$ s. avancé et du début $d u v^{e} s$. On ne décèle plus aucune trace d'habitation au-delà de cette période.

\section{État V}

Après l'abandon de la villa, plusieurs tombes ont été aménagées dans ses ruines : dans la pars urbana une tombe très remaniée et dans la partie sud-est du plateau, deux tombes qui ont pu être fouillées.

- Tombe 3 : inhumation en pleine terre, orientée est-ouest, d'un enfant reposant sur le dos, mains jointes sur le ventre, sans mobilier.

- Tombe 4 : inhumation entre des lauzes de grès sous la précédente, orientée ouest-est. Le corps d'un adulte reposait sur le dos; une dalle de grès protégeait la tête. Aucun mobilier funéraire (fig. 26).

D'après le type des tombes, ce petit cimetière est à rapporter au Haut Moyen Age.

\section{***}

L'installation dès le milieu du $\mathrm{I}^{\mathrm{er}} \mathrm{s}$. avant J.-C. d'un habitat de plaine sur le site de Saint-Michel n'est pas surprenante. Toutes les villae importantes du Haut-Empire dans le Var tirent leur origine d'une implantation parfois modeste de cette époque. Cette vague de fondation d'habitats en des lieux rarement 
occupés auparavant, plaines, bassins, pieds de colline, correspond chronologiquement aux bouleversements sociaux et fonciers liés aux guerres civiles et aux déductions des colonies de vétérans, ici celle d'Arles ${ }^{51}$. Peut-être faut-il pousser plus loin l'analyse et faire ici la place à une hypothèse inédite due à Gérard Chouquer. L'examen des photographies aériennes de la région de Toulon lui a permis de repérer, à la suite de Soyer (1973) des traces de cadastration probablement antique et à en proposer une nouvelle interprétation. A un réseau grec dans la région d'Olbia, peut-être plus étendu vers le nord que ne le propose Benoit (1985), auraient succédé une première centuriation romaine orientée $25^{\circ} 45^{\prime}$ Est d'un module de $707 \mathrm{~m}$, puis une seconde orientée $1^{\circ} 45^{\prime}$ Est d'un module de $710 \mathrm{~m}$ (fig. $1 \mathrm{~b}$ ). Cette dernière, mieux conservée se retrouverait également à l'ouest de Toulon dans la plaine de Six-Fours et le bassin du Beausset. Nos informations sur l'habitat rural dans ce secteur sont encore trop lacunaires pour mesurer la validité de ces hypothèses qui nous interrogent à la fois sur l'origine des villae et sur la forme des propriétés. On remarque que les habitats dont l'apparition est ancienne (dans les années 50/20 avant J.-C.) sont situés à proximité de limites de la première centuriation alors que les quelques habitats plus tardifs, comme la villa de La Tourrache, sont dans des angles de centuries du second cadastre. La conjonction de ces deux observations renforcerait l'hypothèse ailleurs émise que l'origine de nombre de domaines, notamment ceux de Saint-Michel et du Grand Loou à la Roquebrussanne remonterait à la déduction de la colonie d'Arles ${ }^{52}$. L'apparition d'autres habitats plus tardifs, si elle est liée à une nouvelle cadastration, pourrait correspondre à une renormatio flavienne.

Dès le départ, Saint-Michel semble s'être distingué des autres sites contemporains fouillés dans le Var. Autant qu'on puisse les connaître, les constructions de l'état IA paraissent avoir été édifiées avec un certain soin (constructions assez spacieuses, sol en argile lissée), alors qu'à la même époque, le site de L'Ormeau à Taradeau ne connaissait que des cabanes peu étendues et celui du Grand Loou que des baraquements en bois ${ }^{53}$. On est loin cependant de la

51 Voir note 3.

52 Le problème de l'abandon des habitats de hauteur et de l'apparition des sites de plaine est évoqué à travers les fouilles récentes dans Brun et alii, 1985, p. 237. Aux origines de la villa du Grand Loou, on trouve des baraquements en bois dont les traces ressemblent a celles laissées par les constructions militaires (notamment les greniers).

53 L'emploi de sols en argile et de murs en terre n'est pas forcément le signe de constructions modestes ou indigènes. qualité des constructions italiques contemporaines ou même de celle des villae suburbaines de Vaison ${ }^{54}$. Diverses transformations dont la destination nous échappe furent effectuées au début $d u{ }{ }^{\text {er }} \mathrm{s}$. après J.-C. La présence d'un cuveau bétonné indique déjà une installation oléicole, mais les quantités produites devaient être limitées et destinées à la consommation domaniale. Au cours du siècle, la production des olivettes augmenta puisqu'il fut nécessaire de construire de nouveaux pressoirs et d'accroître leurs capacités de traitement (états ID à IE).

Au début du II s., les changements furent radicaux : les vieilles constructions furent arasées, une vaste huilerie presque "industrielle" et une villa urbana relativement luxueuse furent édifiées. Les bâtiments et les dépendances de ce vaste établissement rural s'étendaient sur près de 1 ha $^{55}$. Cette superficie classe la villa de Saint-Michel parmi les plus grandes du Var avec celles de La Madrague de Saint-Cyr et celle de Muscapeù à Tourves devant celles de Pardigon 2 à La Croix-Valmer $\left(4500 \mathrm{~m}^{2}\right)$, du Grand Loou à La Roquebrussanne $\left(3500 \mathrm{~m}^{2}\right)$ et de Pardigon 1-3 à Cavalaire $\left(3000 \mathrm{~m}^{2}\right)$ (Ambard, 1955; CDAV, 1983, 1984, 1986).

L'huilerie, rationnellement construite comportait deux batteries de trois pressoirs auxquelles étaient associées deux séries de trois cuves. L'estimation de la production de ces pressoirs est rendue difficile par le manque d'information sur les capacités de stockage et de traitement ${ }^{56}$. Caton indique qu'un domaine possédant une oliveraie de 120 jugères (30 ha) doit compter deux ensembles de pressura-

L'emploi de l'adobe et du pisé était connu à l'Age du Fer en Gaule méridionale (Chazelles et alii, 1985, p. 61 sq.) mais également en Italie (Lequément, 1985).

54 C'est l'époque où furent construites les villae de Settefinestre (Carandini, Settis, 1979, p. 90) et de Posto à Francolise par exemple (Cotton, 1979, p. 8). Dans le premier état de la Maison au Dauphin à Vaison, construit vers -40/-30, l'appareil des murs est irrégulier, mais le plan, complexe, est d'inspiration italique et les aménagements sont luxueux (péristyle, sols décorés d'opus sectile).

55 Cette superficie n'a rien d'exceptionnel, surtout. lorsqu'on la compare avec celle des grandes fermes de la Somme (Agache, 1978, p. 316). La villa de Saint-Michel est légèrement plus grande que celles de la plaine d'Aix (3000 à $8000 \mathrm{~m}^{2}$ : Soyer, 1968 , p. 205-208, Monguilan, 1981, p. 54-57), mais la dispersion des bâtiments sur les pentes de la colline fausse le calcul.

56 Les seuls rendements connus de ce type de presse sont ceux d'Idanha Velha au Portugal : 19000 litres d'huile par campagne grâce à deux pressoirs à levier et vis. Ces données ne sont pas transposables car il s'agit d'un moulin artisanal travaillant pour plusieurs exploitants et non d'une huilerie domaniale (Amouretti et alii, 1984, p. 389-401 et rapport inédit). 
ge $(A g r ., 3,5)$ et qu'un autre dont l'oliveraie couvre 240 jugères ( $60 \mathrm{ha}$ ) doit être équipé de 5 pressoirs et de 100 dolia de stockage de l'huile (Agr., 10,2) ${ }^{57}$. Dans des conditions traditionnelles de production, le rendement moyen à l'hectare varie entre 700 et $1000 \mathrm{~kg}$ donnant une production de 100 à 150 litres d'huile ${ }^{58}$, soit environ 6000 à 10000 litres d'huile pour 60 ha. La présence de six ensembles de pressurage nous incite à majorer ces estimations et à supposer une oliveraie d'une centaine d'hectares donnant une production de l'ordre de 10000 à 30000 litres. Ces estimations évidemment très larges ne peuvent être prises que comme ordre de grandeur; seule la fouille d'un cellier à huile permettrait de limiter leur imprécision ${ }^{59}$. Le domaine pouvait donc se composer d'une centaine d'hectares d'oliviers sur les pentes de la colline du Thouar et peut-être aussi de Baudouvin ${ }^{60}$, de terres à blé et de vignes ${ }^{61}$ et de pâlurages dans la plaine de La Garde. Bois et maquis sur le sommet des collines et sur leurs versants septentrionaux devaient compléter les ressources du domaine. Son ampleur n'est pas comparable à celle

57 Caton n'indique pas la contenance des dolia: s'il s'agit de dolia quadragenia ou quinquagenia de 500/600 litres (selon Goujard, 1975, p. 243 et non Pauly, Wissowa, 1893, s.v. dolium : 50 amphores, soit 1300 litres), les capacités de stockage seraient de l'ordre de $5000 / 6000$ litres soit un rendement de l'ordre de 100 litres à l'hectare, proche des rendements de l'oléiculture traditionnelle.

58 Cette estimation a été réalisée à partir des données de Loussert, Brousse, 1978, p. 445 et de Amouretti, Comet, 1979 , p. 75-76. Nous n'ignorons pas combien ces extrapolations sont fragiles, la production moyenne d'un hectare d'oliviers dépend d'abord de la variété plantée, ensuite des conditions de culture (sols, travaux, ètat phytosanitaire, taille). Selon les variétés, les rendements d'huile sont de 15 à $25 \%$ du poids des olives (Maillard, 1981, p. $35 s q$.).

59 La fouille d'un cellier sur le site de Peymeinade a permis à Georges Vindry d'estimer à $6000 / 7000$ litres les capacités de stockage de l'huile pour un seul ensemble de production. En extrapolant aux trois îlots, on aurait une capacité de l'ordre de 20000 litres.

60 Pour la construction de certaines parties de la villa, on a utilisé du calcaire provenant de la colline de Baudouvin distante de 2,3 km vers le nord. Si celle-ci faisait partie de la proprièté, le domaine pourrait avoir formé une bande nord-sud entre ceux du Prieuré et de La Chaberte. L'ètude des villae de Cavalaire et La Croix-Valmer a conduit à utiliser les indications fournies par les matériaux de construction et leurs carrières pour tenter de restituer leurs domaines (CDAV, 1985, p. 212).

61 L'analyse des charbons montre qu'au cours de l'état II, on cultivait des vignes dans les environs de la villa. Restent à découvrir les installations vinicoles. peut-être situées au sud de l'huilerie. des exploitations de L'Ormeau (Brun, 1986a, p. 215). A Saint-Michel, les installations semblent avoir été conçues pour une production de masse destinée à la vente alors que dans les deux fermes de L'Ormeau, il s'agissait probablement de production pour la consommation domaniale avec commercialisation éventuelle, peut-être régulière des surplus. SaintMichel est l'une des rares huileries provençales, avec celle de Peymeinade à pouvoir être comparée aux huileries des grandes régions productrices d'huile : la Bétique, l'Afrique, l'Istrie ${ }^{62}$. L'huile ainsi extraite était vraisemblablement acheminée vers le port de Telo Martius dont les fouilles récentes montrent l'importance insoupçonnée au Haut-Empire ${ }^{63}$.

Durant tout le $\mathbf{I I}^{\mathrm{r}} \mathrm{s}$. et la première moitié du ${ }^{I I I^{\circ}}$ s., la production oléicole paraît n'avoir connu aucune crise majeure et le domaine être resté florissant. Les remaniements que l'on constate dans les cuves 16 et 17 correspondent à des aménagements techniques dans lesquels il serait hasardeux de voir des signes de baisse sensible de la production ${ }^{64}$.

Dans la seconde moitié du iII s., la production d'huile chuta fortement. Elle paraît avoir seulement fourni les besoins de la villa. Les vastes bâtiments de l'huilerie furent délaissés en tant qu'instrument de production et devinrent un lieu d'abattage des bêtes où les ordures s'accumulèrent. Comme à la période précédente, une polyculture de subsistance (blé et huile au moins) continuait à être pratiquée et l'élevage des bovins connut un certain essor attestant une prospérité relative. Toutefois, l'analyse des charbons de bois montre que les alentours de la villa, et peut-être l'ensemble du domaine, étaient moins

62 Pour l'Espagne, on manque d'ensembles oléicoles correctement publiès mais les prospections attestent l'existence d'huileries à trois pressoirs au moins (Ponsich, 1974-1979). En Afrique, voir les exemples de Henchir el Kousset (CampsFabrer, 1953, p. 52) et de En Snab Taouriouine (Leveau, 1984, p. 369). L'Istrie a livré des ensembles de pressurage parfois très importants ( 7 pressoirs au moins à Barbariga-nord, 4 à Kolci Hill - voir en dernier lieu, Matijasic, 1982).

63 Les fouilles du port de Toulon en 1987 ont mis au jour un quai en bois et un quartier de boutiques construit selon un plan d'urbanisme vers la fin du jer $s$. après J.-C. Le port s'est progressivement envasé au cours des ${ }^{\prime \prime} \mathrm{I}^{\circ}$ et $1 \mathrm{I}^{\circ} \mathrm{s}$. La fouille des couches de comblement a livré d'importantes quantités d'amphores vinaires provençales, indice de la vitalité du commerce du vin au cours de cette période (CDAV, 1987).

64 Il convient de souligner ici que nombre d'exploitations périclitent dès la fin du $I^{*} s$. : les fermes de Taradeau et. $\mathrm{du}$ Grand Loou sont abandonnées vers la fin $\mathrm{du} \mathrm{Ir}^{*}$ ou au début du $1 \mathrm{I}^{\mathrm{P}}$ s., celle de Pardigon 1-3 vers 230-240 après J.-C. (CDAV, 1983, 1985 et 1986). 
bien entretenus : les friches et les bois s'étendent ce que nous traduisons par abandon des olivettes Ces observations sont convergentes: même si les produits agricoles continuaient à être vendus, la production n'était plus volontairement tournée vers la commercialisation. Le domaine commençait à se replier sur lui-même.

Ce changement dans le type de production et la diminution des surfaces cultivées amorça le déclin progressif de la villa. Au IV' s., elle paraît n'être plus que partiellement habitée. Les bâtiments, trop grands, trop fastueux pour les revenus des occupants se ruinèrent peu à peu. L'abandon total de cet établissement inadapté aux nouvelles conditions économiques de la région eut lieu vers le début du $v^{e} s$.

J.-P. B.

\title{
I. STRATIGRAPHIES COMMENTEESS
}

\author{
par J.-P. BRuN
}

Les recherches ont été conduites en grands décapages en gardant comme cadre les structures antiques de l'état majeur. Parmi les nombreuses coupes stratigraphiques présentées dans les rapports de fouille pour expliquer tel ou tel point particulier, nous avons choisi d'en publier cinq qui résument pour l'essentiel la succession chronologique des états tels qu'ils ont été présentés plus haut. Pour chacune nous donnons la liste des couches, l'interprétation proposée, l'état auquel elles sont attribuées et leur datation. Les coupes sont situées sur le plan figure 3 .

\section{Coupes de la COUR 13}

(fig. 27 à 29)

- couche 1: terre arable

- couche 2 : décombres

- couche A2 : destruction, état III stade 6 , fin du III s. après J.-C.

- couche A3 : remblai dont la surface a servi de sol

- couche A4 : couche de fragments provenant de l'écrêtement du dolium 1, état III

- couches A5-A7 : comblement. La couche A6 contenait des fragments de dalles des murettes de séparation des pressoirs, état III

- couches B4-B5 : remblais de fragments de dolia et de terre servant à caler les dolia 1 et 2 , état IIBI

- couche C3 : sol de béton de tuileau, état IIA2, début du II $\mathrm{s}$. après J.-C.
- couche C4 : hérisson du sol C3, état IIA2

- couches C5-C5A : remblai de schiste et remplissage de la tranchée de fondation du mur 31B, état $I B$, début du $\mathrm{I}^{\text {er }} \mathrm{s}$. après $\mathrm{J}$.-C.

- couche C6 : colluvions, ètat IA, fin du $\mathrm{r}^{\mathrm{er}} \mathrm{s}$. avant J.-C.

- couche C7: couche de destruction, adobe fondu, état IA

- couche C8: occupation de l'état IA

- surface C9: sol d'argile, chaux, cailloux calcaires, état IA, seconde moitié du $\mathrm{I}^{\mathrm{er}} \mathrm{s}$. avant J.-C.

- couches C10-C11 : hérisson et remblai du sol C9, état IA

- couche G3 : couche de béton de tuileau du sol du pressoir 12, état IIA2

- couche G4A : hérisson du sol du pressoir, galets, état IIA2

- couche G4B : premier hérisson du sol du pressoir, blocs de grès, état IIA2

- couche G4C: remblai de terre du sol du pressoir, état IIA2

- couches G5A-G5B : comblement de tranchée du mur $4 \mathrm{C}$, état IIAI

- surface G5: sol de schiste, occupation de l'état IB, début du $\mathrm{I}^{\text {er }} \mathrm{s}$. après $\mathrm{J} . \mathrm{C}$.

- couche G6 : colluvions, état IA

- couche G7 : destruction, adobe fondu, analogue à $\mathrm{C7}$, état IA

- surfaces G8-G8A : sol de terre en pente; au bas de la pente, grossier empierrement, etat IA, seconde moitié du $\mathrm{I}^{\mathrm{rr}} \mathrm{s}$. avant $\mathrm{J}$.-C. 


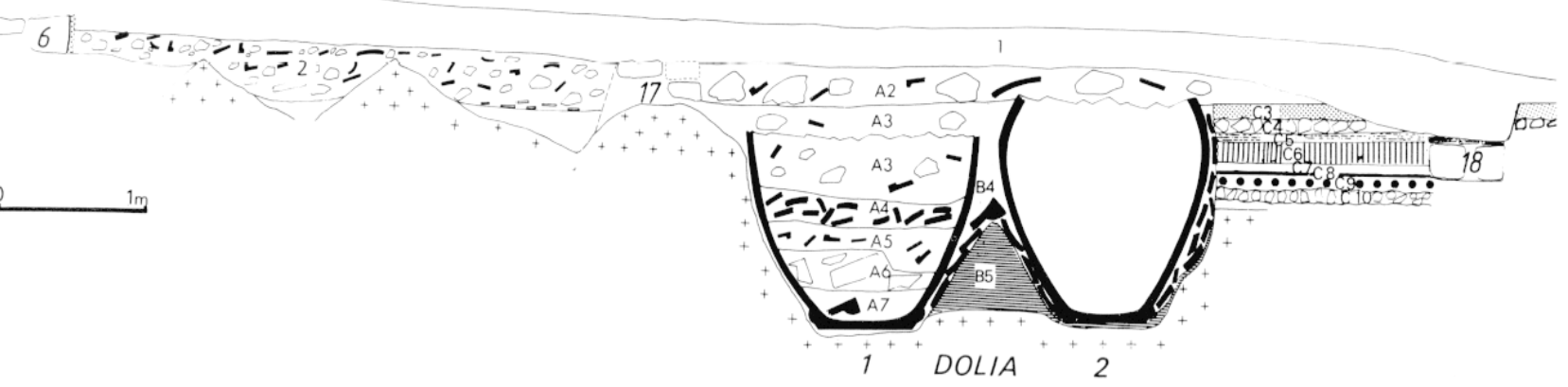

Fig. 27 - Coupe de la cour 13 au niveau des dolia.

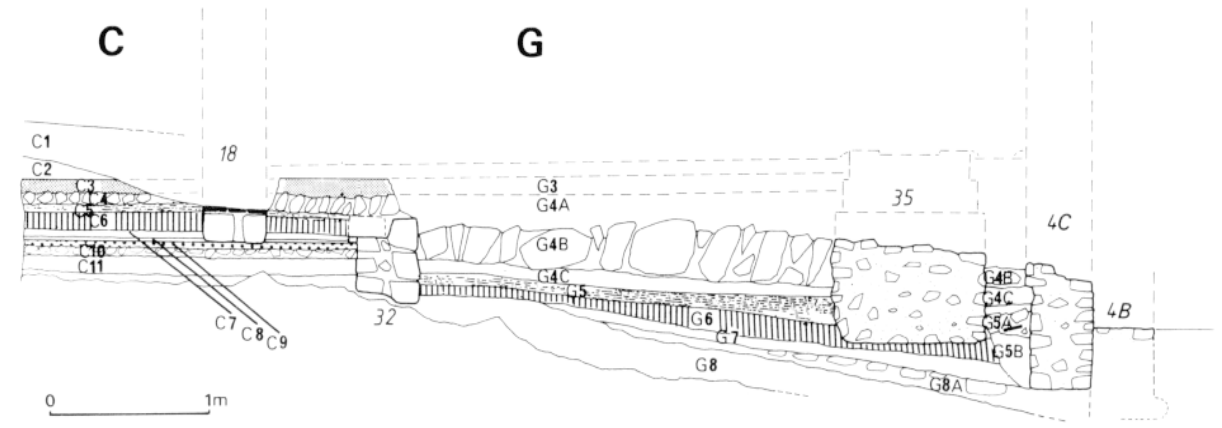

Fig. 28 - Coupe du pressoir 12 et de la pièce 14 .

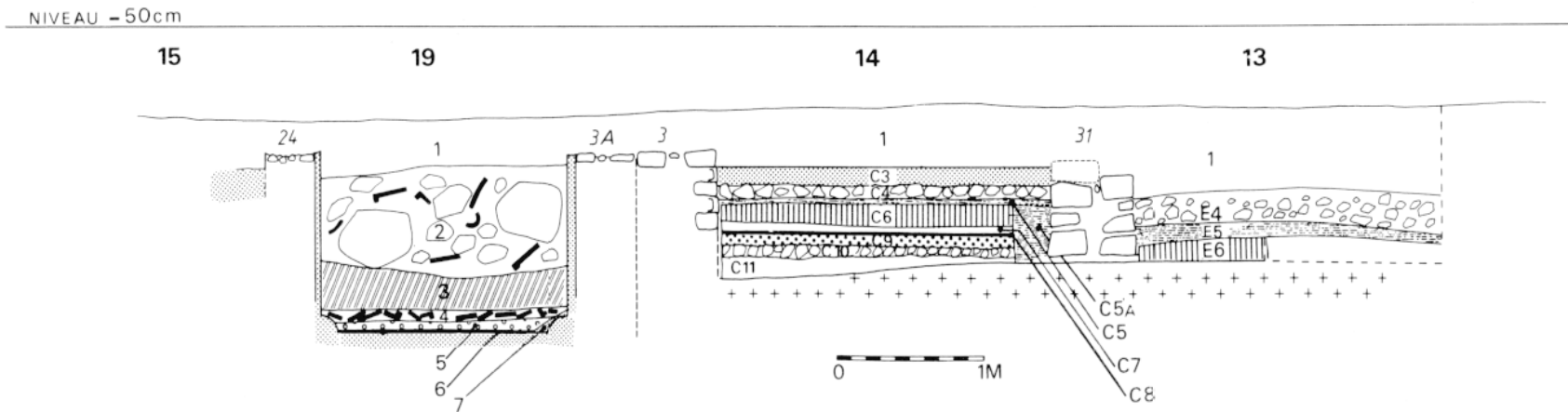

Fig. 29 - Coupe de la cuve 19 et de la zone C.

Coupe de la cuve 19 et de la cour 13 (fig. 29)

Cuve 19 : voir infra, coupes des cuves 16 à 21 .

Pièce C : voir supra, coupes de la cour 13, fig. 29.
Cour 13:

- couche E4 : remblai, terre et gravats, état $\mathrm{IC}$, première moitié $\mathrm{du} \mathrm{I}^{\mathrm{er}} \mathrm{s}$. après $\mathrm{J}$.-C.

- surface E5 : sol de schiste tassé, occupation de l'état $\mathrm{IB}$, début du $\mathrm{I}^{\mathrm{er}} \mathrm{s}$. après J.-C.

- couche E6 : colluvions, état IA, fin du $I^{\text {er }} \mathrm{s}$. avant J.-C. 


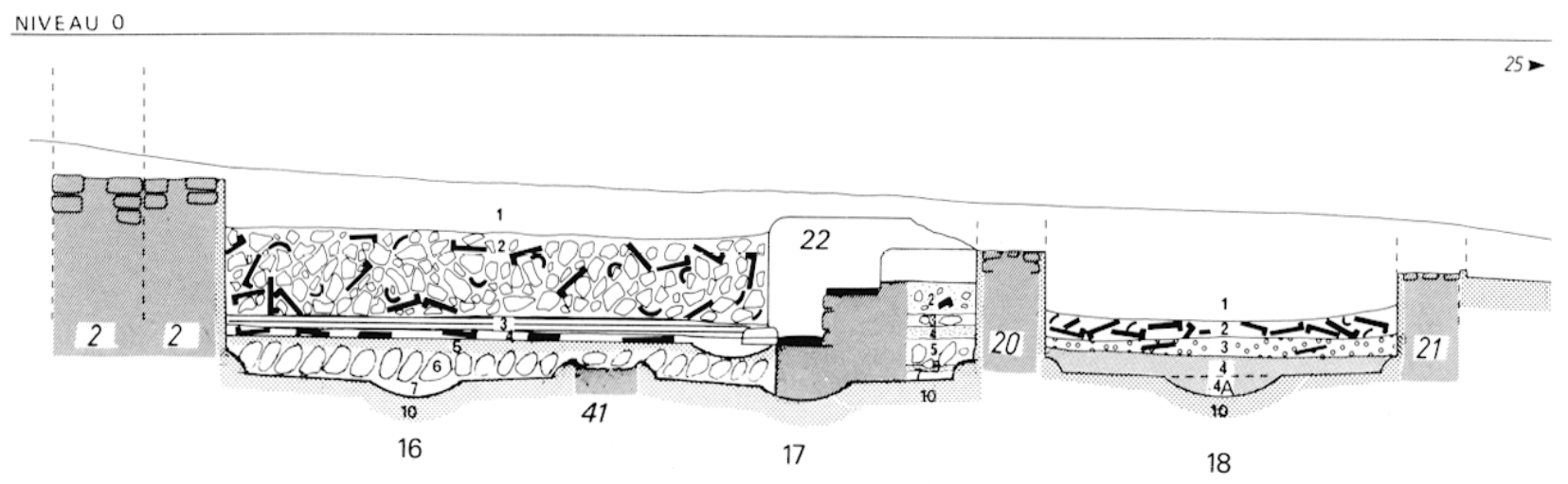

Fig. 30 - Coupes des cuves.

Coupes des cuves 16 ì 21

(fig. 30)

\section{CUVES 16-17}

- couche 2: destruction de la cuve et du mur 3, époque moderne

- couche 3 : colluvions déposées après l'abandon du site

- couche 4: tuiles, gravillons et chaux, délabrement de la cuve après abandon

- surface 5: sol de béton de la cuve 16-17, état IIB3

- couche 6 : hérisson du sol 6, état IIB3

- couche 7 : colluvions, état IIB2

- surface 10 : sol des cuves 16 à 21 , béton de tuileau, état IIAl

- couches A2 à A7 : remblai de l'escalier, état IIB3

CUVE 18

- couche 2 : tuiles utilisées en remblai?, état III, stade 4, seconde moitié du III $^{e} \mathrm{~s}$.

- couche 3 : détritus, faune très abondante, état III, stade 3, seconde moitié du III $^{e} \mathrm{~s}$.

- couche 4 : détritus, balayures et céramiques, état III, stade 2 , seconde moitié du $\mathrm{III}^{\mathrm{e}} \mathrm{s}$.

CUVE 19

- couche 1 : terre arable

- couche 2 : destruction, état III, stade 6 , fin du $\mathrm{III}^{\mathrm{e}} \mathrm{s}$.

- couche 3 : détritus, monnaies de Gallien, état III, stade 5 , seconde moitié du III $\mathrm{s}$.

- couche 4 : remblai, gros fragments de dolia et de tuiles, état III, stade 4
- couche 5: détritus, faune très abondante, monnaie de Claude II, état III, stade 3

- couche 6 : détritus et cendres, état III, stade 2

- couche 7: gravillons et nodules de chaux, délabrement des cuves, état III, stade 1

CUVE 20

- couches 2-3 : destruction, gravats, état III, stade 6

- couche 4: détritus et balayures, état III, stade 5

- couche 5: remblai de tuiles, état III, stade 4

- couche 6 : détritus et balayures, monnaie de Claude II, état III, stade 2

- couche 7 : détritus et cendres, faune abondante, état III, stade 2

- couches 7A-8-9: colluvions, gravillons et chaux, état III, stade 1

CUVE 21

- couche 2: destruction, gravats, état III, stade 6

- couche 3 : détritus, état III, stade 5

- surface 4 : tuiles : effondrements de la toiture du préau ou remblai? État III, stade 4

- couches 4-4A : détritus et dégradation de la cuve, état III, stade 2

CANIVEAU $4 A / B$

- couche 4 : hérisson du caniveau, état IIA2

- couche 5: remblai de fondation des murs 4A/B, terre et gravats, état IIA2

- couche 6 : argile stérile sur rocher 


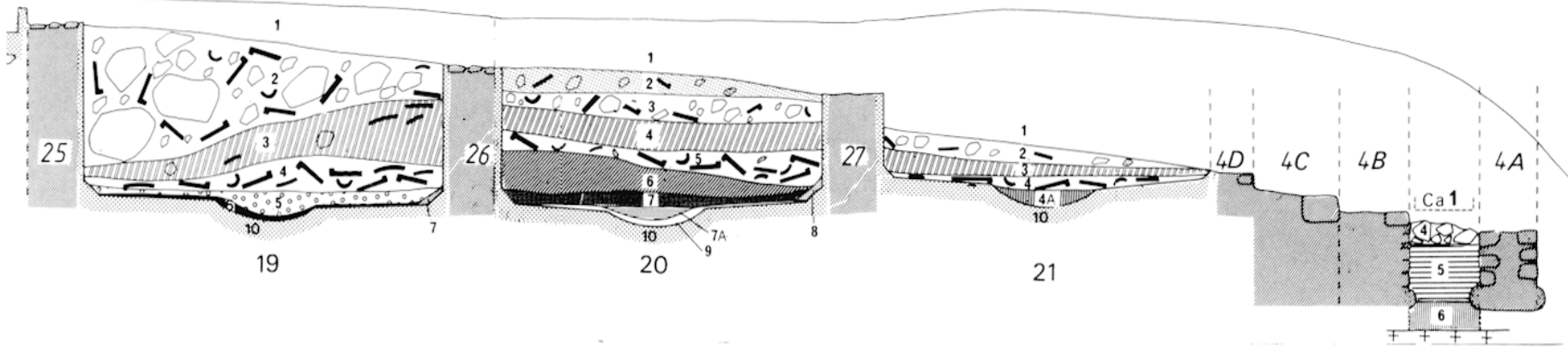

COUPE DES PIÈCES 205 ET 202

(fig. 31)

PIÉCE 205

- couche 1: terre arable

- couche $2:$ destruction des murs

- couche 3 : colluvions et déchets, état IV, IV"s.

- couche 4 : cendres et charbons provenant d'un incendie, état IV, IV $s$.

- couche 5: destruction

- couche 6 : cendres d'un foyer installé dans l'abside après la destruction de la suspensura et du sol 8, état IIA/B
- couche 7 : remblai de l'écoinçon formé par les murs 208-209-211, état IIA, fin du $\mathrm{I}^{\text {er }} \mathrm{s}$.

- surface $8 \mathrm{~b}$ : sol de legulae retournées, état IIA, fin du $\mathrm{I}^{\text {er }} \mathrm{s}$.

- couche 8 : remblai du sol $8 b$

PIÉCE 202

- couche $2:$ destruction des murs

- couche 3 : cendres entre les pilettes, état IIB, II $^{\mathrm{e}} \mathrm{s}$.

- surface 4 : sol en béton de tuileau, état IIB, II $\mathrm{S}$.

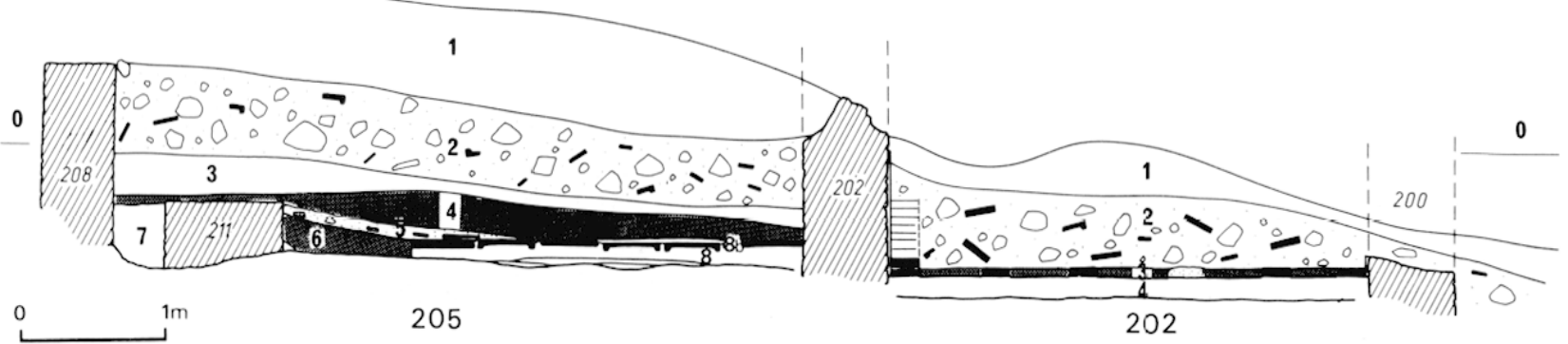

Fig. 31 - Coupe longitudinale des pièces 205 et 202 . 


\section{LES MONNAIES}

par Georges B. Rogers

\section{État IC}

1. PB de Marseille (flan découpé) : 1,91 g

V tête à droite

R7 taureau cornupète à droite

La Saussaye, $1842 \quad n^{\circ} 304 \ldots$; La Tour, 1892 $n^{\circ} 1673 \ldots$

\section{État IIA}

2. As de Nîmes : $12,8 \mathrm{~g}$

W IMP DIVI F PP- têtes adossées d'Auguste et Agrippa

Ry COL NEM-crocodile et palmier

Série III, 2 avant J.-C.-14 après J.-C.

État II, occupation

3. Sesterce probablement d'Antonin le Pieux: $23,16 \mathrm{~g}$

V tète à droite

R7 usé à plat

138-161 après J.-C.

Contexte : pars urbana

4. Sesterce de Faustine : $20,64 \mathrm{~g}$

W [DIVA FAVSTIN $\Lambda$ ]-tête à droite

R7 [AVGV]S[TA]SC

Mattingly, Sydenham, RIC 1127; Mattingly, BMC 1524

141-161 après J.-C.

Contexte : égout $98 / 99$

5. As de Faustine : 9,38 $\mathrm{g}$

V FAVSTINA AVG AN-TONINI AVG PII FILtête à droite

R7 [...]SC-Vénus? à droite

Mattingly, Sydenham, RIC 1410c; Mattingly, BMC 2169

147-161 après J.-C.

Contexte : dépotoir (ramassage 1975)

6. As de Marc-Aurèle : $10,60 \mathrm{~g}$

V AVRELIVS CAESAR-AVG PII F - tête à droite R7 TR POT XIIII-COS II SC-Mars à droite

Mattingly, Sydenham, RIC 1354a; Mattingly, BMC 2106

159-160 après J.-C.

Contexte : dépotoir (ramassage 1975)
7. Sesterce de Faustine la Jeune : $18,89 \mathrm{~g}$

V [FAVS]TINA-[AVGVSTA]- tête à droite

Ry [FEGVN]D[ITAS] SC- Fecunditas avec sceptre et enfant

Mattingly, Sydenham, RIC 1638; Mattingly, $B M C$ 905/908

161-175 après J.-C.

Contexte : égout 98/99

8. As d'Hadrien ? : $5,02 \mathrm{~g}$

$\forall$ tête laurée à droite

Ry illisible

Contexte : égout $115 / 116$

9. As : $5,45 \mathrm{~g}$

V tête laurée à droite

R7 corrodé

Contexte : égout 98/99

10. $\Lambda \mathrm{s}: 6,20 \mathrm{~g}$

V tête laurée à droite

R7 corrodé

Contexte : égout 98/99

\section{État III}

11. Antoninianus de Gallien : $2,87 \mathrm{~g}$

W GALLIENVS AVG-K-

R) AETERNITAS - Sol à gauche tenant un globe $/ \Gamma$ dans le champ

Mattingly, Sydenham, RIC 160

260-268 après J.-C.

Contexte : remplissage de la cuve 19

12. Antoninianus de Salonine : $2,51 \mathrm{~g}$

V SALONINA AVG

R/ FECVNDITAS- figure tenant cornucopia / $\Delta$ dans le champ

Mattingly, Sydenham, RIC (Salonine) 5

260-268 après J.-C.

Contexte : sol de la cour 15

13. Antoninianus de Claude II : 2,57 g

Y IMP C CLAVDIVS $\Lambda$ VG - A-

R7 ANNONA AVG-Annone debout à gauche

Mattingly, Sydenham, RIC 18a

269-270 après J.-C.

Contexte : remplissage de la cuve 19 
14. Antoninianus de Claude II : 2,24 g

W IMP CLAVDIVS [PF AVG]-A-

R7 PROVI-D AVG - figure debout à gauche

Mattingly, Sydenham, RIC 163 (atelier de Milan)

269-270 après $\mathbf{J}$.-C.

Contexte : remplissage de la cuve 20

15. Antoninianus de Claude II : 2,25 g

V [IMP CLAVDIVS PF AVG]-K-

R7 PROVIDENT AV]G-figure debout à gauche

/XII dans le champ

Mattingly, Sydenham, RIC 92
269 après $\mathrm{J} .-\mathrm{C}$.

Contexte : remplissage de la cuve 19

16. Antoninianus d'Aurélien : $2,83 \mathrm{~g}$

V IMP AVRELIANVS AVG -F-

R7 VIR-T AVG-Mars

Mattingly, Sydenham, RIC 341 (atelier de Cyziquepoint sous le buste)

270-274 après J.-C.

Contexte : couche de destruction de l'égout 115/116

\section{LE MATÉRIEL ARCHÉOLOGIQUE}

par J.-P. BRUN

\section{ABLEAu I : MATÉRIEL DE L'ÉtAT IA}

\begin{tabular}{|c|c|c|c|c|c|c|c|c|}
\hline tat & Contexte & Classe & Type & Forme & $\begin{array}{l}\text { Tes- } \\
\text { sons }\end{array}$ & $\begin{array}{l}\text { Indi- } \\
\text { vidus }\end{array}$ & Observations & Figures \\
\hline $\mathrm{Al}$ & Construction & $\begin{array}{l}\text { Céramique fine } \\
\text { Céramique modelée } \\
\text { Amphore } \\
\text { Dolium }\end{array}$ & $\begin{array}{l}\text { campanienne A tardive } \\
\text { marseillaise } \\
\text { italique } \\
\text { marseillaise }\end{array}$ & $\begin{array}{l}\text { Lamboglia A27B } \\
\text { Arcelin } 4 \mathrm{C} \\
\text { Dressel } 1\end{array}$ & $\begin{array}{r}4 \\
10 \\
33 \\
1 \\
1\end{array}$ & $\begin{array}{l}1 \\
1 \\
5 \\
1 \\
1\end{array}$ & $\begin{array}{l}\text { épaulements, anse, quille, panse poissée } \\
\text { pâte micacée, petite taille }\end{array}$ & $\begin{array}{l}32,2 \\
32,1\end{array}$ \\
\hline $\mathrm{A} 2$ & Occupation & $\begin{array}{l}\text { Céramique fine } \\
\text { Céramique modelée } \\
\text { Céramique commune }\end{array}$ & $\begin{array}{l}\text { catalane } \\
\text { régionale } \\
\text { italique }\end{array}$ & Giacobbi 9 & $\begin{array}{r}1 \\
1 \\
11\end{array}$ & $\begin{array}{l}1 \\
1 \\
1\end{array}$ & $\begin{array}{l}\text { fragment de panse d'œnochoé } \\
\text { bord d'urnette } \\
\text { Tchernia, Pomey, Hesnard, 1978, p. } 65\end{array}$ & 32,3 \\
\hline A3 & Destruction & $\begin{array}{l}\text { Céramique fine } \\
\text { Céramique modelée } \\
\text { Céramique commune } \\
\text { Amphore } \\
\text { Fer }\end{array}$ & $\begin{array}{l}\text { campanienne A tardive } \\
\text { campanienne A tardive } \\
\text { campanienne B } \\
\text { campãnienne C? } \\
\text { marseillaise } \\
\text { régionale } \\
\text { italique } \\
\text { cuisson mode A } \\
\text { cuisson mode A } \\
\text { cuisson mode A } \\
\text { marseillaise } \\
\text { adriatique } \\
\text { italique } \\
\text { scories }\end{array}$ & $\begin{array}{l}\text { Lamboglia } 31 \\
\text { Lamboglia } 1 \\
\text { Lamboglia } 7 \\
\\
\text { Lamboglia } 2 \\
\text { Dressel } 1\end{array}$ & \begin{tabular}{r|}
3 \\
1 \\
2 \\
1 \\
4 \\
8 \\
1 \\
5 \\
7 \\
10 \\
1 \\
2 \\
60
\end{tabular} & $\begin{array}{l}1 \\
1 \\
1 \\
1 \\
1 \\
1 \\
1 \\
1 \\
1 \\
2 \\
2 \\
1 \\
1 \\
2\end{array}$ & $\begin{array}{l}\text { Morel } 2954 \text { ou } 2978 \mathrm{~b} \\
\text { Morel } 2323 \\
\text { Morel } 2284 \mathrm{~d} \mathrm{l} \\
\text { fond } \\
\text { une anse boudin } \\
\text { pâte beige-orangée, chamotte, origine marseillaise? } \\
\text { pâte beige vacuolaire, dégraissant calcaire } \\
\text { pàte beige, grosses impuretés rouges } \\
\text { épaule, } 2 \text { quilles, } 2 \text { anses } \\
\text { très abondantes dans la couche E6 }\end{array}$ & $\begin{array}{l}32,4 \\
32,5\end{array}$ \\
\hline $\mathrm{A}$ & Hors contexte & $\begin{array}{l}\text { Céramique fine } \\
\text { Amphore }\end{array}$ & $\begin{array}{l}\text { campanienne } \mathrm{A} \text { tardive } \\
\text { campanienne } \mathrm{C} \text { ? } \\
\text { campanienne } \mathrm{A} \text { tardive } \\
\text { campanienne } \mathrm{A} \text { tardive } \\
\text { italique }\end{array}$ & $\begin{array}{l}\text { Lamboglia } 7 \\
\text { Lamboglia } 8 \mathrm{Bc} \\
\text { Lamboglia } 31 \\
\text { Dressel 1A }\end{array}$ & \begin{tabular}{l|l}
3 & \\
1 & \\
1 & 1 \\
1 & 1
\end{tabular} & $\begin{array}{l}1 \\
1 \\
1 \\
1 \\
1\end{array}$ & $\begin{array}{l}1 \text { fragment avec trace de réparation, trouvé au sud du mur } 5 \\
\text { Morel } 2284 \\
\text { Morel } 2942, \text { trouvé au contact du rocher } \\
\text { Morel } 2954 \text { ou } 2978 \text { b, trouvé dans une couche d'argile au sud } \\
\text { du mur } 5 \\
\text { timbre SES et ancre (Manacorda, } 1981, \text { p. } 51 \text { ) }\end{array}$ & $\begin{array}{l}32,6 \\
32,7\end{array}$ \\
\hline
\end{tabular}

'ABLEAU II : MATÉRIEL DE I.'́́tAT IB

\begin{tabular}{|c|c|c|c|c|c|c|c|c|}
\hline Stat & Contexte & Classe & Type & Forme & $\begin{array}{c}\text { Tes- } \\
\text { sons }\end{array}$ & $\begin{array}{l}\text { Indi- } \\
\text { vidus }\end{array}$ & Observations & Figures \\
\hline IB & Construction & $\begin{array}{l}\text { Lampe } \\
\text { Céramique fine } \\
\text { Céramique modelée } \\
\text { Céramique commune } \\
\text { Amphore }\end{array}$ & $\begin{array}{l}\text { campanienne A } \\
\text { campanienne B } \\
\text { sigillée arétine } \\
\text { catalane } \\
\text { régionale } \\
\text { de Lorgues? } \\
\text { cuisson mode A } \\
\text { cuisson mode A } \\
\text { italique }\end{array}$ & $\begin{array}{l}\text { Lamboglia A27b-c } \\
\text { Goudineau } 17 \mathrm{c} \\
\text { Amann A5 } \\
\text { Pasqualini } 610 \\
\text { Dressel } 1\end{array}$ & $\begin{array}{l}1 \\
4 \\
1 \\
3 \\
1 \\
8 \\
1 \\
14 \\
16 \\
18\end{array}$ & $\begin{array}{l}1 \\
1 \\
1 \\
1 \\
1 \\
1 \\
1 \\
1 \\
1 \\
1 \\
1\end{array}$ & $\begin{array}{l}\text { bandeau } \\
\text { Morel } 2825 \mathrm{c} \\
\\
\text { pàte beige micacée, engobe brun à noir, imitant la forme } \\
\text { Lamb. A31 } \\
\text { pâte jaune tendre, dégraissant sableux, engobe marron } \\
\text { mortier, dégraissant calcaire }\end{array}$ & $\begin{array}{l}32,8 \\
32,9 \\
32,11\end{array}$ \\
\hline IB & Occupation & $\begin{array}{l}\text { Céramique fine } \\
\text { Céramique commune } \\
\text { Amphore }\end{array}$ & $\begin{array}{l}\text { campanienne A } \\
\text { cuisson mode A } \\
\text { italique }\end{array}$ & $\begin{array}{l}\text { Lamboglia A27b-c } \\
\text { Dressel } 1\end{array}$ & $\begin{array}{r}1 \\
16 \\
5\end{array}$ & $\begin{array}{l}1 \\
1 \\
1\end{array}$ & $\begin{array}{l}\text { Morel } 2825 \mathrm{c} \text { ou } 2974 \mathrm{al} \\
\text { vase fermé, origine marseillaise? }\end{array}$ & 32,10 \\
\hline
\end{tabular}


Tableau III : Matériel DF, I.'État IC

\begin{tabular}{|c|c|c|c|c|c|c|c|c|}
\hline Etat & Contexte & Classe & Type & Forme & $\begin{array}{l}\text { Tes- } \\
\text { sons }\end{array}$ & $\begin{array}{l}\text { Indi- } \\
\text { vidus }\end{array}$ & Observations & Figur \\
\hline IC & Construction & $\begin{array}{l}\text { Céramique fine } \\
\text { Céramique modelée } \\
\text { Céramique commune } \\
\text { Amphore }\end{array}$ & $\begin{array}{l}\text { campanienne A tardive } \\
\text { campanienne A tardive } \\
\text { marseillaise } \\
\text { régionale } \\
\text { de Lorgues? } \\
\text { cuisson mode A } \\
\text { cuisson mode A } \\
\text { cuisson mode A } \\
\text { marseillaise } \\
\text { italique } \\
\text { indéterminée }\end{array}$ & $\begin{array}{l}\text { Lamboglia A31 } \\
\text { Dressel } 1\end{array}$ & $\begin{array}{r}4 \\
5 \\
1 \\
6 \\
3 \\
20 \\
3 \\
1 \\
1 \\
20 \\
9\end{array}$ & \begin{tabular}{l|l}
1 \\
2 \\
1 \\
1 \\
1 \\
1 \\
1 \\
1 \\
1 \\
1 \\
1 \\
2
\end{tabular} & $\begin{array}{l}\text { Morel } 2954 \text { ou } 1978 \mathrm{~b} \text {, vernis noir à rouge } \\
\text { mortier, pâte orangée, dégraissant de mica et quartz } \\
\text { hord de cruche, pâte jaune, fin mica, chaux, chamottc }\end{array}$ & 32,12 \\
\hline
\end{tabular}
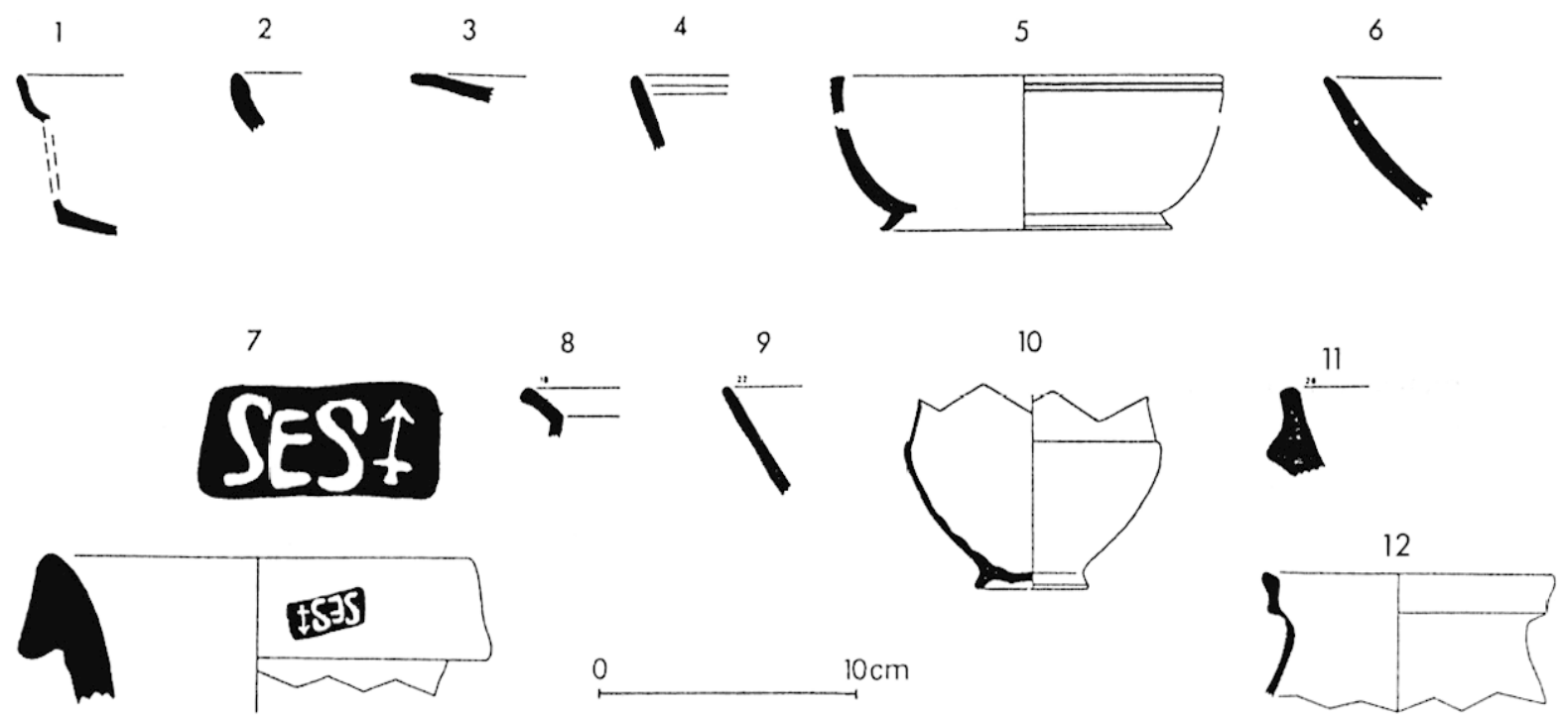

Fig. 32 - Matériel de l'état IA : $n^{\text {*s }} 1$ à 7 ; matériel des états IB et IC : nos 8 à 12 .
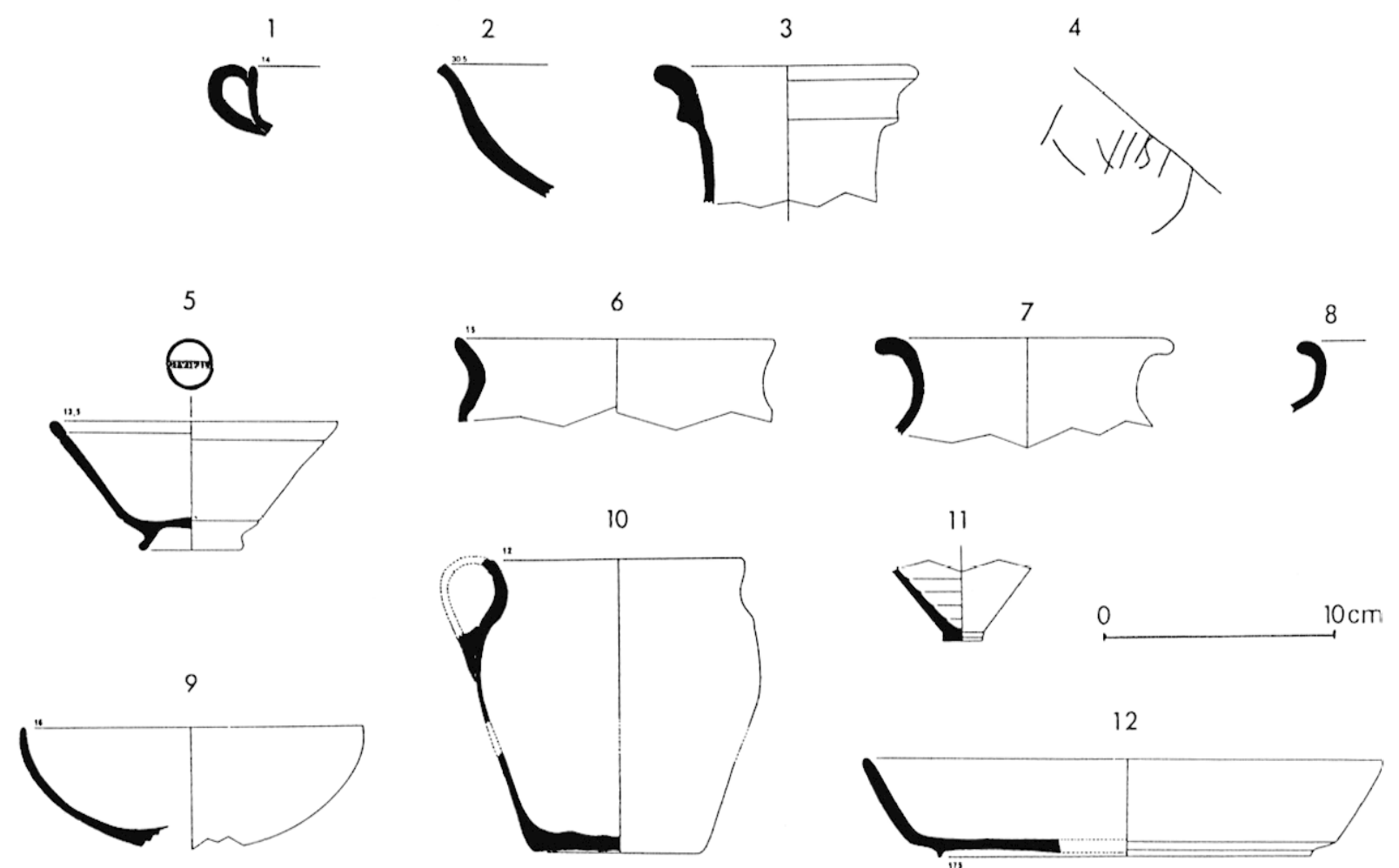

Fig. 33 - Etat IIA : matériel des couches de fondation de l'huilerie : nos 1 à 4 .

État II : matériel des foyers A, B, D : no* 5 à 12 . 
ГABleau IV : Matérifl de l'État IIA : CONSTRUCTION DF l.'HUILERIE

\begin{tabular}{|c|c|c|c|c|c|c|c|c|}
\hline État & Contexte & Classe & Type & Forme & $\begin{array}{l}\text { Tes- } \\
\text { sons } \\
\end{array}$ & $\begin{array}{l}\text { Indi- } \\
\text { vidus }\end{array}$ & Observations & Figures \\
\hline IIAI & cour 13, contruction & $\begin{array}{l}\text { Céramique fine } \\
\text { Céramique commune } \\
\text { Amphore }\end{array}$ & $\begin{array}{l}\text { campanienne A tardive } \\
\text { de Lorgues? } \\
\text { grise de Vaison } \\
\text { gauloise } \\
\text { de Bétique }\end{array}$ & $\begin{array}{l}\text { Goudineau } 1 \\
\text { Dressel } 20\end{array}$ & $\begin{array}{r}1 \\
1 \\
8 \\
10 \\
6\end{array}$ & $\begin{array}{l}1 \\
1 \\
1 \\
1 \\
1\end{array}$ & $\begin{array}{l}\text { coupe carénée, dégraissant de fin mica, engobe orangé à } \\
\text { marron } \\
\text { bord à lèvre ronde }\end{array}$ & 33,1 \\
\hline IIA2 & 12 et 13 , construction & $\begin{array}{l}\text { Lampe } \\
\text { Céramique fine } \\
\text { Céramique commune } \\
\text { Amphore } \\
\text { Tuile }\end{array}$ & $\begin{array}{l}\text { paroi-fine } \\
\text { cuisson mode A } \\
\text { cuisson mode A } \\
\text { cuisson mode A } \\
\text { grise de Vaison } \\
\text { italique } \\
\text { gauloise } \\
\text { de Bétique }\end{array}$ & $\begin{array}{l}\text { Goudineau } 1 \\
\text { Gauloise 2? } \\
\text { Dressel } 20\end{array}$ & $\begin{array}{r}5 \\
1 \\
3 \\
40 \\
7 \\
5 \\
1 \\
7 \\
8 \\
1\end{array}$ & $\begin{array}{l}2 \\
1 \\
1 \\
3 \\
1 \\
1 \\
1 \\
1 \\
1\end{array}$ & $\begin{array}{l}\text { mortier, pâte blanche, dégraissant calcaire } \\
\text { coupe, pàte beige, dégraissant calcaire } \\
\text { fragment de tuile portant un graffite après cuisson: } \\
\text { LVIBIS (?) }\end{array}$ & $\begin{array}{l}32,2 \\
33,3 \\
33,4\end{array}$ \\
\hline
\end{tabular}

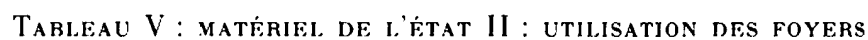

\begin{tabular}{|c|c|c|c|c|c|c|c|c|}
\hline État & Contexte & Classe & Type & Forme & $\begin{array}{l}\text { Tes- } \\
\text { sons }\end{array}$ & $\begin{array}{l}\text { Indi- } \\
\text { vidus }\end{array}$ & Observations & Figures \\
\hline II & Foyer A & $\begin{array}{l}\text { Lampe } \\
\text { Lampe } \\
\text { Céramique fine } \\
\text { Céramique modelée } \\
\text { Céramique commune } \\
\text { Amphore } \\
\text { Bronze } \\
\text { Fer }\end{array}$ & $\begin{array}{l}\text { campanienne A tardive } \\
\text { paroi-fine } \\
\text { paroi-fine } \\
\text { paroi-fine } \\
\text { sigilleee sud-gauloise } \\
\text { sigillée sud-gauloise } \\
\text { sigillée sud-gauloise } \\
\text { sigilleee sud-gauloise } \\
\text { sigillèe claire A } \\
\text { varoise } \\
\text { de Lorgues } \\
\text { cuisson mode A } \\
\text { cuisson mode A } \\
\text { cuisson mode A } \\
\text { grise de Vaison } \\
\text { grise de Vaison } \\
\text { grise de Vaison } \\
\text { gauloise } \\
\text { de Bétique } \\
\text { tige } \\
\text { clef laconienne } \\
\text { clous }\end{array}$ & $\begin{array}{l}\text { Deneauve VD? } \\
\text { Deneauve VIIIA } \\
\text { Mayet XXIV } \\
\text { Mayet XXXVII } \\
\text { Drag. } 33 \\
\text { Drag. } 35 / 36 \\
\text { Drag. } 37 \\
\text { Hayes } 23 \\
\text { Bérato } 16 \\
\text { Pasqualini } 717 \\
\\
\\
\text { Goudineau } 1 \\
\text { Goudineau 2a } \\
\text { Goudineau 2c }\end{array}$ & $\begin{array}{r}1 \\
6 \\
1 \\
10 \\
8 \\
1 \\
13 \\
1 \\
1 \\
14 \\
1 \\
50 \\
9 \\
1 \\
50 \\
2 \\
25 \\
17 \\
13 \\
24 \\
1\end{array}$ & $\begin{array}{r}1 \\
1 \\
1 \\
1 \\
1 \\
1 \\
1 \\
1 \\
1 \\
1 \\
1 \\
2 \\
2 \\
1 \\
4 \\
1 \\
1 \\
1 \\
1 \\
1 \\
1 \\
1 \\
1 \\
10\end{array}$ & $\begin{array}{l}\text { médaillon et anse, décor proche de Deneauve } 592 \\
\text { décor de résille de losanges } \\
\text { timbre OF VIRILI de La Graufesenque, Oswald, 1920, p. } 337 \\
\text { sur ce type de céramique voir Bérato, } 1984 \text { et Rivet } 1982 \\
\text { pâte orangée très micacée, engobe rouge-orangé } \\
\text { petit vase fermé engobé } \\
\text { coupe à bord rentrant non engobée } \\
\text { dégraissant assez gros } \\
\text { panse striée horizontalement }\end{array}$ & \begin{tabular}{|l}
33,5 \\
\\
\\
33,6 \\
33,9 \\
33,11 \\
\\
\\
33,7 \\
33,8
\end{tabular} \\
\hline & Foyer B & $\begin{array}{l}\text { Lampe } \\
\text { Céramique fine } \\
\text { Céramique modelée } \\
\text { Céramique commune } \\
\text { Amphore }\end{array}$ & $\begin{array}{l}\text { campanienne A tardive } \\
\text { paroi-fine } \\
\text { sigillée sud-gauloise } \\
\text { varoise } \\
\text { cuisson mode A } \\
\text { grise de Vaison } \\
\text { gauloise }\end{array}$ & Bérato 15 & $\begin{array}{r}1 \\
1 \\
1 \\
1 \\
30 \\
3 \\
1 \\
3\end{array}$ & $\begin{array}{l}1 \\
1 \\
1\end{array}$ & $\begin{array}{l}\text { décor d'écailles } \\
\text { fragment de la mème urne que celle du foyer } \mathrm{A}\end{array}$ & 33,10 \\
\hline & Foyer C & Céramique fine & sigillée sud-gauloise & & 1 & 1 & & \\
\hline & Foyer D & Céramique fine & sigillée claire $\mathrm{A}$ & Hayes 31 & 1 & 1 & & 33,12 \\
\hline
\end{tabular}

TABLeau VI : Matériel de l'état II : utilisation du dépotolr

\begin{tabular}{|c|c|c|c|c|c|c|c|c|}
\hline État & Contexte & Classe & Type & Forme & $\begin{array}{l}\text { Tes- } \\
\text { sons }\end{array}$ & $\begin{array}{l}\text { Indi- } \\
\text { vidus }\end{array}$ & Observations & Figures \\
\hline II & Ramassage 1976 & $\begin{array}{l}\text { Lampe } \\
\text { Céramique fine }\end{array}$ & $\begin{array}{l}\text { paroi-fine } \\
\text { glaçure plombifère } \\
\text { sigillée sud-gauloise }\end{array}$ & $\begin{array}{l}\text { Mayet XXXVIIIB } \\
\text { Mayet XX } \\
\text { Drag. } 37 \\
\text { Drag. } 37 \\
\text { Drag. } 37\end{array}$ & $\begin{array}{r}5 \\
3 \\
2 \\
1 \\
1 \\
37 \\
2\end{array}$ & $\begin{array}{r}2 \\
2 \\
1 \\
1 \\
1 \\
13 \\
1\end{array}$ & $\begin{array}{l}\text { un fond avec marque JSEI/ } \\
\text { décor de perles et mamelons } \\
\text { décor d'écailles } \\
\text { Graufesenque, Diane Hermet } 5 \\
\text { Graufesenque, fonds, bords et panses } \\
\text { Banassac, métopes: cygne Oswald } 2257 \text { et satyre Oswald } \\
623 \text {, Hermet } 85\end{array}$ & \\
\hline
\end{tabular}



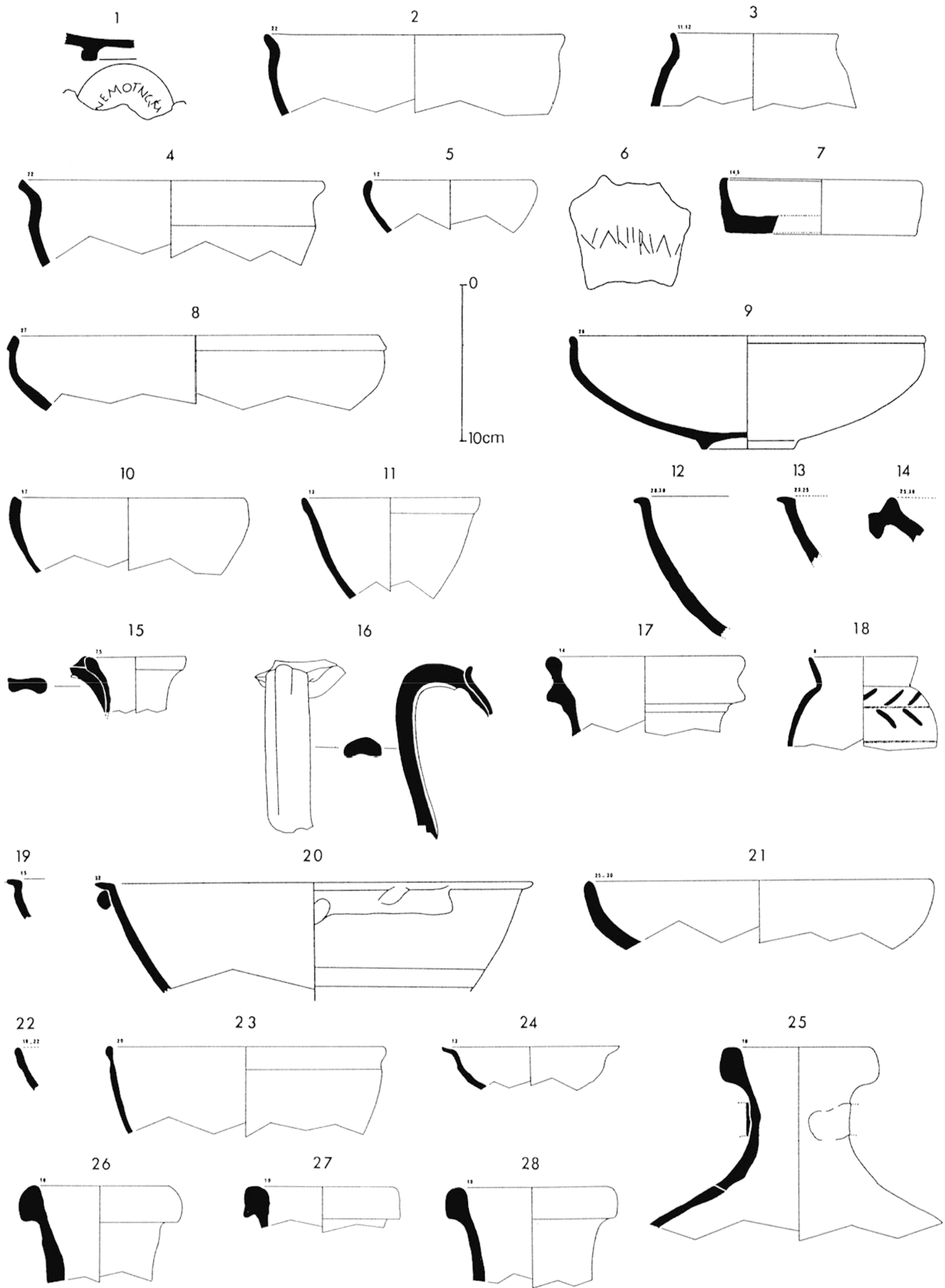

Fig. 34 - État II : matériel du dépotoir. 


\begin{tabular}{|c|c|c|c|c|c|c|c|}
\hline & $\begin{array}{l}\text { Céramique modelée } \\
\text { Céramique commune }\end{array}$ & $\begin{array}{l}\text { sigillée claire A } \\
\text { sigillée claire B } \\
\text { varoise } \\
\text { africaine } \\
\text { de Lorgues } \\
\text { cuisson mode A } \\
\text { grise } \\
\text { grise de Vaison }\end{array}$ & 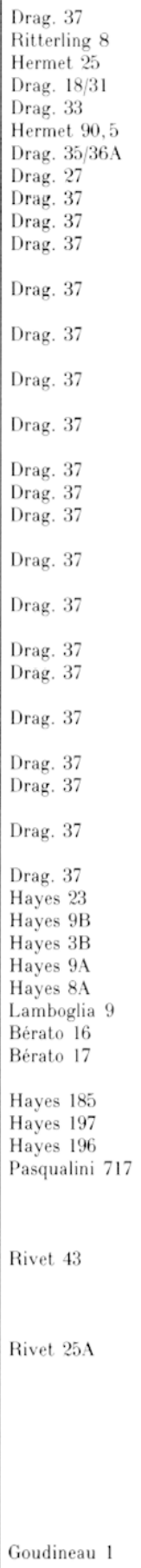 & 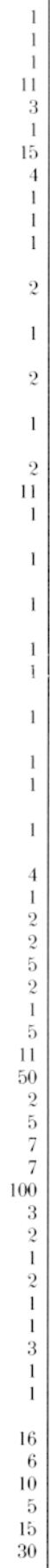 & 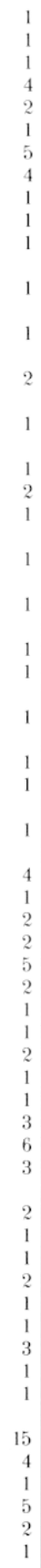 & 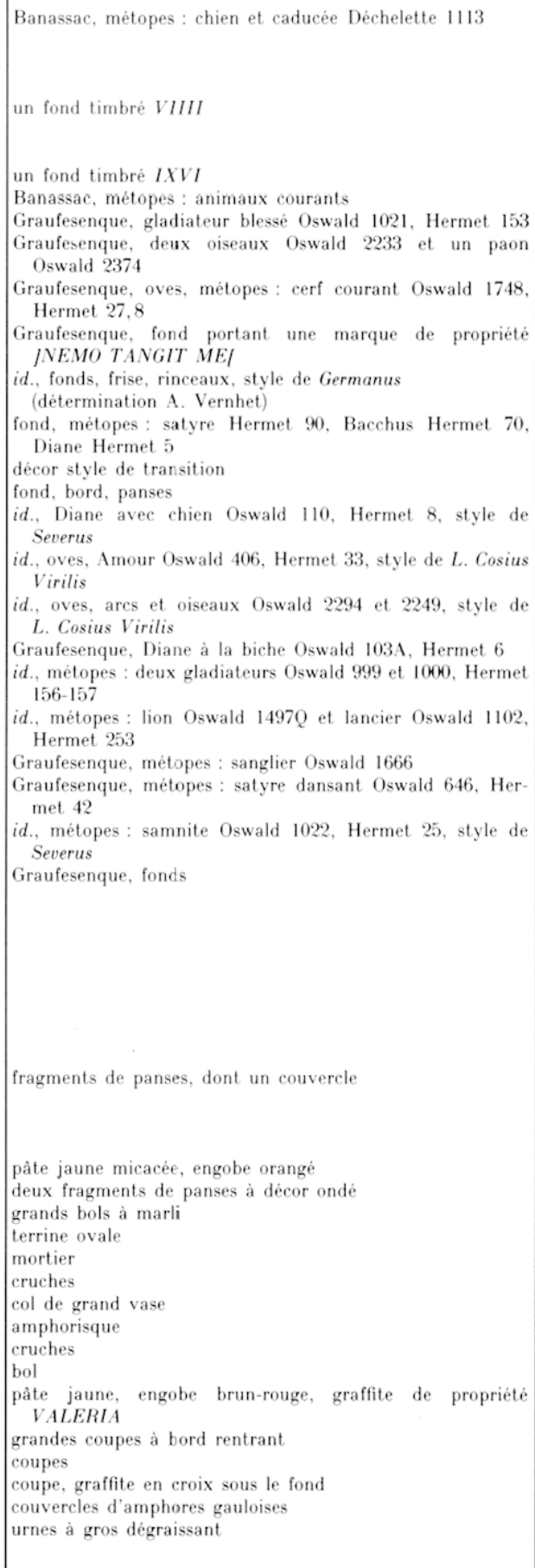 & $\begin{array}{l}34,3 \\
34,2-4 \\
\\
\\
34,5 \\
\\
34,12-13 \\
\\
34,14 \\
34,16 \\
\\
34,15 \\
34,11 \\
\\
34,6 \\
34,8 \\
34,10 \\
34,9 \\
34,7\end{array}$ \\
\hline Fouille 1978 & $\begin{array}{l}\text { Cèramique fine } \\
\text { Céramique modelée } \\
\text { Céramique commune }\end{array}$ & $\begin{array}{l}\text { sigillée sud-gauloise } \\
\text { sigillée claire A } \\
\text { sigillée claire B } \\
\text { rouge pompéien } \\
\text { varoise } \\
\text { africaine } \\
\text { cuisson mode A }\end{array}$ & $\begin{array}{l}\text { Drag. 27 } \\
\text { Drag. 18/31 } \\
\text { Drag. 33 } \\
\text { Hermet } 25 \\
\\
\text { Drag. 35/36 } \\
\text { Hayes 9A } \\
\text { Hayes 23B } \\
\text { Hayes } 8 \mathrm{~A} \\
\text { Hayes 140A } \\
\\
\text { Bérato } 16 \\
\text { Hayes } 185 \\
\text { Hayes } 196\end{array}$ & $\begin{array}{r}1 \\
2 \\
1 \\
5 \\
1 \\
3 \\
1 \\
3 \\
2 \\
1 \\
1 \\
2 \\
29 \\
1 \\
3 \\
1 \\
2\end{array}$ & $\begin{array}{l}1 \\
1 \\
1 \\
1 \\
1 \\
3 \\
3 \\
1 \\
1 \\
1 \\
1 \\
1 \\
1 \\
4 \\
1 \\
1 \\
1 \\
2\end{array}$ & $\begin{array}{l}\text { fond timbré COSI de La Graufesenque, Oswald, } 1920 \text {, } \\
\text { p. } 89-90 .\end{array}$ & $34,19-20$ \\
\hline
\end{tabular}




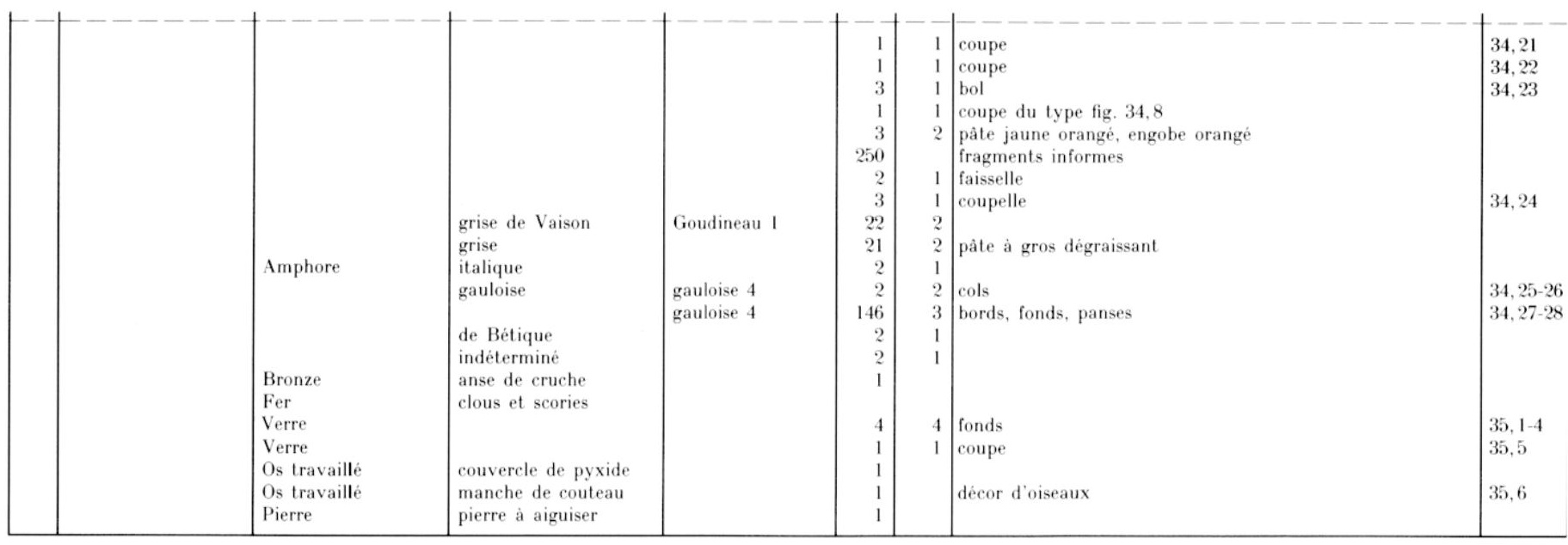

Tableau VII : Matériel de l'État II : utilisation des Égouts

\begin{tabular}{|c|c|c|c|c|c|c|c|c|}
\hline État & Contexte & Classe & Type & Forme & $\begin{array}{l}\text { Tes- } \\
\text { sons }\end{array}$ & $\begin{array}{l}\text { Indi- } \\
\text { vidus }\end{array}$ & Observations & Figures \\
\hline II & Égout $115 / 116$ & $\begin{array}{l}\text { Lampe } \\
\text { Lampe } \\
\text { Céramique fine } \\
\text { Céramique modelée } \\
\text { Céramique commune } \\
\text { Amphore } \\
\text { Verre }\end{array}$ & $\begin{array}{l}\text { de la Plaine du Pô } \\
\text { paroi fine } \\
\text { glaçure plombifère } \\
\text { sigillée sud-gauloise } \\
\text { sigillée claire B } \\
\text { sigillée claire A } \\
\text { rouge-pompéien } \\
\text { varoise } \\
\text { cuisson mode A } \\
\text { grise de Vaison } \\
\text { grise } \\
\text { grise } \\
\text { gauloise } \\
\text { de Bétique }\end{array}$ & $\begin{array}{l}\text { Deneauve VIIC } \\
\text { Drag. } 37 \\
\text { Drag. 37 } \\
\text { Drag. 18/31 } \\
\text { Drag. 35/36 } \\
\text { Drag. 27 } \\
\text { Hermet 90,5 } \\
\text { Lamboglia } 8 \\
\text { Lamboglia 9 } \\
\text { Hayes } 8 \mathrm{~A} \\
\text { Hayes } 14 \mathrm{~A} \\
\text { Hayes 17A } \\
\text { Hayes 23B } \\
\text { Bérato } 17 \\
\text { Bérato } 16 \\
\end{array}$ & $\begin{array}{r}4 \\
1 \\
10 \\
1 \\
2 \\
5 \\
4 \\
2 \\
1 \\
1 \\
6 \\
1 \\
2 \\
3 \\
11 \\
3 \\
1 \\
5 \\
2 \\
9 \\
19 \\
1 \\
5 \\
4 \\
2 \\
3 \\
3 \\
8 \\
1 \\
230 \\
4 \\
2 \\
27 \\
113 \\
1 \\
1\end{array}$ & $\begin{array}{l}1 \\
1 \\
2 \\
1 \\
1 \\
1 \\
2 \\
1 \\
1 \\
1 \\
1 \\
1 \\
1 \\
2 \\
1 \\
1 \\
1 \\
1 \\
2 \\
6 \\
1 \\
1 \\
4 \\
2 \\
1 \\
3 \\
5 \\
1 \\
1 \\
1 \\
1 \\
1 \\
1 \\
1\end{array}$ & $\begin{array}{l}\text { décor pointillé et guilloché } \\
\text { décor lion Hermet } 11 \text { et sanglier Hermet } 40 \\
\text { fragments informes } \\
\text { fragments informes } \\
\text { couvercle } \\
\text { urne, pàte rouge, dégraissant mica et quartz } \\
\text { bols et coupes } \\
\text { plats } \\
\text { terrine ovale } \\
\text { couvercles d'amphores gauloises } \\
\text { cruches } \\
\text { cruche } \\
\text { fragments informes } \\
\text { urne à bord noirci } \\
\text { cruche } \\
\text { bord, fond, anse } \\
\text { fond décor de rouelles }\end{array}$ & $\begin{array}{l}36,1-2 \\
36,3-4 \\
36,6 \\
36,7-10 \\
36,11-12 \\
36,13 \\
36,14-16 \\
36,17 \\
36,5 \\
36,18 \\
36,19\end{array}$ \\
\hline 11 & Égout 98/99 & $\begin{array}{l}\text { Lampe } \\
\text { Lampe } \\
\text { Céramique fine } \\
\text { Céramique modelée } \\
\text { Céramique commune }\end{array}$ & $\begin{array}{l}\text { de la Plaine du Pò } \\
\text { paroi-fine } \\
\text { glaçure plombifère } \\
\text { sigillée sud-gauloise } \\
\text { sigillée claire A } \\
\text { sigillée claire C } \\
\text { sigillée claire B } \\
\text { varoise } \\
\text { varoise } \\
\text { africaine } \\
\text { africaine } \\
\text { africaine } \\
\text { de Lorgues }\end{array}$ & $\begin{array}{l}\text { Drag. } 37 \\
\text { Drag. } 37 \\
\text { Drag. 18/31 } \\
\text { Drag. 35/36A } \\
\text { Drag. 27 } \\
\text { Hayes } 3 \\
\text { Hayes } 9 \mathrm{~A} \\
\text { Hayes 23B } \\
\text { Hayes 50A } \\
\text { Lamboglia 2/37 } \\
\text { Berato } 16 \\
\text { Berrato } 17 \\
\text { Hayes } 197 \\
\text { Hayes } 196\end{array}$ & $\begin{array}{r}3 \\
1 \\
4 \\
2 \\
15 \\
4 \\
2 \\
10 \\
1 \\
2 \\
35 \\
10 \\
12 \\
6 \\
61 \\
2 \\
7 \\
2 \\
6 \\
5\end{array}$ & $\begin{array}{l}1 \\
1 \\
2 \\
2 \\
4 \\
3 \\
2 \\
1 \\
1 \\
1 \\
3 \\
4 \\
3 \\
1 \\
7 \\
1 \\
3 \\
2 \\
1 \\
1\end{array}$ & $\begin{array}{l}\text { décors d'écailles et de feuilles d'eau } \\
\text { cratères à poucier italiques, décor de volutes et rosettes } \\
\text { La Graufesenque, décors à métopes, un archet Hermet } 264 \\
\text { Banassac, oves Hoffman A, décors à métopes } \\
\text { grande marmite }\end{array}$ & $\begin{array}{l}37,3 \\
37,2\end{array}$ \\
\hline
\end{tabular}



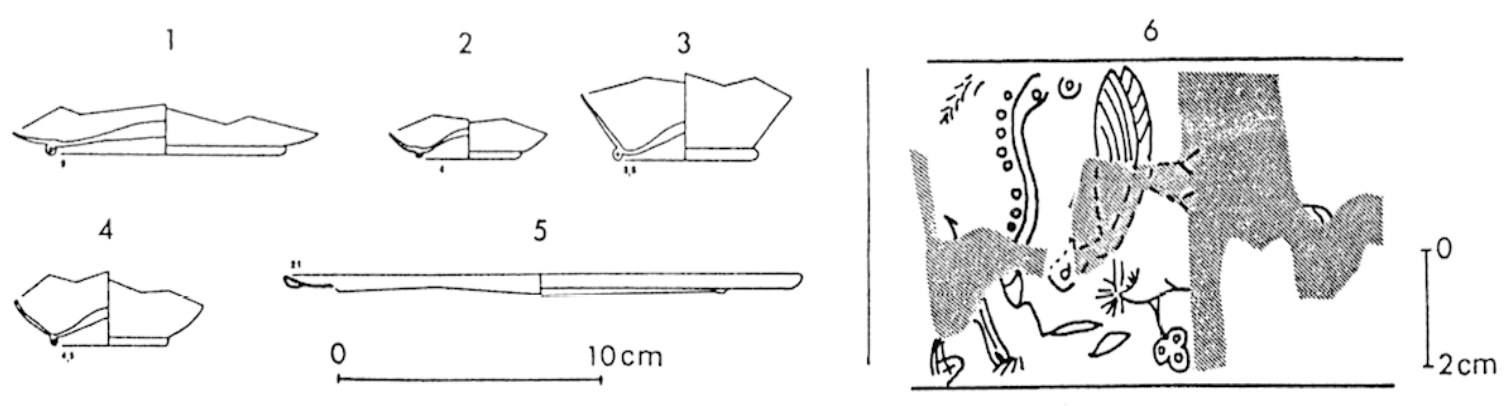

Fig. 35 - État II : matériel du dépotoir.
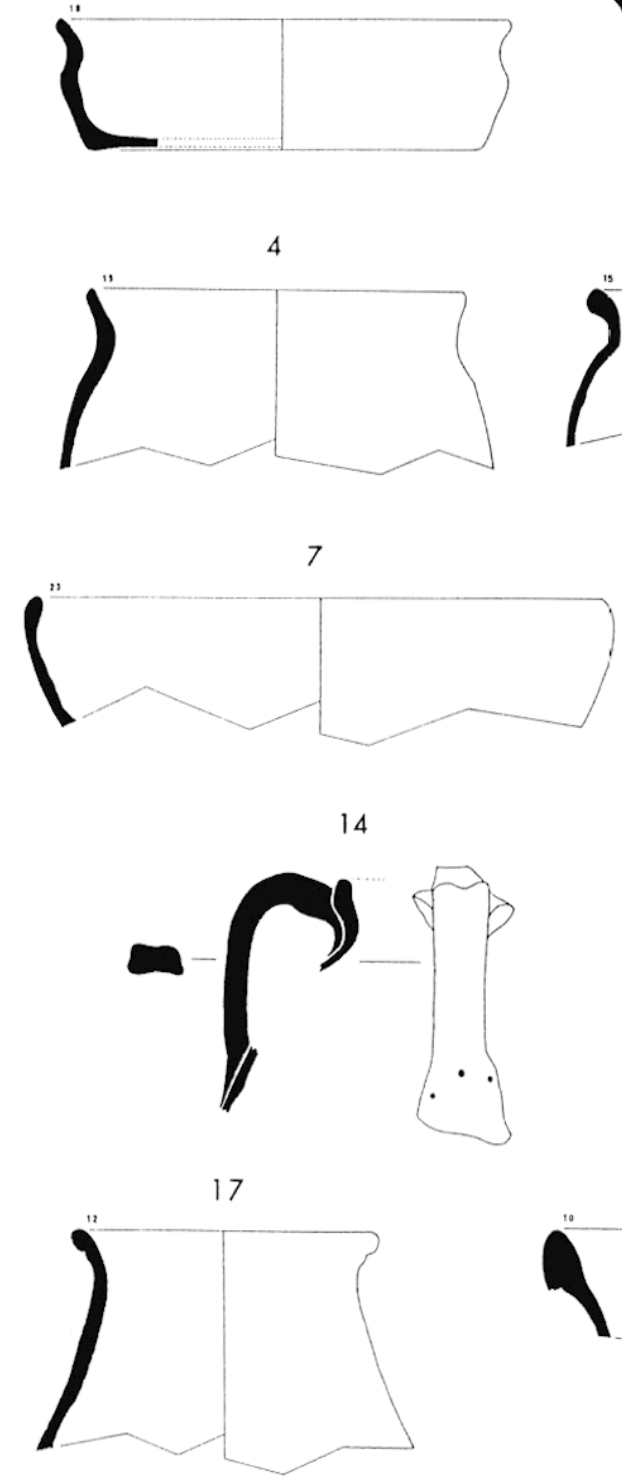
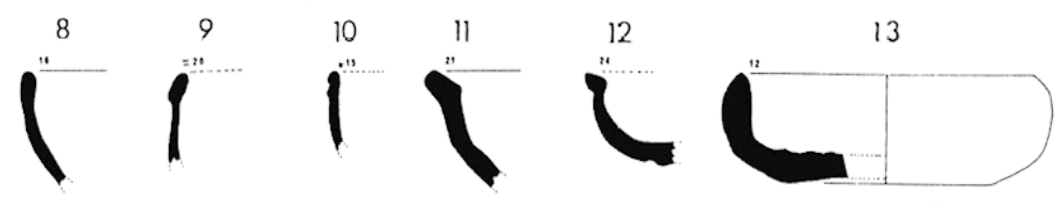

15

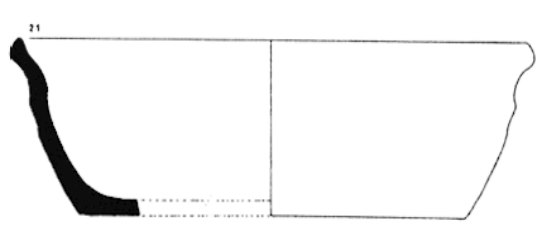

5
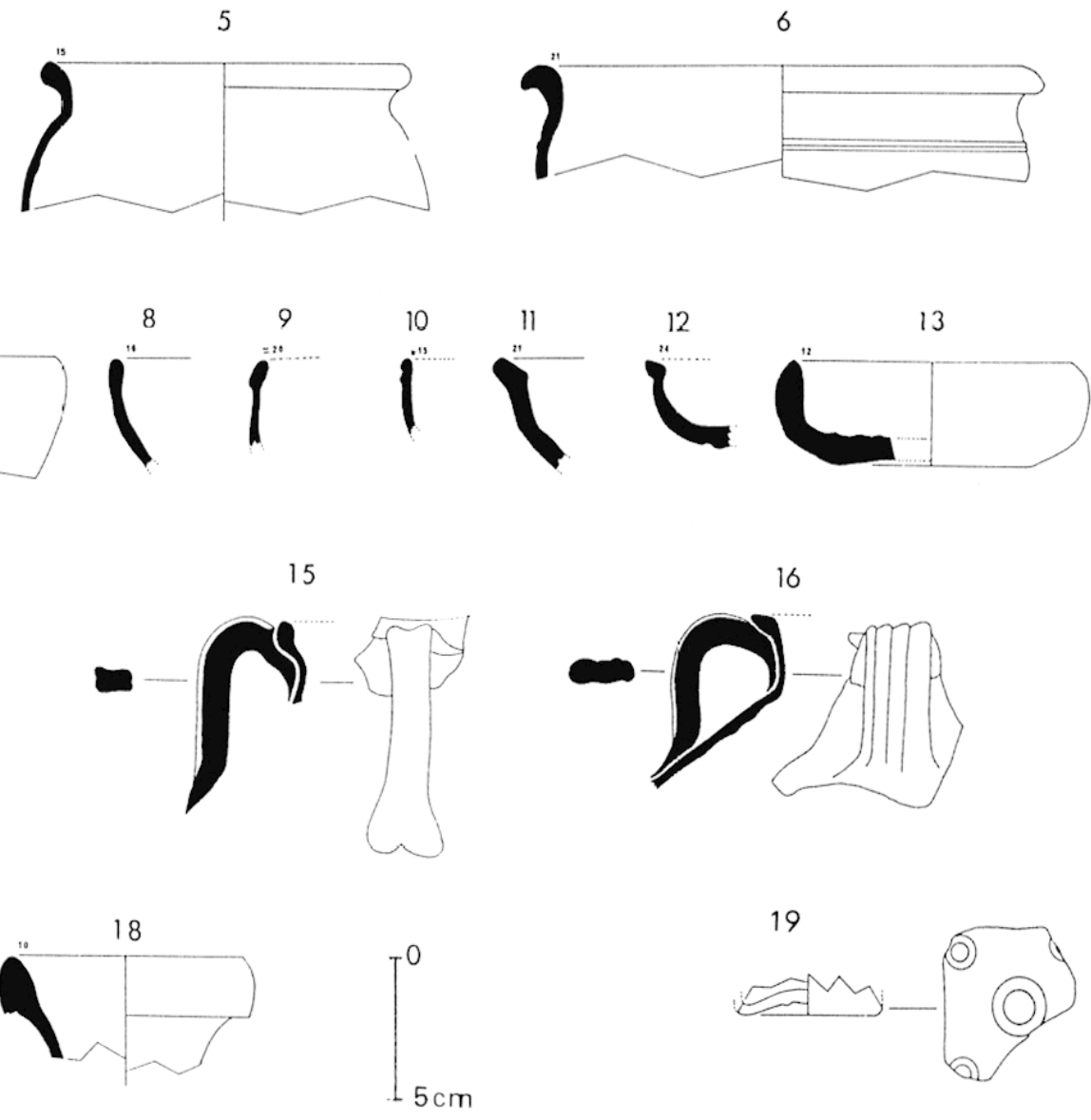

Fig. 36 - Etat II : matériel de l'égout 115/116. 

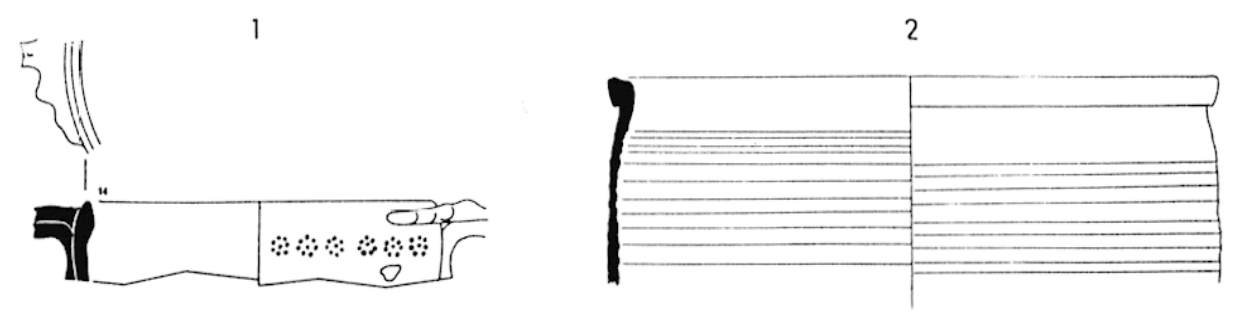

3
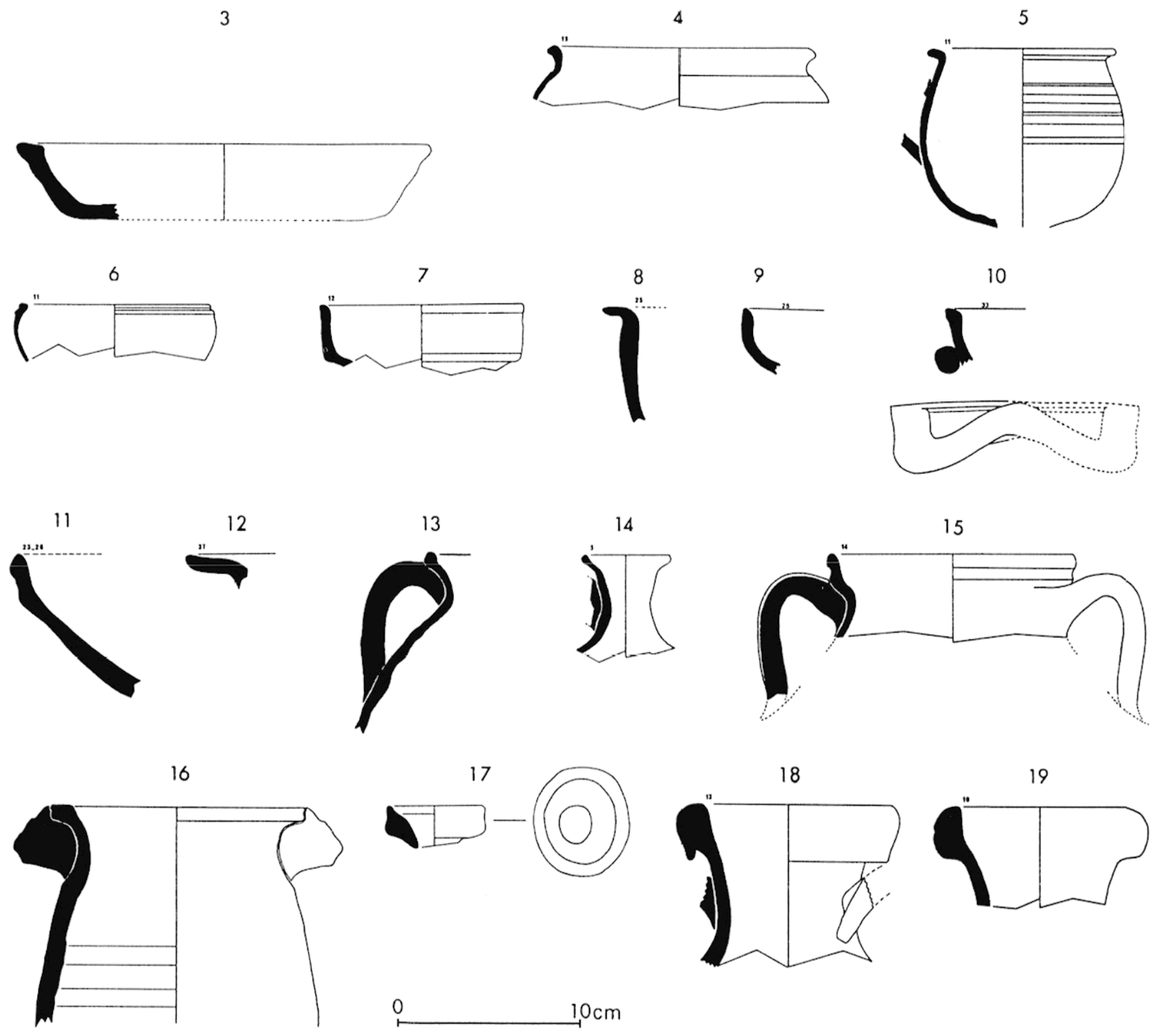

20

21
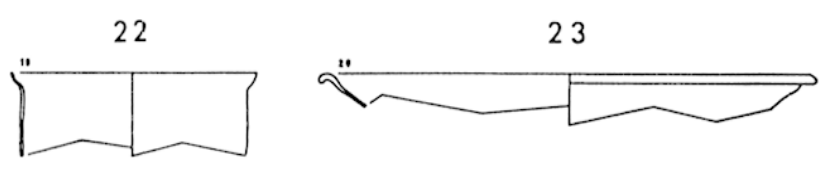

Fig. 37 - Etat II : matériel de l'égout 98/99. 


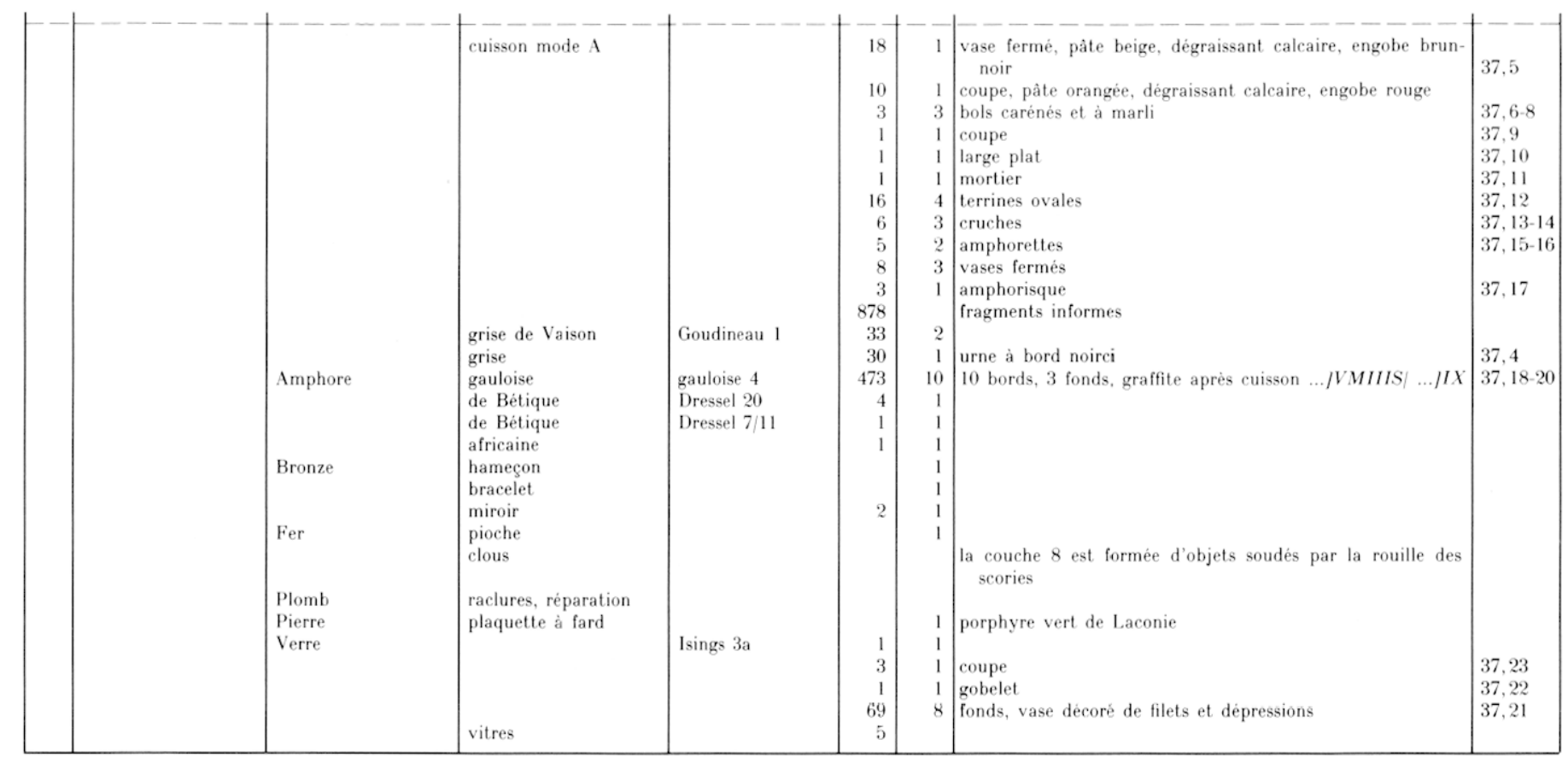

Tabieau VIII : MatÉrifi. DF l'État II : PIÈce 205

\begin{tabular}{|c|c|c|c|c|c|c|c|c|}
\hline État & Contexte & Classe & Type & Forme & $\begin{array}{l}\text { Tes- } \\
\text { sons }\end{array}$ & $\begin{array}{l}\text { Indi- } \\
\text { vidus }\end{array}$ & Observations & Figures \\
\hline IIA & 205 , occupation & $\begin{array}{l}\text { Céramique fine } \\
\text { Céramique commune }\end{array}$ & $\begin{array}{l}\text { paroi-fine } \\
\text { sigillée sud-gauloise } \\
\text { cuisson mode A }\end{array}$ & & $\begin{array}{l}2 \\
2 \\
2\end{array}$ & $\begin{array}{l}1 \\
2 \\
1\end{array}$ & fragment décoré & \\
\hline IIB & 205 , construction & $\begin{array}{l}\text { Lampe } \\
\text { Céramique fine } \\
\text { Céramique modelée } \\
\text { Céramique commune } \\
\text { Amphore }\end{array}$ & $\begin{array}{l}\text { sigillée sud-gauloise } \\
\text { sigillée claire A } \\
\text { varoise } \\
\text { cuisson mode A } \\
\text { gauloise }\end{array}$ & $\begin{array}{l}\text { Drag. } 37 \\
\text { gauloise } 4\end{array}$ & $\begin{array}{r}1 \\
1 \\
2 \\
4 \\
4 \\
45 \\
3 \\
9 \\
1 \\
46\end{array}$ & $\begin{array}{l}1 \\
1 \\
1 \\
1 \\
2 \\
1 \\
1 \\
1 \\
2\end{array}$ & $\begin{array}{l}\text { terrines ovales } \\
\text { fragments informes } \\
\text { coupe profonde, pâte micacée, engobe blanc } \\
\text { cruche } \\
\text { amphorette? } \\
\text { épaulements, fond }\end{array}$ & $\begin{array}{l}38,3 \\
38,4 \\
38,1 \\
38,2\end{array}$ \\
\hline
\end{tabular}

Tableau IX : matériei. de l.'état III : occupation des locaux de l'huilerie après sa mise hors d'Usage

\begin{tabular}{|c|c|c|c|c|c|c|c|c|}
\hline État & Contexte & Classe & Type & Forme & $\begin{array}{l}\text { Tes- } \\
\text { sons }\end{array}$ & $\begin{array}{l}\text { Indi- } \\
\text { vidus }\end{array}$ & Observations & Figures \\
\hline III & Cour 15 , occupation & $\begin{array}{l}\text { Céramique fine } \\
\text { Céramique modelée } \\
\text { Céramique commune } \\
\text { Amphore } \\
\text { Verre } \\
\text { Fer } \\
\text { Pierre } \\
\text { Tuile }\end{array}$ & $\begin{array}{l}\text { sigillée claire A } \\
\text { sigillée claire C } \\
\text { sigillée luisante } \\
\text { varoise } \\
\text { africaine } \\
\text { africaine } \\
\text { cuisson mode A } \\
\text { grise } \\
\text { gauloise } \\
\text { africaine } \\
\text { indéterminée } \\
\text { perle } \\
\text { vitres } \\
\text { scie } \\
\text { corniches, plaques }\end{array}$ & $\begin{array}{l}\text { Hayes } 23 \mathrm{~B} \\
\text { Hayes } 50 \mathrm{~A} \\
\text { Hayes } 182 \\
\text { Hayes } 196\end{array}$ & $\begin{array}{r}4 \\
6 \\
1 \\
2 \\
13 \\
1 \\
159 \\
18 \\
72 \\
65 \\
1 \\
1 \\
1 \\
20\end{array}$ & $\begin{array}{l}1 \\
1 \\
1 \\
1 \\
1 \\
1 \\
2 \\
2 \\
2 \\
1 \\
1 \\
1 \\
1\end{array}$ & $\begin{array}{l}\text { une coupe à marli, un vase engobé de brun } \\
\text { urnes } \\
\text { quatre anses, un fond } \\
\text { anse bifide } \\
\text { anse } \\
\text { verre bleu } \\
\text { marbre de Mani, de Thessalie, du Cap de Garde } \\
\text { timbre MARI }\end{array}$ & $\begin{array}{l}40,1 \\
40,2 \\
40,3-4\end{array}$ \\
\hline III & Cuves, comblement & $\begin{array}{l}\text { Lampe } \\
\text { Lampe } \\
\text { Lampe } \\
\text { Céramique fine }\end{array}$ & $\begin{array}{l}\text { sigillée sud-gauloise } \\
\text { sigillée claire A } \\
\text { sigillée claire A }\end{array}$ & $\begin{array}{l}\text { Deneauve VIIIB } \\
\text { Deneauve VIIIB } \\
\text { Deneauve VIIIB } \\
\text { Drag. } 37 \\
\text { Hayes } 27 / 31 \\
\text { Hayes } 17 \mathrm{~A}\end{array}$ & $\begin{array}{r}3 \\
1 \\
4 \\
3 \\
20 \\
14\end{array}$ & $\begin{array}{l}1 \\
1 \\
1 \\
2 \\
1 \\
2\end{array}$ & $\begin{array}{l}\text { bandeau décoré de gros grénetis } \\
\text { décor: amour pilotant une barque } \\
\text { bandeau décoré de feuilles de laurier }\end{array}$ & $\begin{array}{l}40,6 \\
39 \\
40,5 \\
40,12 \\
40,8-9\end{array}$ \\
\hline
\end{tabular}




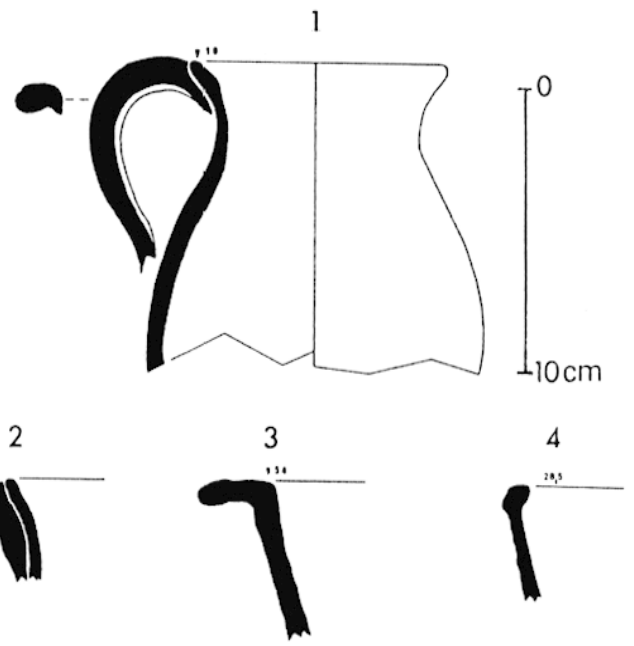

Fig. 38 - État II : matériel de la pièce 205.

Fig. 39 - Etat III : lampe (remplissage de $\rightarrow$ la cuve 21 ).
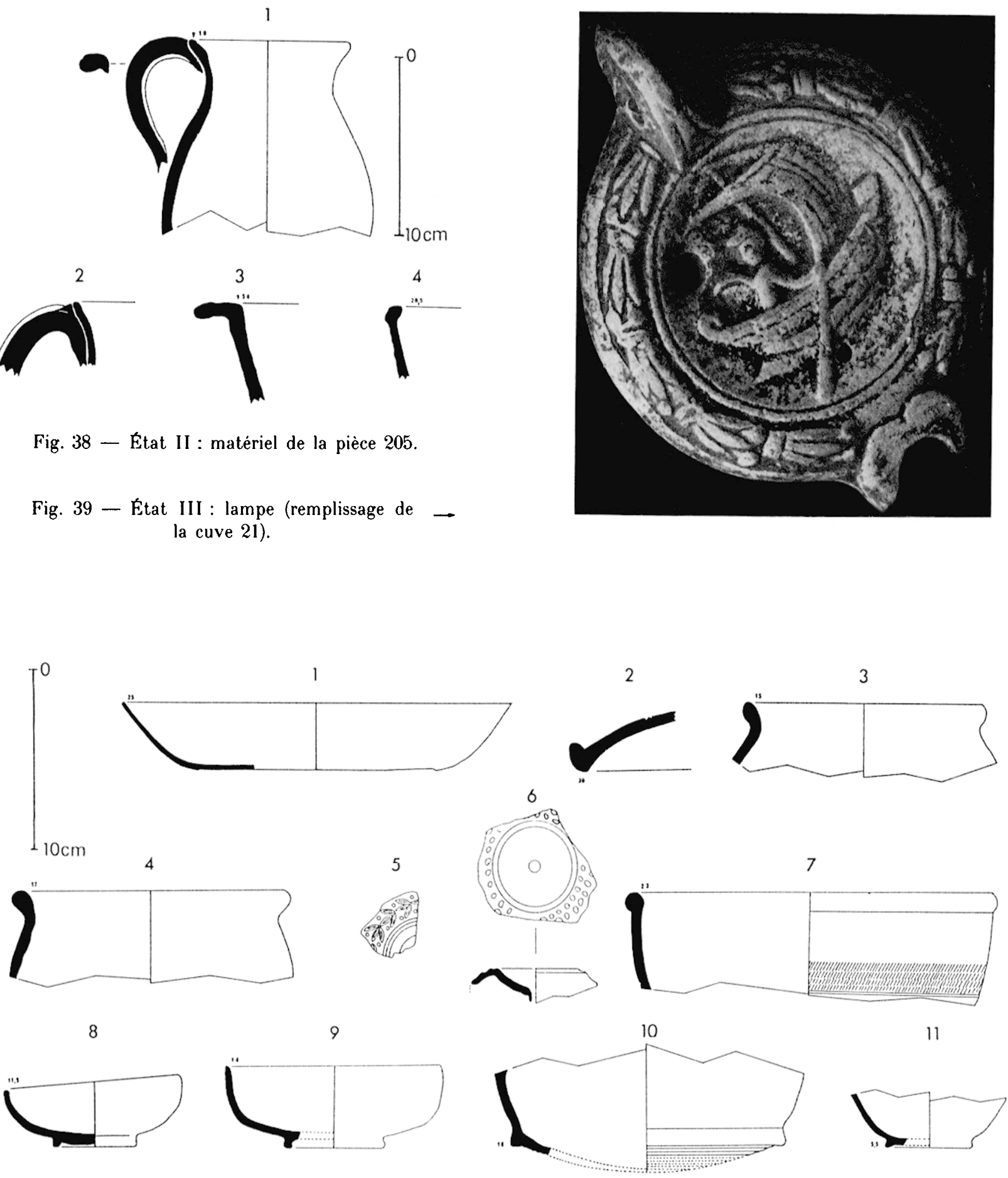

11

12
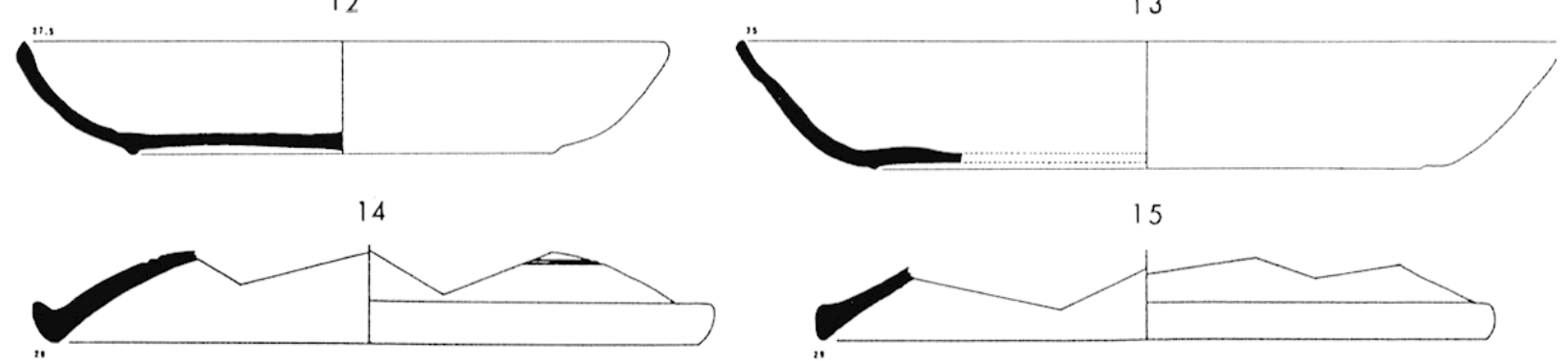

Fig. 40 - État III : matériel de la cour $15: n^{\circ s} 1$ à 4 ; matériel de remplissage des cuves : $n^{\circ \mathrm{os}} 5$ à 15 . 

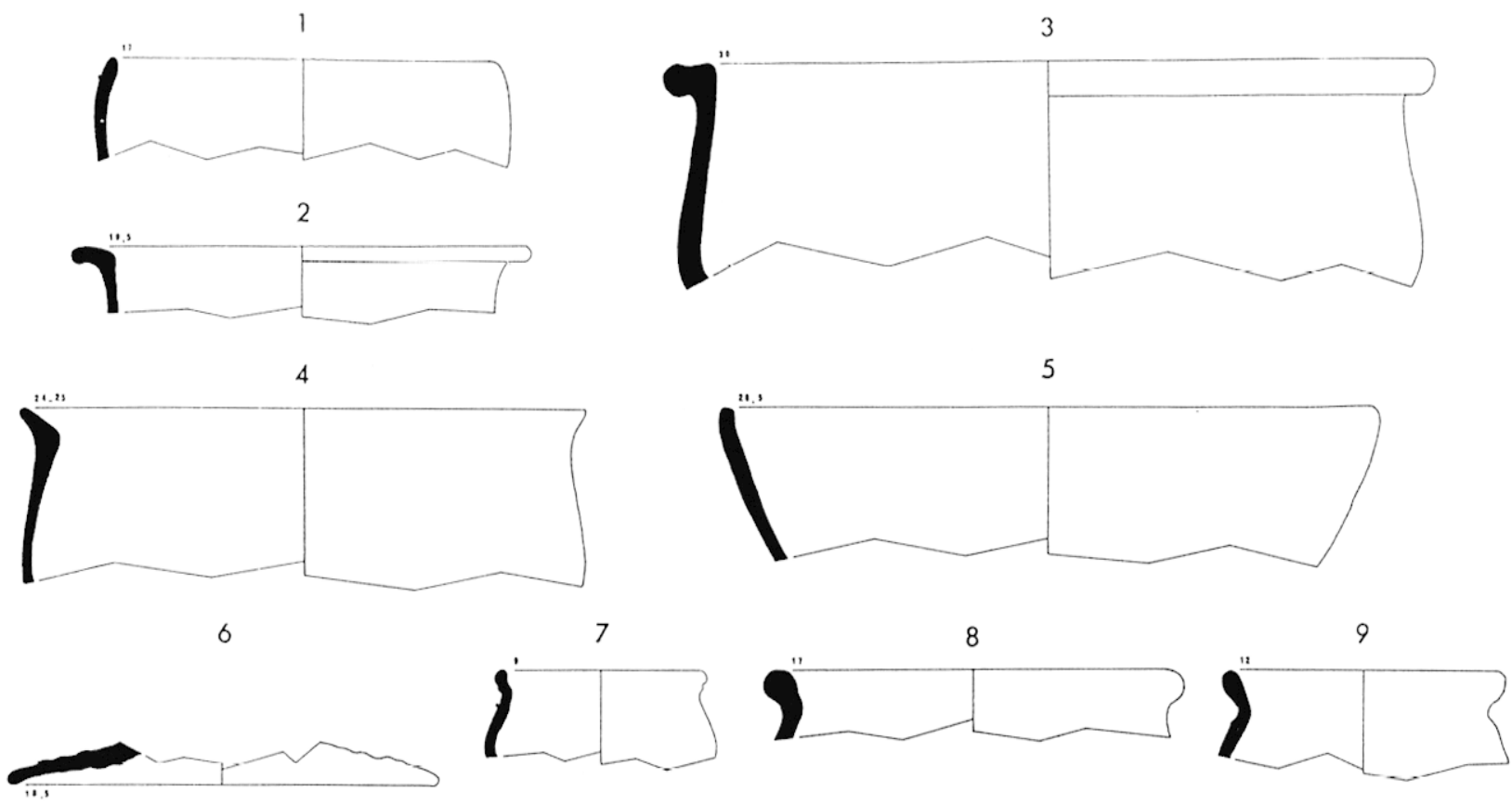

10

11

12
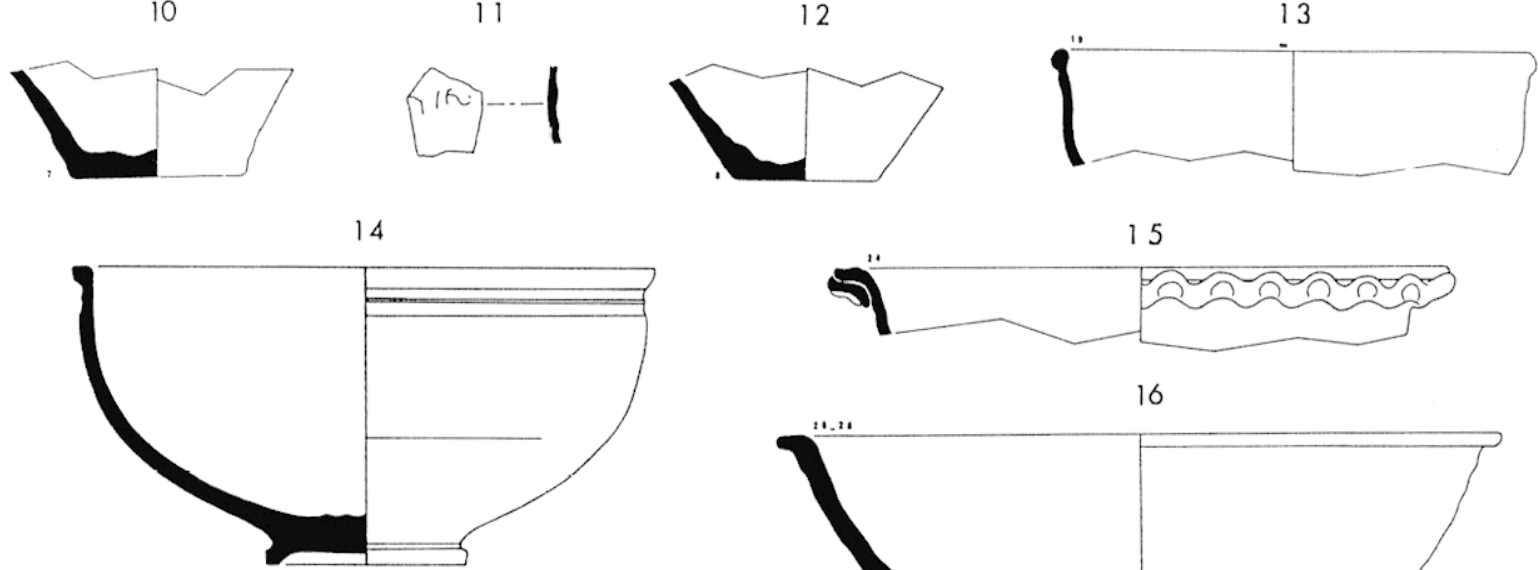

in -.1

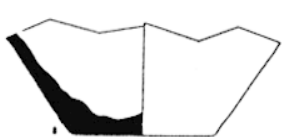

16
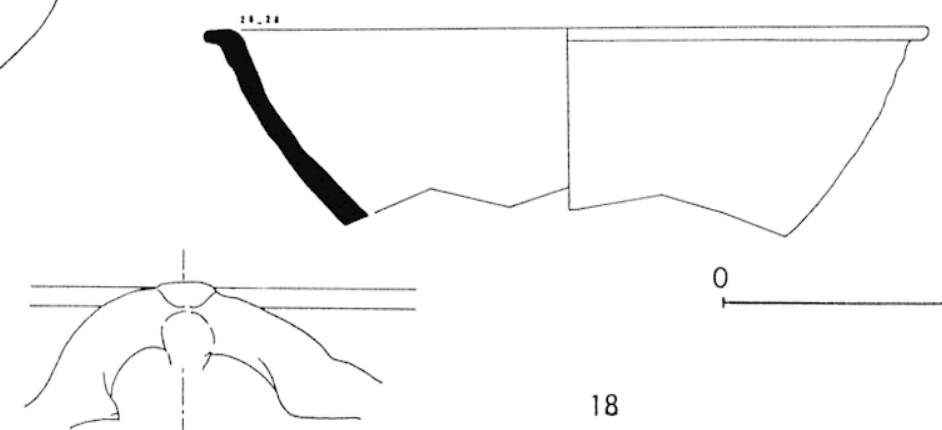

0 $10 \mathrm{~cm}$

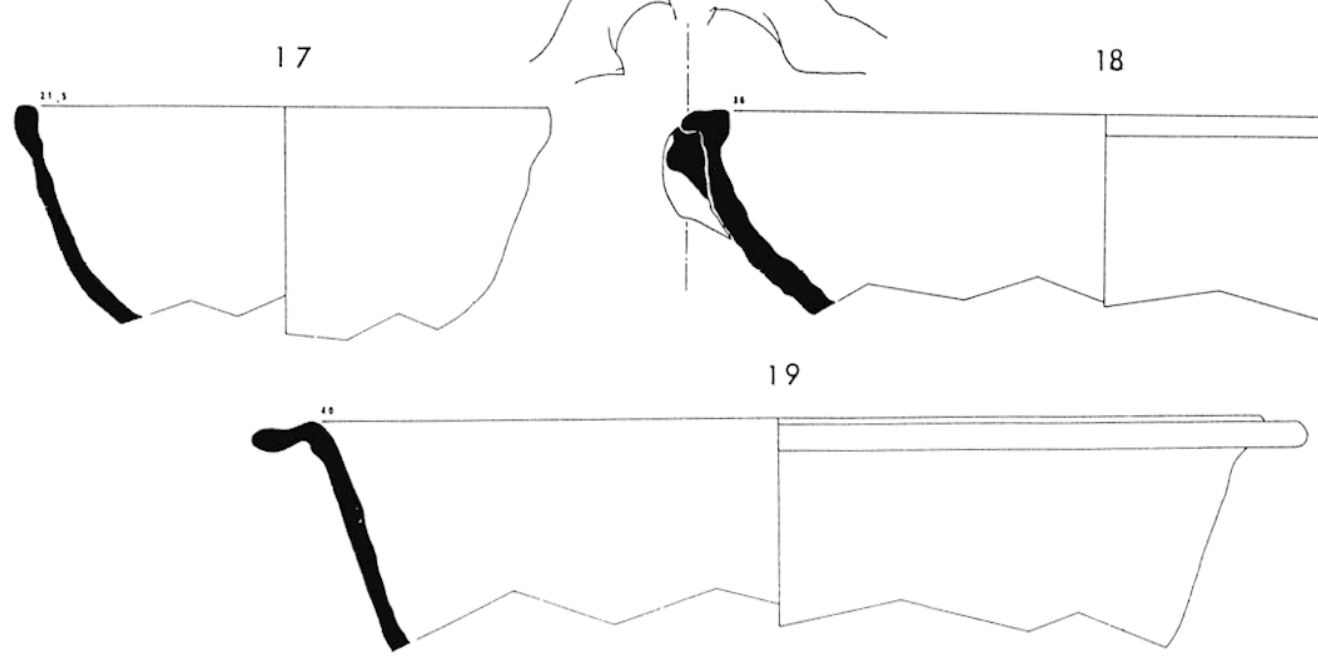

Fig. 41 - État III : matériel de remplissage des cuves. 


\begin{tabular}{|c|c|c|c|c|c|c|c|}
\hline & $\begin{array}{l}\text { Céramique modelée } \\
\text { Céramique commune }\end{array}$ & $\begin{array}{l}\text { sigillée claire A } \\
\text { sigillée claire A } \\
\text { sigillée claire A } \\
\text { sigillée claire C } \\
\text { sigillée claire C } \\
\text { sigillée claire B } \\
\text { sigillée luisante } \\
\text { sigillée luisante } \\
\text { régionale } \\
\text { varoise } \\
\text { varoise } \\
\text { varoise } \\
\text { africaine } \\
\text { africaine } \\
\text { africaine } \\
\text { cuisson mode A } \\
\text { cuisson mode A } \\
\text { cuisson mode A } \\
\text { cuisson mode A } \\
\text { cuisson mode A } \\
\text { cuisson mode A } \\
\text { cuisson mode A } \\
\text { cuisson mode A } \\
\text { cuisson mode A } \\
\text { cuisson mode A } \\
\text { grise } \\
\text { grise } \\
\text { grise } \\
\text { grisé } \\
\text { grise } \\
\text { italique } \\
\text { gauloise } \\
\text { africaine } \\
\text { indéterminée } \\
\text { italique } \\
\\
\text { anneau emmanché } \\
\text { clou } \\
\text { anneau } \\
\text { clous } \\
\text { scellements }\end{array}$ & $\begin{array}{l}\text { Hayes 23B } \\
\text { Hayes } 3 \\
\text { Hayes 14B } \\
\text { Hayes } 44 \\
\text { Hayes } 50 \mathrm{~A} \\
\text { Lamboglia } 4 \\
\text { Lamboglia } 1 / 3\end{array}$ & $\begin{array}{r}2 \\
1 \\
4 \\
5 \\
50 \\
1 \\
9 \\
1 \\
2 \\
6 \\
11 \\
11 \\
30 \\
4 \\
2 \\
3 \\
5 \\
4 \\
18 \\
11 \\
197 \\
47 \\
340 \\
12 \\
3 \\
3 \\
3 \\
4 \\
1 \\
7 \\
4 \\
61 \\
3 \\
272 \\
82 \\
8 \\
5 \\
15\end{array}$ & $\begin{array}{r}1 \\
1 \\
1 \\
1 \\
4 \\
1 \\
1 \\
1 \\
1 \\
1 \\
1 \\
1 \\
1 \\
1 \\
1 \\
1 \\
2 \\
1 \\
3 \\
2 \\
2 \\
4 \\
2 \\
27 \\
1 \\
1 \\
1 \\
1 \\
1 \\
1 \\
1 \\
1 \\
1 \\
1 \\
1 \\
4 \\
3 \\
1 \\
1 \\
1 \\
2 \\
1 \\
1 \\
1 \\
1 \\
1 \\
1 \\
1 \\
1 \\
1 \\
1\end{array}$ & 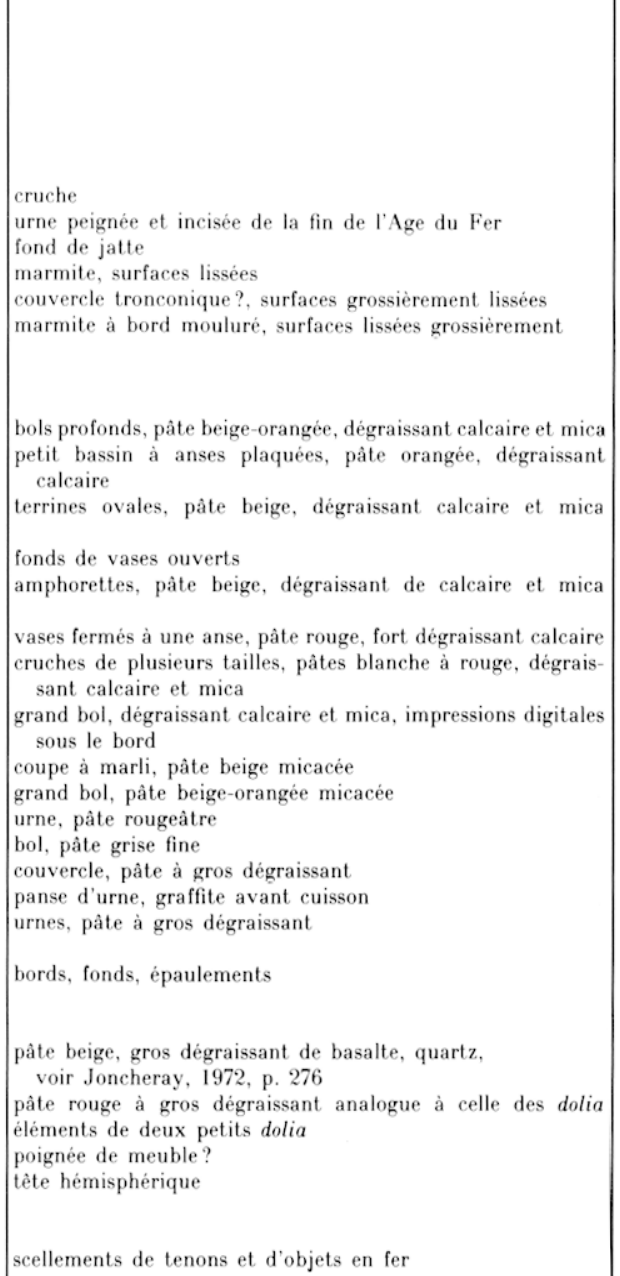 & $\begin{array}{l}41,4 \\
41,5 \\
41,3 \\
40,14 \\
40,15 \\
41,1 \\
41,17 \\
41,18 \\
41,19 \\
42,1 \\
42,2 ; \\
43,1-3 \\
43,4-15 \\
18 \\
41,15 \\
41,16 \\
41,14 \\
41,12 \\
41,13 \\
41,6 \\
41,11 \\
41,7-10 \\
43,16-17 \\
43,19\end{array}$ \\
\hline
\end{tabular}
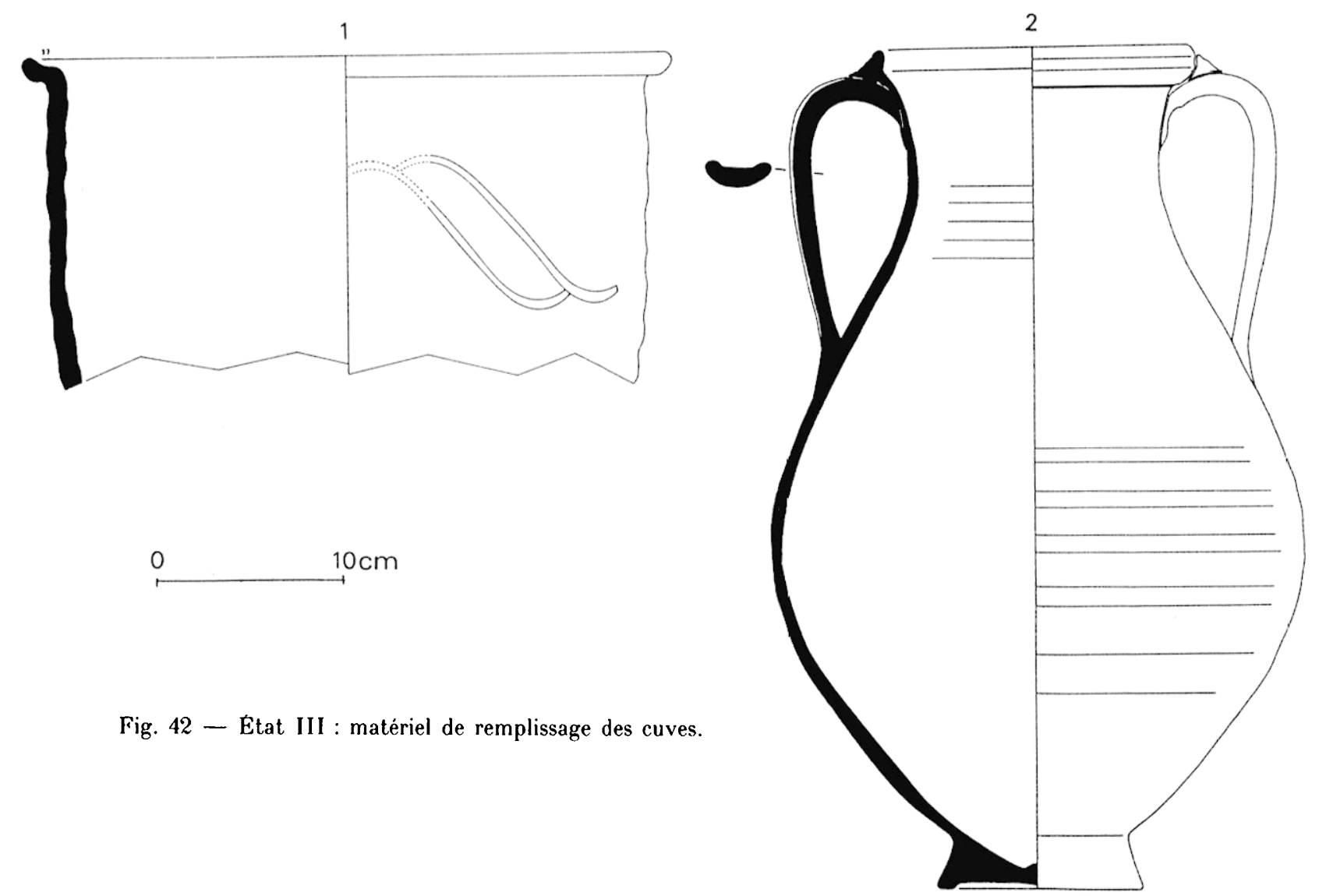

Fig. 42 - Etat III : matériel de remplissage des cuves. 

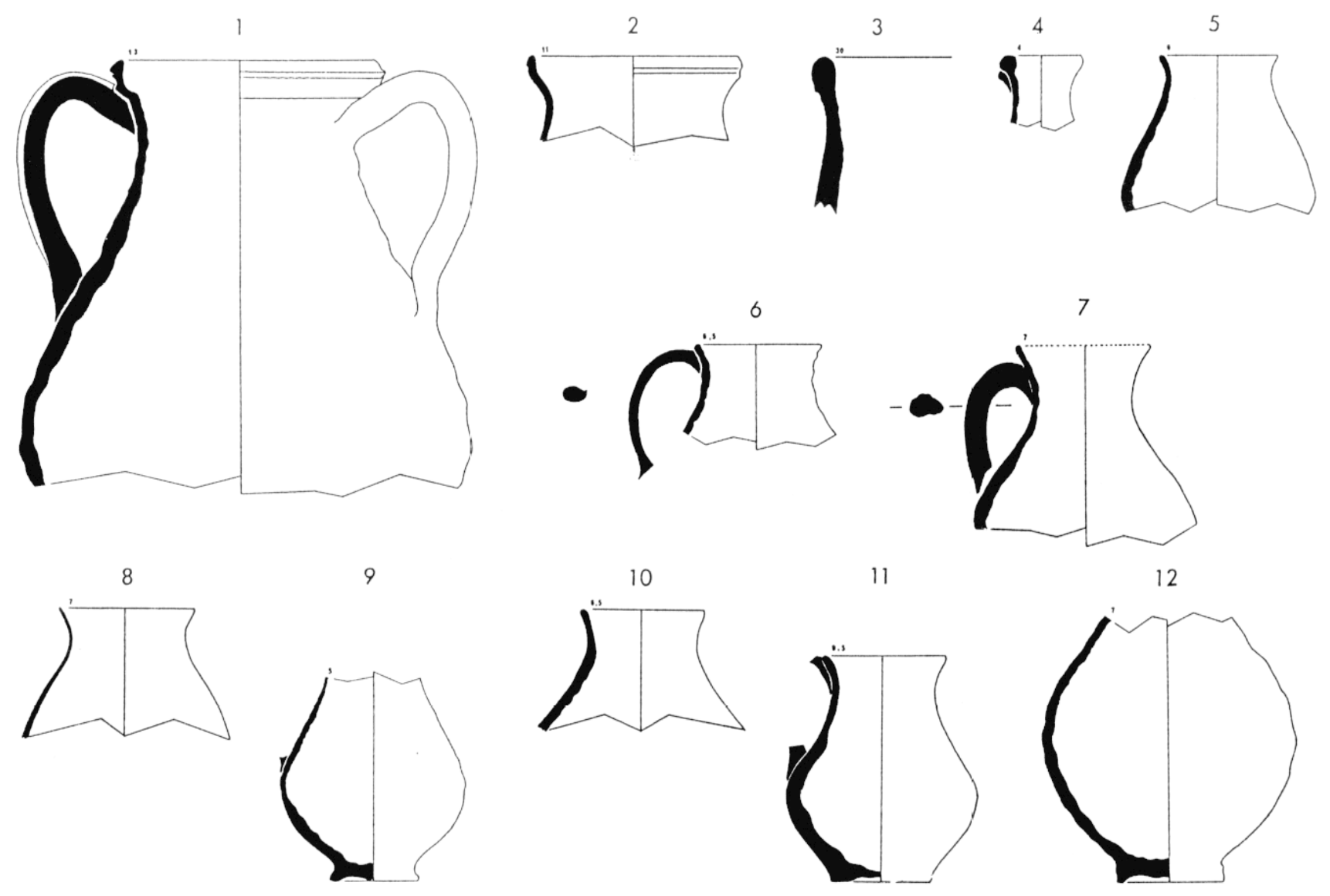

11
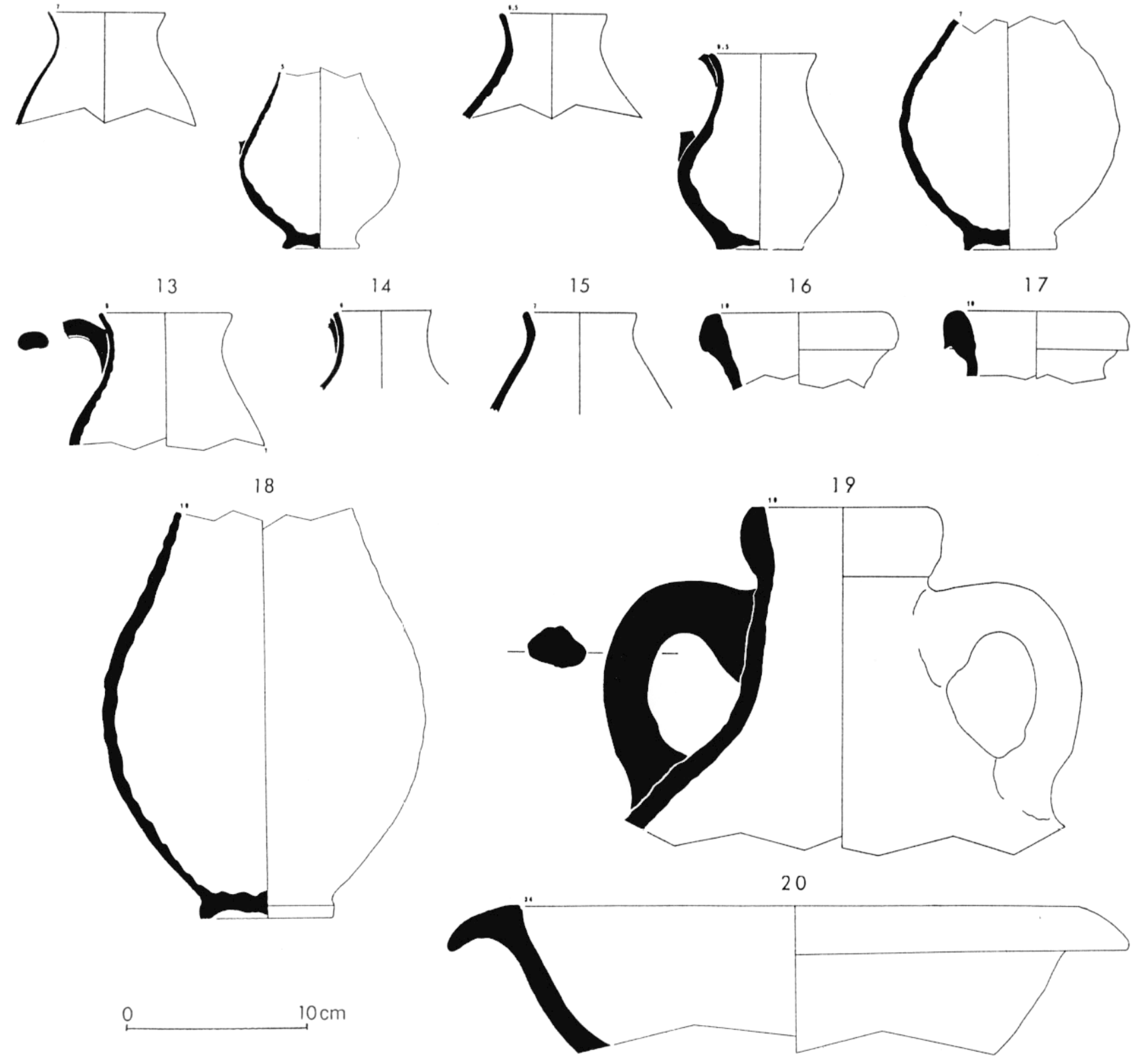

Fig. 43 - État III : matériel de remplissage des cuves. 

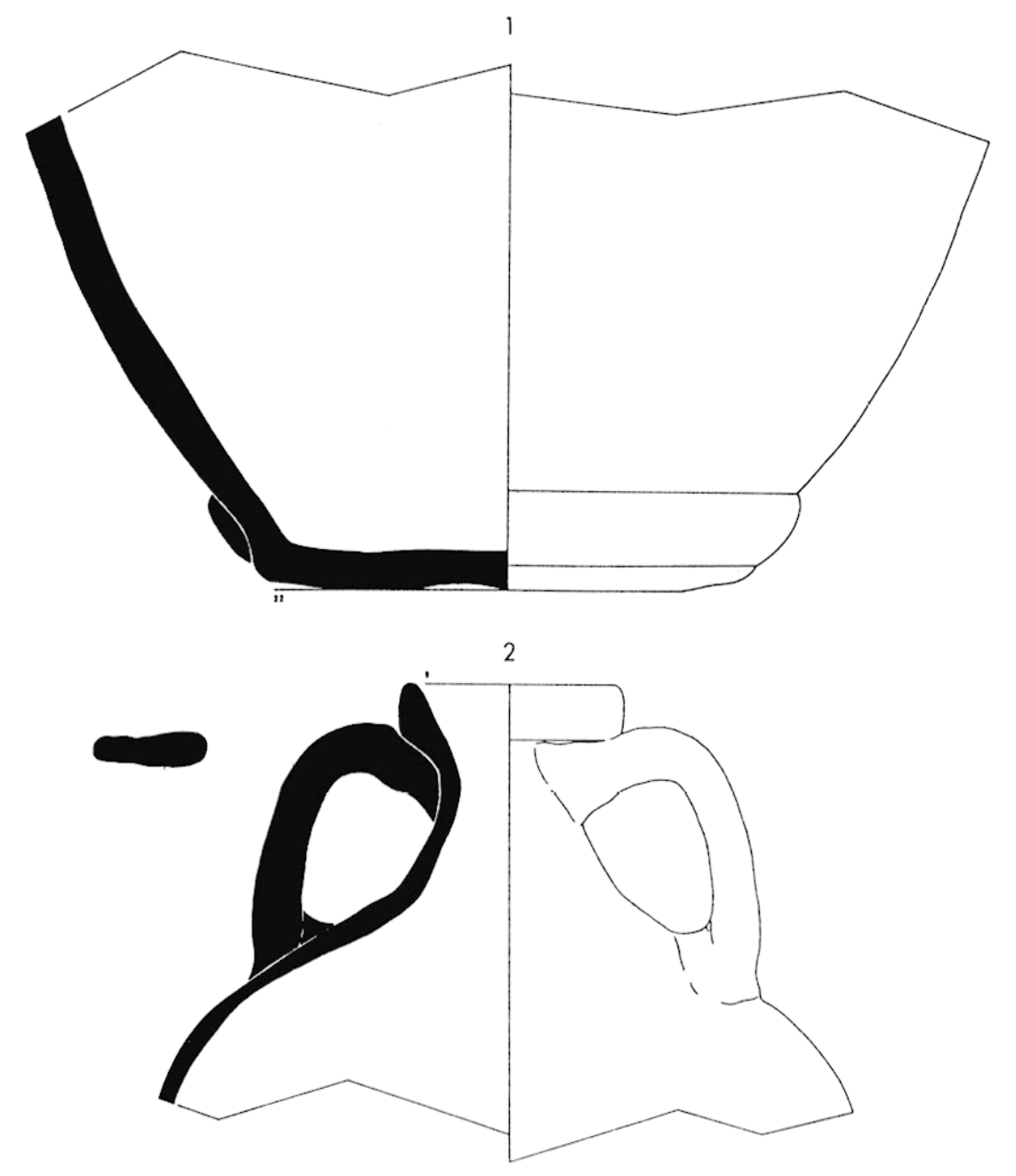

Fig. 44 - Etat III :

1, matériel de remplissage des cuves;

2 , matériel du dolium 1 .

Fig. 45 - Etat III :

matériel funéraire

des tombes 1 et 2 .
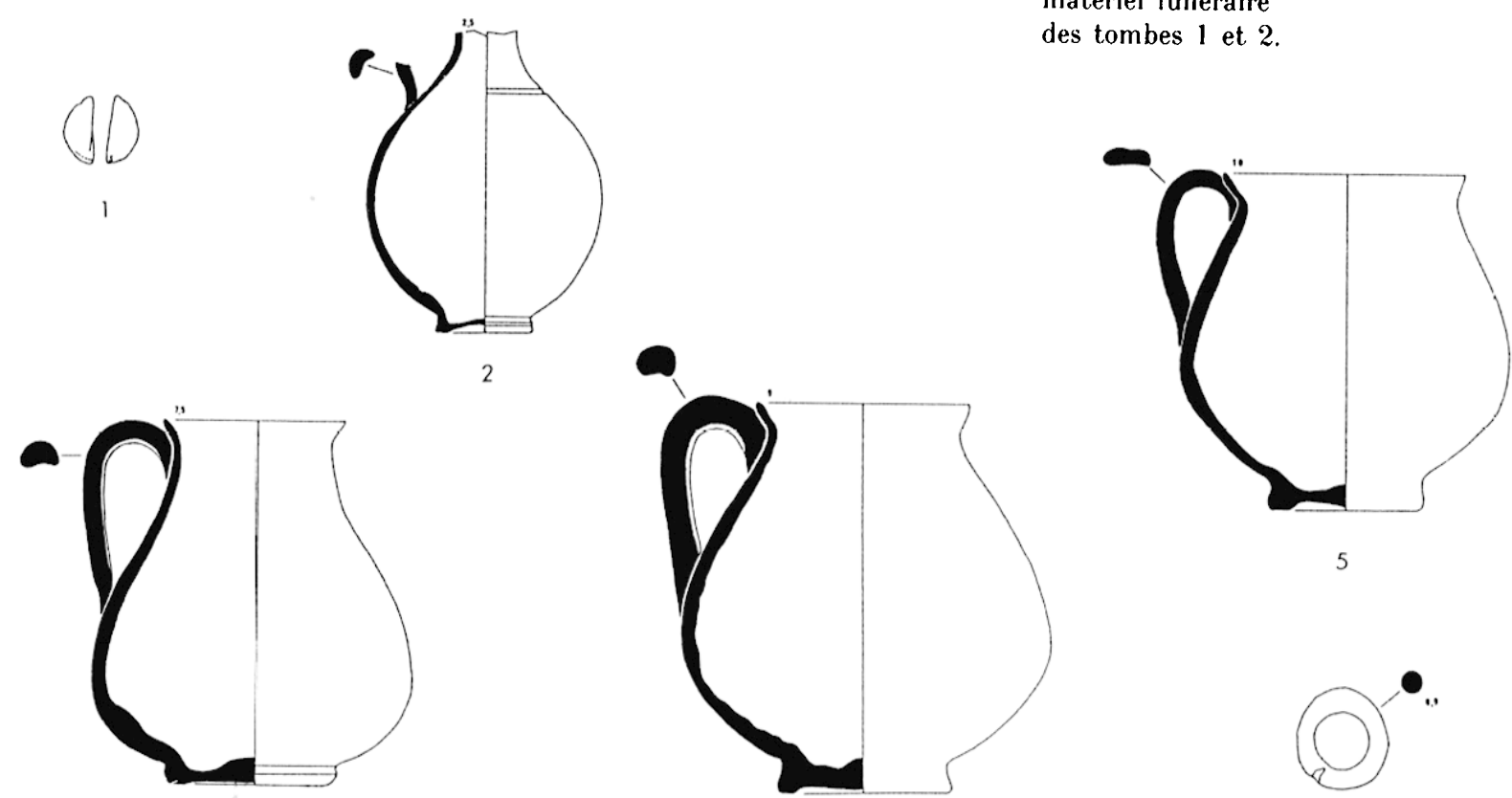

5 


\begin{tabular}{|c|c|c|c|c|c|c|c|c|}
\hline & & $\begin{array}{l}\text { Pierre } \\
\text { Pierre } \\
\text { Pierre }\end{array}$ & $\begin{array}{l}\text { vasque } \\
\text { plaquette à fard } \\
\text { plaques }\end{array}$ & & & $\begin{array}{l}1 \\
1\end{array}$ & $\begin{array}{l}\text { marbre de Chemtou } \\
\text { schiste } \\
\text { marbre du Cap de Garde, de Thessalie }\end{array}$ & \\
\hline III & Dolium, comblement & $\begin{array}{l}\text { Céramique fine } \\
\text { Céramique modelée } \\
\text { Céramique commune } \\
\text { Amphore }\end{array}$ & $\begin{array}{l}\text { sigillée claire A } \\
\text { sigillée claire C } \\
\text { varoise } \\
\text { cuisson mode A } \\
\text { cuisson mode A } \\
\text { cuisson mode A } \\
\text { grise } \\
\text { gauloise } \\
\text { africaine } \\
\text { lusitanienne } \\
\text { indėterminée }\end{array}$ & $\begin{array}{l}\text { Hayes 23B } \\
\text { Hayes } 50 \mathrm{~A} \\
\\
\text { gauloise } 4\end{array}$ & $\begin{array}{r}3 \\
1 \\
3 \\
2 \\
41 \\
2 \\
4 \\
15 \\
6 \\
11 \\
3\end{array}$ & $\begin{array}{l}1 \\
1 \\
1 \\
1 \\
3 \\
3 \\
2 \\
1 \\
2 \\
1 \\
1 \\
1\end{array}$ & $\begin{array}{l}\text { coupe à marli } \\
\text { cruches } \\
\text { fonds de bol et coupe } \\
\text { urne, pàte à gros dégraissant } \\
\text { Parker, } 1977 \text {, p. } 36, \text { col complet transformé en entonnoir }\end{array}$ & 44,2 \\
\hline
\end{tabular}

TABleaU X : État III : Matériel funÉraire

\begin{tabular}{|l|l|l|l|l|r|l|l|l|}
\hline État & \multicolumn{1}{|c|}{ Contexte } & \multicolumn{1}{|c|}{ Classe } & \multicolumn{1}{|c|}{ Type } & Forme & $\begin{array}{l}\text { Tes- } \\
\text { sons }\end{array}$ & $\begin{array}{l}\text { Indi- } \\
\text { vidus }\end{array}$ & Figures \\
\hline III & Tombe 1 & $\begin{array}{l}\text { Monnaie } \\
\text { Céramique commune } \\
\text { Céramique commune }\end{array}$ & $\begin{array}{l}\text { antoninianus fruste } \\
\text { cuisson mode A } \\
\text { cuisson mode A }\end{array}$ & & 1 & 1 & $\begin{array}{l}\text { pièce coupée en deux } \\
\text { cruche globulaire, påte jaune, engobe marron } \\
\text { cruche à large ouverture, pâte jaune }\end{array}$ \\
\hline & $\begin{array}{l}\text { Monnaie } \\
\text { Céramique commune } \\
\text { Bronze }\end{array}$ & $\begin{array}{l}\text { antoninianus fruste } \\
\text { cuisson mode A } \\
\text { anneau }\end{array}$ & & $\begin{array}{l}45,1 \\
45,2 \\
45,3\end{array}$ \\
\hline
\end{tabular}

\section{Tableau XI : Matériel. de l'état IV}

\begin{tabular}{|c|c|c|c|c|c|c|c|c|}
\hline État & Contexte & Classe & Type & Forme & $\begin{array}{l}\text { Tes- } \\
\text { sons }\end{array}$ & $\begin{array}{l}\text { Indi- } \\
\text { vidus }\end{array}$ & Observations & Figures \\
\hline IV & 204, occupation & $\begin{array}{l}\text { Lampe } \\
\text { Céramique fine }\end{array}$ & $\begin{array}{l}\text { sigillée sud-gauloise } \\
\text { sigillée claire D } \\
\text { sigillée luisante } \\
\text { dérivés-sigillées-paléo }\end{array}$ & $\begin{array}{l}\text { Deneauve VIIIB } \\
\text { Drag. } 29 \\
\text { Hayes } 61 \mathrm{~A} \\
\text { Lamboglia } 1 / 3 \\
\text { Rigoir } 24 \mathrm{~B}\end{array}$ & $\begin{array}{l}2 \\
1 \\
1 \\
1 \\
1\end{array}$ & \begin{tabular}{l|l}
2 & 1 \\
1 & 1 \\
1 & 1
\end{tabular} & $\begin{array}{l}\text { bandeaux décorés de feuilles et rinceaux } \\
\text { bord de petit vase à pâte grise }\end{array}$ & \\
\hline IV & 205 , occupation & $\begin{array}{l}\text { Céramique fine } \\
\text { Céramique modelée } \\
\text { Céramique commune } \\
\text { Amphore }\end{array}$ & $\begin{array}{l}\text { sigillèe arétine } \\
\text { sigillée sud-gauloise } \\
\text { sigillée sud-gauloise } \\
\text { sigillée sud-gauloise } \\
\text { sigillée sud-gauloise } \\
\text { sigillée claire A } \\
\text { sigillée claire D } \\
\text { sigillée luisante } \\
\text { sigillée luisante } \\
\text { varoise } \\
\text { africaine } \\
\text { cuisson mode A } \\
\text { cuisson mode A } \\
\text { grise } \\
\text { grise de Vaison } \\
\text { gauloise } \\
\text { africaine } \\
\text { indéterminée }\end{array}$ & $\begin{array}{l}\text { Goudineau } 27 \\
\text { Drag. } 37 \\
\text { Drag. } 27 \\
\text { Drag. } 29 \\
\text { Drag. } 37 \\
\text { Hayes } 14 \\
\text { Hayes } 59 \mathrm{~A} \\
\text { Lamboglia } 1 / 3 \\
\text { Lamboglia } 14 / 26 \\
\text { Hayes } 196 \\
\\
\text { Goudineau } 1 \\
\text { gauloise } 4\end{array}$ & $\begin{array}{r}3 \\
1 \\
1 \\
1 \\
2 \\
1 \\
6 \\
13 \\
2 \\
5 \\
1 \\
2 \\
95 \\
73 \\
2 \\
41 \\
6 \\
15\end{array}$ & $\begin{array}{l}1 \\
1 \\
1 \\
1 \\
1 \\
1 \\
1 \\
2 \\
1 \\
1 \\
1 \\
1 \\
3 \\
3 \\
1 \\
3 \\
1 \\
1\end{array}$ & $\begin{array}{l}\text { Banassac } \\
\text { vernis jaune marbré } \\
\text { urnette à bord noirci } \\
\text { urnes } \\
\text { urnes, pàte à gros dégraissant } \\
\text { fonds }\end{array}$ & $\begin{array}{l} \\
\\
\\
\\
46,1 \\
\\
\\
\\
\\
46,4 \\
46,3 \\
46,2,5\end{array}$ \\
\hline
\end{tabular}

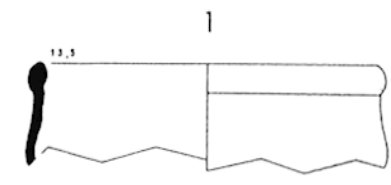

2

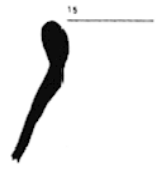

3

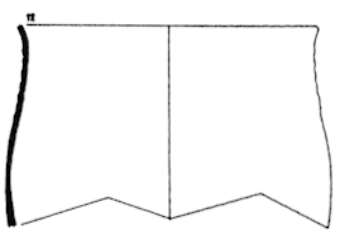

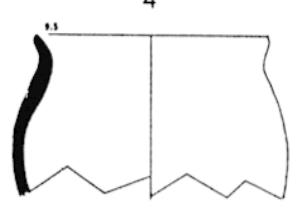

5
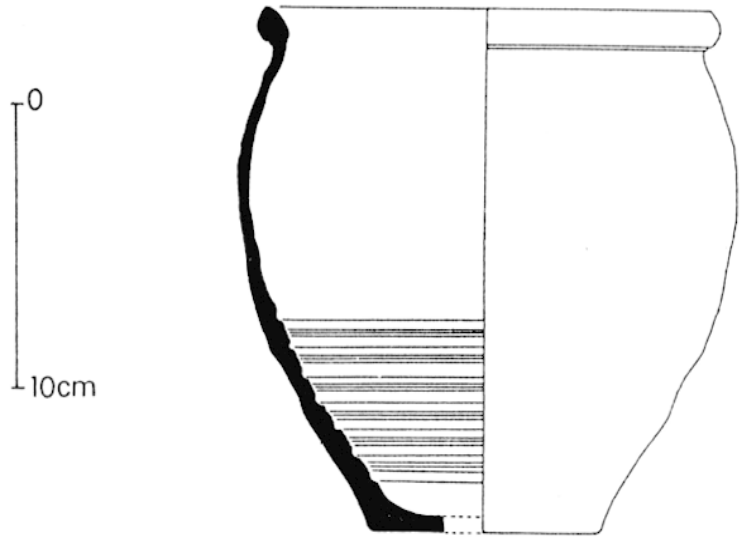

Fig. 46 - Etat IV : matériel de la pièce 205. 


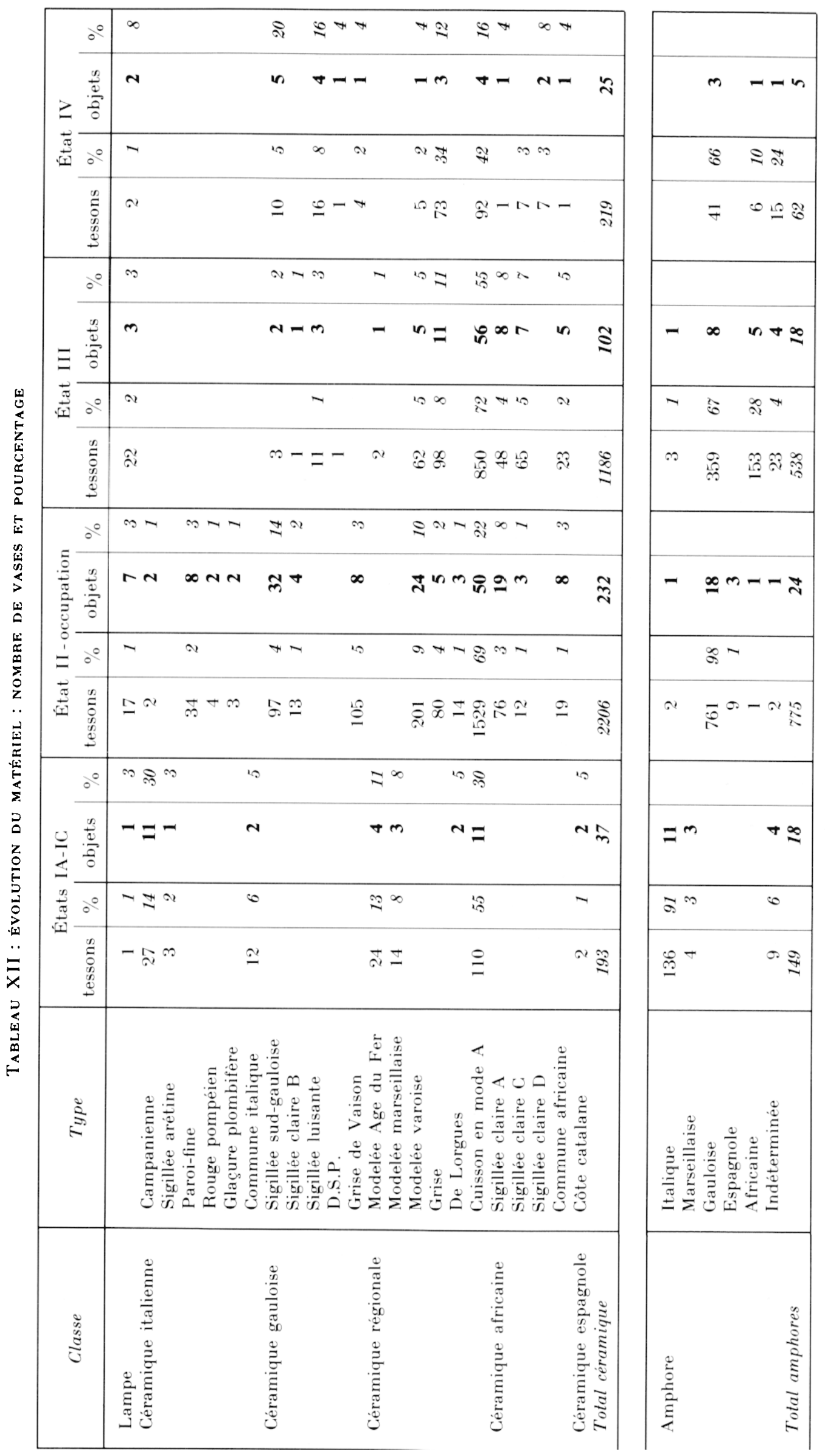




\section{TYPES}

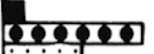

campanienne

sigillée arétine
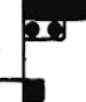

à paroi fine
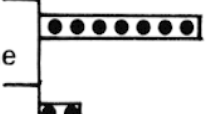

rouge pompéien

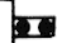

$$
\text { en }
$$

glaçure plombifère

commune italique

sigillée sud-gauloise

sigillée claire

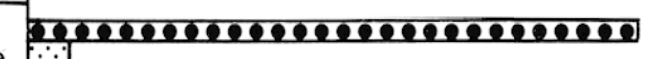

sigillée luisante

D.S.P

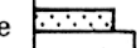

P.

grise de Vaison

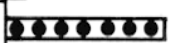

modelée Age du Fer

modelée marseillaise

7

modelée varois
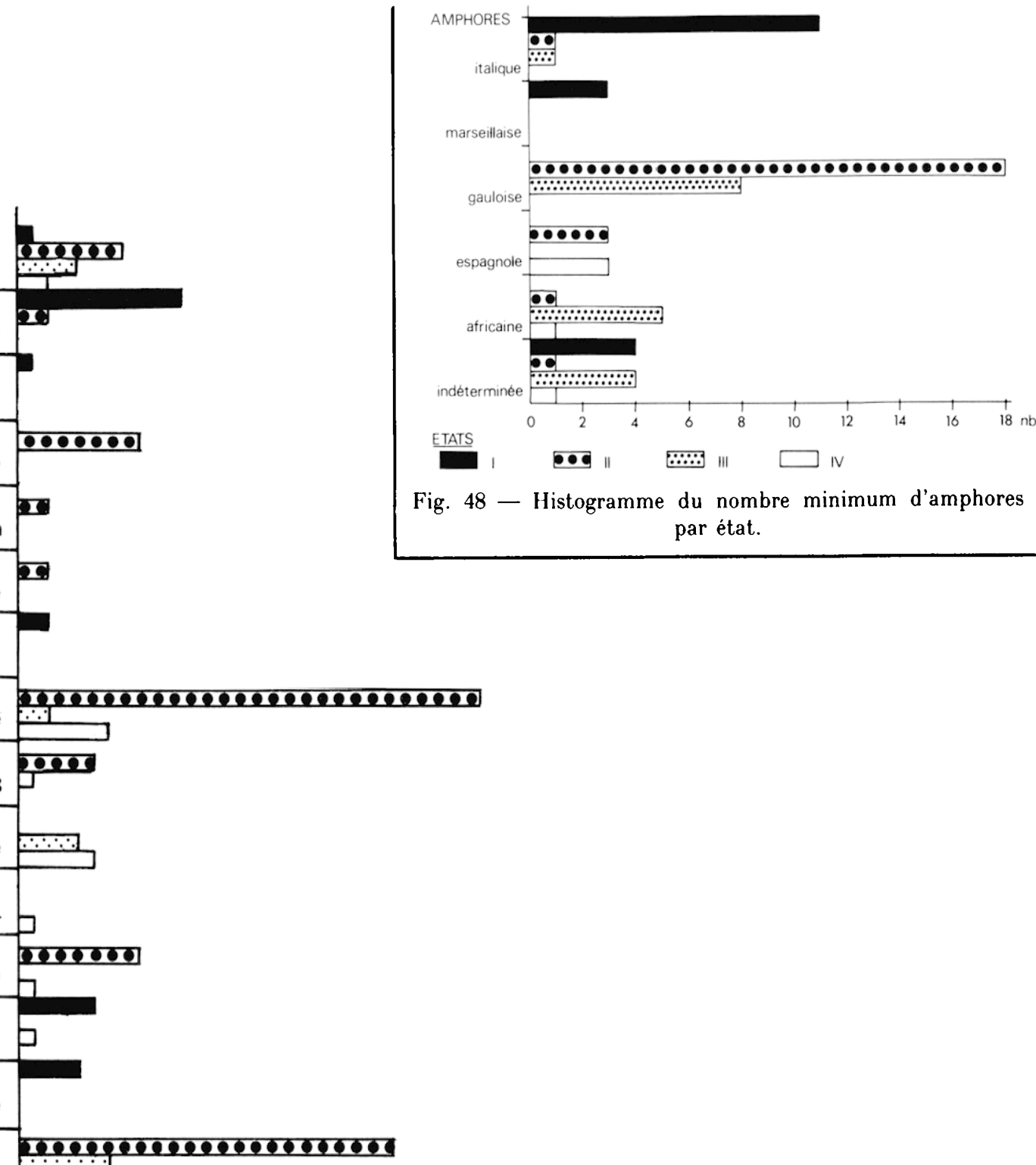

Fig. 48 - Histogramme du nombre minimum d'amphores par état.

grise

0000

de Lorgues

खृत्र

cuisson en mode $A$

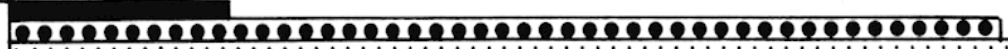

A $\because \because \because \because \cdots$

प00000000000

sigillée claire $A$

$\because \because \because \because \cdots$

sigillée claire

sigillée claire D

200

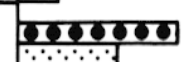

commune africaine

ESPAGNOLE côte catalane

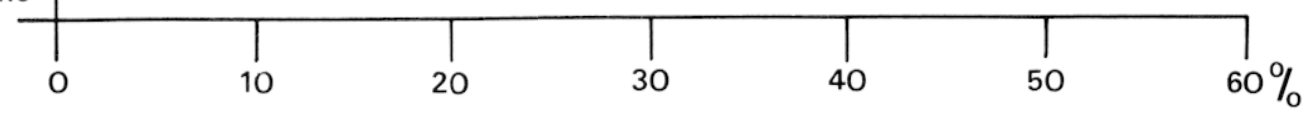

ETATS

2000 ॥

$\because \because \cdots$ III

IV

Fig. 47 - Histogramme du nombre minimum de céramiques par état. 


\title{
IV. ÉTUDE DE LA FAUNE
}

\author{
par Philippe Columeau*
}

L'étude de la faune archéologique provenant des fouilles de la villa de Saint-Michel à La Garde, Var, a permis de déterminer 251 individus, répartis dans les espèces suivantes:

- Invertébrés : Ostrea edulis, Tapes (decussatus?), Mytillus gallo-provincialis, Murex brandaris, Cardium edule, Buccinum undatum, Patella (tarentilla), Nassa reliculata, Helix pomalia;
- Vertébrés: Daurade (Chrysophrys aurata), des oiseaux galliformes, Chien (Canis familiaris L.), Fouine? (Mustela foina?), Lapin de garenne (Oryctolagus cunniculus Huxlei), Mulot? (Mus sylvaticus?), Porc (Sus domesticus L.), Sanglier (Sus scrofa L.), Bœuf (Bos taurus L.)', Cerf (Cervus elaphus L.), Mouton (Ovis aries L.), Chèvre (Capra hircus L.), Ane (Equus asinus L.), Cheval (Equus caballus L.), Tortue terrestre (Testudo Hermannii?).

La faune dans son ensemble

\begin{tabular}{|c|c|c|c|c|c|c|c|c|}
\hline \multicolumn{7}{|c|}{ INDIVIDUS (NMI) } & \multirow{2}{*}{$\frac{\mathrm{P}}{\mathrm{PV}}$} & \multirow{2}{*}{$\frac{\text { P.V. }}{\% \text { P.V. }}$} \\
\hline Espèces & $\mathrm{A}$ & $\mathrm{J}$ & $\mathrm{Tj}$ & Ind. & $\mathrm{T}$ & $\%$ & & \\
\hline OVIS & 5 & 1 & & & 6 & & 96 & \\
\hline CAPRA & 1 & 3 & & 2 & 6 & 19,5 & 84 & 4,9 \\
\hline OVIS/CAPRA & 20 & 8 & 8 & & 37 & & 480 & \\
\hline PORC & 20 & 19 & 10 & & 49 & 19,5 & 1204 & 9 \\
\hline BOEUF & 40 & 24 & 1 & 6 & 71 & 28,2 & 10972 & 82 \\
\hline CHEVAL & 2 & & & & 2 & 0,8 & 360 & 2,7 \\
\hline ANE & & & & 1 & 1 & 0,4 & 75 & 0,5 \\
\hline CHIEN & & & & 1 & 1 & 0,4 & 10 & 0,07 \\
\hline GALLUS & & & & 3 & 3 & 1,2 & 4,5 & 0,03 \\
\hline CERF & 1 & & & & 1 & 0,4 & 75 & 0,5 \\
\hline LAPIN G & 3 & 1 & 1 & 3 & 8 & 3,1 & 10 & 0,07 \\
\hline MULOT? & 2 & 1 & & 3 & 6 & 2,3 & & \\
\hline FOUINE? & & & & 1 & 1 & 0,4 & & \\
\hline OISEAUX & & & & 6 & 6 & 2,3 & & \\
\hline TORTUE H. & & & & 1 & 1 & 0,3 & & \\
\hline DAURADE & & & & 3 & 3 & 1,2 & 3 & 0,02 \\
\hline COQUILLAGES & & & & 49 & 19,5 & & & \\
\hline TOTAL & & & & 251 & & & 13373,5 & \\
\hline
\end{tabular}

* Centre Camille Jullian, C.NRS.

1 Il semble désormais attesté qu'il ait existé à cette époque deux formes de bœufs, plus l'aurochs. Laissons ce dernier de côté, ainsi que son descendant présumé, qui ne semble pas se trouver, même sous sa forme domestique dans ce gisement. Les mensurations que Jourdan 1976, a publiées correspondent pour la plupart des cas à celles que j'ai pu observer ici. Il paraît très probable qu'il s'agisse d'une double population de bceufs, qui comprendraient des formes de Bos $T$. brachyceros et de Bos $T$. brachycephalus, avec des types intermédiaires, obtenus par croisement. Mais il ne faut pas écarter l'hypothèse d'une différenciation sexuelle qui viendrait nuancer encore cette séparation trop rigoureuse. 
La fouille de cette huilerie gallo-romaine a mis en évidence une occupation en quatre états successifs; la faune que chaque période d'occupation a livrée varie beaucoup de l'une à l'autre, du moins pour le nombre d'individus. Les espèces varient peu. La faune de chaque phase archéologique se présente comme suit :

\section{Etat I}

\begin{tabular}{|l|l|l|l|l|l|l|}
\hline Espèces & $\mathrm{A}$ & $\mathrm{J}$ & $\mathrm{Tj}$ & Ind. & $\mathrm{T}$ & $\mathrm{P} . \mathrm{V}$. \\
\hline OVIS/CAPRA & 1 & 1 & & & 2 & 28 \\
CERF & 1 & & & & 1 & 75 \\
TORTUE H. & & & 1 & & 1 & \\
\hline TOTAL & & & & & 4 & 103 \\
\hline
\end{tabular}

\section{Etat II}

\begin{tabular}{|l|c|l|l|l|l|c|c|c|}
\hline \multicolumn{9}{|c|}{ INDIVIDUS (NMI) } \\
\hline Espèces & $\mathrm{A}$ & $\mathrm{J}$ & $\mathrm{Tj}$ & Ind. & $\mathrm{T}$ & $\%$ & P.V. & $\%$ P.V. \\
\hline OVIS & 5 & 1 & & & 6 & & 96 & \\
CAPRA & 1 & 1 & & 1 & 3 & 38,89 & 45 & 10,5 \\
OVIS/CAPRA & 5 & 4 & 3 & & 12 & & 148,5 & \\
PORC & 5 & 4 & 3 & & 12 & 22 & 423 & 15,3 \\
BOEUF & 8 & 1 & & 1 & 10 & 18,5 & 1730 & 62,8 \\
CERF & 1 & 1 & & & 2 & 3,7 & 125 & 4,5 \\
CHEVAL & 1 & & & & 1 & 1,8 & 180 & 6,5 \\
OISEAU G. & & & & 3 & 3 & 5,5 & 4,5 & 0,1 \\
OISEAU & & & & 1 & 1 & 1,8 & & \\
COQUILLAGES & & & & 4 & 4 & 7,4 & & \\
\hline TOTAL & & & & & 54 & & 2752 & \\
\hline
\end{tabular}

\section{Etat III}

\begin{tabular}{|l|c|l|l|l|l|r|r|r|}
\hline \multicolumn{9}{|c|}{ INDIVIDUS (NMI) } \\
\hline Espèces & $\mathrm{A}$ & $\mathrm{J}$ & $\mathrm{Tj}$ & Ind. & $\mathrm{T}$ & $\%$ & P.V. & P.V. P.V. \\
\hline CAPRA & & 2 & & & 2 & & 22 & \\
OVIS/CAPRA & 12 & 3 & 4 & & 19 & 10,9 & 263 & 2,5 \\
PORC & 14 & 14 & 5 & & 33 & 17,1 & 1241 & 11,1 \\
BOEUF & 29 & 22 & 1 & 5 & 57 & 29,6 & 8592 & 77,1 \\
ANE & & & & 1 & 1 & 0,5 & 75 & 0,6 \\
CHIEN & & & & 1 & 1 & 0,5 & 10 & 0,01 \\
CERF & 6 & 5 & & & 11 & 5,7 & 700 & 6,2 \\
SANGLIER & 1 & 3 & & & 4 & 2 & 220 & 1,9 \\
OISEAUX & & & & 5 & 5 & 2,6 & & \\
LAPIN G. & 3 & 1 & 1 & 3 & 8 & 4,1 & 10,5 & 0,09 \\
MULOT? & 2 & 1 & & 3 & 6 & 3,1 & & \\
FOUINE? & & & & 1 & 1 & 0,5 & & \\
DAURADE? & & & & 3 & 3 & 1,5 & 3 & 0,02 \\
COQUILLAGES & & & & 41 & 41 & 21,3 & & \\
\hline TOTAL & & & & 192 & & & 11136,5 & \\
\hline
\end{tabular}

\section{Etat IV}

\begin{tabular}{|l|c|l|l|l|l|c|c|c|}
\hline \multicolumn{9}{|c|}{ INDIVIDUS (NMI) } \\
\hline Espèces & A & J & Tj & Ind. & T & $\%$ & P.V. & $\%$ P.V. \\
\hline CAPRA & & & & 1 & 1 & & 17 & \\
OVIS/CAPRA & 2 & 1 & 1 & & 4 & 25 & 51,5 & 6,04 \\
PORC & 1 & 1 & 2 & & 4 & 20 & 110 & 9,7 \\
BOEUF & 3 & 1 & & & 4 & 20 & 650 & 57,3 \\
CHEVAL & 1 & & & & 1 & 5 & 180 & 15,8 \\
CERF & 1 & 1 & & & 2 & 10 & 125 & 11 \\
COQUILLAGES & & & & 4 & 4 & 20 & & \\
\hline TOTAL & & & & & 20 & & 1133,5 & \\
\hline
\end{tabular}


Les fluctuations des quantités de faune mise au jour pour chaque état archéologique correspondent à des modifications profondes des structures étudiées.

Un établissement agricole (état I) est transformé en une importante huilerie (état II); ces installations oléicoles sont abandonnées et servent de dépotoirs, notamment pour des déchets alimentaires (état III); enfin, soit le domaine est réoccupé partiellement, soit le secteur fouillé devient de plus en plus marginal.

Les individus déterminés pour l'état I sont beaucoup trop peu nombreux pour signifier quoi que ce soit. La présence du cerf dans une station aussi proche de la mer est désormais connue. Il en a été trouvé dans des couches datées du ve s. avant J.-C., dans le site du Mont Garou (Columeau, 1982, p. 131137) près de Sanary dans le Var et L. Jourdan en a déterminé plusieurs dans la faune de la Bourse à Marseille (Jourdan, 1976).

$\mathrm{Au}$ cours de l'état II, alors que l'huilerie fonctionne, le cheptel se compose pour moitié environ de moutons et de chèvres, un quart de porcs, un cinquième de bœufs. Le cerf est toujours présent, mais à peine plus fréquent que le cheval; son apport en viande reste négligeable (autour de $3 \%$ ).

Au cours de l'état III, les cuves à huile, inexploitées, servent de dépotoir pour un grand nombre de restes animaux. Les ossements de moutons et de chèvres deviennent relativement plus rares (près de $15 \%$, soit $30 \%$ de moins que lors de l'état II) le porc reste stationnaire, de même que le cerf. Le fléchissement de la fréquence du mouton et de la chèvre s'est opéré au profit du bœuf, qui représente près de la moitié des individus déterminés. Les vestiges de bœuf mis au jour au cours de la fouille sont, dans une très large mesure, des fragments de membres. Le crâne, le rachis et les côtes ne sont que très faiblement représentés. Le cheval disparaît au cours de cette période, mais l'âne et le chien viennent, à l'inverse, enrichir la liste des espèces déterminées.

Au cours de l'état $I V$, le secteur fouillé prend l'aspect d'un domaine plus ou moins abandonné, ou tout au moins bien amoindri. Le nombre d'individus est très faible -16- mais il est tout de même frappant de remarquer que le bœuf n'a plus la prédominance écrasante qu'il connaissait au cours de la phase précédente.

En poids de viande, la hiérarchisation des espèces est bien moins perturbée d'une période à une autre: le bœuf fournit d'un bout à l'autre de l'occupation du site, l'essentiel de la viande. Cependant le mouton et la chèvre accusent, à ce niveau-là aussi, un très net fléchissement.

Il se peut que la faune de l'état II soit le reflet de l'exploitation moyenne du cheptel dans une villa gallo-romaine, alors que le domaine a pour activité principale la production d'huile d'olive, comme en témoignent les vestiges architecturaux et le matériel mis au jour par les fouilleurs. Puis, plus ou moins brusquement, la production d'huile est laissée de côté, sauf celle nécessaire à une consommation locale. Il convient de refondre l'exploitation du domaine. Les propriétaires se tournent alors vers l'élevage, en augmentant l'espèce la plus rentable, le bœuf. De temps en temps, certains animaux sont abattus à la demande, à l'écart de la maison des maîtres, dans l'ancienne huilerie transformée en communs. Les carcasses sont débitées sur place et les os des membres sont jetés dans les cuves à huile par les écorcheurs, puis recouverts de tuiles pour ne pas rendre cet endroit pestilentiel.

Une telle réadaptation économique revient cher. Elle suppose une certaine quantité de capitaux disponibles, pour acheter du bétail ou, tout au moins les reproducteurs, payer les serviteurs ou acheter les esclaves nécessaires pour soigner ces animaux. La faune de l'état II trahit une certaine aisance, le domaine possède non seulement des moutons et des chèvres, mais aussi des bœufs et des vaches; les propriétaires peuvent mème avoir chassé le cerf. Il est possible qu'ils aient disposé, lorsque cela s'est révélé utile, des capitaux nécessaires pour une telle reconversion.

La faune de l'état III, par sa variété, indique quelle devait être la vie dans un grand domaine du Sud du Var au cours de l'Empire. Le cheval manque, mais la chasse au cerf continue, doublée de celle au sanglier. Mais cette chasse, loin d'être nécessaire au ravitaillement en viande, apparaît plutôt comme le passe-temps des propriétaires. Les animaux qu'ils prennent sont débités au même endroit que les carcasses des animaux domestiques, probablement par les mêmes serviteurs.

La faune de la phase IV peut être rapprochée de cette façon de vivre, mais amoindrie. A moins, plus simplement, que nous n'ayons là que ce qui se trouve en bordure, à la lisière de l'activité, dont le centre se serait déplacé.

Ph. C. 


\title{
V. ÉTUDE DU MATERIEL ANTHRACOLOGIQUE
}

\author{
par Michel THINON*
}

Les charbons de bois récoltés au cours des fouilles de la villa gallo-romaine de Saint-Michel ont été répartis en quatre groupes correspondant aux différentes époques d'occupation du site entre le $\mathrm{I}^{\mathrm{er}} \mathrm{s}$. avant notre ère et le $v^{\mathrm{e}} \mathrm{s}$.

\section{MÉTHODE D'ÉTUDE}

Les charbons de bois sont identifiés à partir de leurs caractères anatomiques qui sont identiques à ceux du bois. L'observation est faite en microscopie épiscopique sur des cassures correspondant aux trois plans ligneux : transversal, longitudinaux radial et tangentiel.

Nous nous bornerons à donner des résultats qualitatifs car nous considérons que les différentes proportions (en poids et surtout en nombre de fragments) des divers taxons parvenus sous le microcospe ne sauraient rendre compte de leur représentation réelle dans la nature à proximité du site. Le choix du combustible et les aléas de la combustion, de la conservation et de la récolte en cours de fouille induisent des distorsions qui rendent illusoire une analyse quantitative significative. Tout au plus, la très nette dominance d'un seul taxon ou d'un groupe de taxons (plus de $50 \%$ en masse) sur une période assez longue et un échantillon suffisant peut-elle suggérer que ceux-ci représentent une fraction relativement importante de la biomasse ligneuse.

\section{TAXONS IDENTIFIÉS}

\section{ÉTAT I}

Quercus sp. à feuillage caduc (Chêne caducifolié) Quercus suber (Chêne liège)

Erica arborea (Bruyère arborescente)

Phillyrea latifolia (Filaria à feuille larges)

Pinus pinea (Pin pignon)

Pinus mesogeensis (Pin mésogéen)

\footnotetext{
* Institut méditerranéen d'Écologie et de Paléoécologie, Faculté St. Jérôme, rue Henri-Poincaré, 13397 Marseille Cedex 13, France.
}

ÉTAT II

Quercus ilex (Chêne vert)

Quercus suber

Vitis vinifera (Vigne)

Pinus pinea

Pinus halepensis (Pin d'Alep)

Juniperus oxycedrus (Genévrier oxycèdre)

Abies alba (Sapin blanc)

E'TAT III

Quercus suber

Ulmus campestris (Orme champêtre)

Erica arborea

Pinus pinea

ÉTAT IV

Quercus suber

Quercus ilex

Quercus sp. à feuillage caduc

Quercus coccifera (Chêne kermès)

Erica arborea

Erica sp.

Cistus salvifolius (Ciste à feuilles de sauge)

Olea europaea (Olivier)

Pinus mesogeensis

Pinus halepensis

Pinus pinea

\section{INTERPRÉTATION PHYTOÉCOLOGIQUE}

L'interprétation du matériel anthracologique du site Saint-Michel s'appuie essentiellement sur les informations écologiques apportées par la présence de chaque taxon identifié.

La végétation actuelle de la plaine de La Garde et de la colline siliceuse du Thouar s'inscrit dans les séries de végétation suivantes : série méditerranéenne du Chêne pubescent et sous-série thermophile du Chêne liège (Loisel, 1976).

\section{État I}

Les espèces identifiées existent encore de nos jours à proximité plus ou moins immédiate du site. Ce sont surtout des espèces arborescentes forestières ou préforestières, plutôt liées à des terrains siliceux. 
Bruyère arborescente et Chêne à feuillage caduc représentent l'essentiel du matériel. Ce dernier taxon, bien qu'il soit très difficile de le différencier anatomiquement, doit sans doute correspondre à Quercus pubescens Willd., le Chêne blanc des Provençaux qui peut de nos jours constituer l'essence principale des formations forestières méditerranéennes caducifoliées, même littorales (série méditerranéenne du Chêne pubescent). L'abondance du Chène et surtout de la Bruyère, espèce héliophile (ainsi que les pins) rejetant bien après la coupe ou le passage du feu évoque des vestiges forestiers largement ouverts par les pratiques agro-pastorales.

\section{État II}

Cette période correspond au développement maximum de l'exploitation et la composition floristique des charbons de bois enregistre quelques modifications. Le Chêne caducifolié disparaît (il présente pourtant un excellent combustible) alors qu'apparaît le Chêne vert. Des charbons de vigne (ceps déformés par la taille) indiquent une activité viticole. Le Pin d'Alep (très abondant) ainsi que le Genévrier oxycèdre apparaissent, ce qui confirme l'existence d'un milieu davantage ouvert avec pratiques pastorales. On notera que les charbons de Chêne vert sont très largement dominants dans la pars urbana, ce qui peut indiquer une sélection de ce combustible de choix pour les bâtiments résidentiels.

La présence du Sapin dans ce contexte très méditerranéen est surprenante mais il correspond à un seul échantillon important (plus de $60 \mathrm{~g}$ ) et localisé dans un remblai du tout début du I $^{\mathrm{e}} \mathrm{s}$. C'est l'époque de l'agrandissement des bâtiments et on peut raisonnablement penser qu'il s'agit des restes carbonisés d'une ancienne charpente édifiée à partir de matériaux importés.

\section{ÉtaT III}

La composition floristique de cet échantillon est assez réduite; l'Orme champêtre existe encore de nos jours dans les zones à sol profond et bien alimentées en eau de la plaine de La Garde.

\section{État IV}

La liste floristique est ici la plus diversifiée. A côté du retour d'une espèce forestière comme le
Chêne à feuillage caduc ou du Pin mésogéen, on observe l'apparition du Chêne kermès et d'un Ciste, espèces de stades de dégradation. Le milieu semble se modifier de manière plus anarchique, avec évolution vers des stades plus fermés coexistant avec des zones encore fortement exploitées.

Il faut noter l'identification d'un seul charbon attribuable à l'Olivier, on peut penser que cet arbre, à cette époque, n'a plus présenté la même valeur et a alors servi de combustible.

D'une façon générale, la végétation est très proche de l'actuelle, les changements floristiques observés dans le spectre anthracologique correspondent à l'intensité et aux divers types des pressions anthropiques exercées sur le milieu. Les études phyto-historiques portant sur la région toulonnaise au sens large sont inexistantes et ces résultats ne peuvent donc être relativisés par une comparaison. Cependant, la disparition des Chênes caducifoliès dans l'état II et leur substitution par le Chène vert est à rapprocher de ce même phénomène, liè à l'action humaine, et mis en évidence 2500 ans plus tôt par des sondages palynologiques réalisés dans la région de Fos-sur-mer (Triat-Laval, 1978). La constance du Pin pignon, espèce aujourd'hui peu répandue, et dans une moindre mesure du Chêne liège pose la question de ressources accessoires comme celles de la récolte des pignons ou du démasclage du liège.

On ne peut manquer de remarquer aussi que la principale activité de l'exploitation à l'état II, l'oléiculture, n'apparaît absolument pas dans les renseignements fournis par les charbons de bois. L'Olivier, arbre longévif, a produit des fruits tout au long de cette période et n'a donc pas été utilisé pour le feu. On ne le retrouve dans les charbons qu'après le déclin de ce type d'exploitation. L'absence dans les résultats anthracologiques d'une espèce pourtant bien représentée dans le milieu illustre les distorsions introduites par ce type d'analyse et rend parfaitement compte des précautions à prendre lors des interprétations.

M. T. 


\section{BIBLIOGRAPHIE}

Akerraz A., Lenoir M.

1981-1982 : Les huileries de Volubilis, Bulletin d'Archéologie marocaine, XIV, p. 69-101.

Agache R.

1978 : La Somme préromaine et romaine, Mémoire de la Socièté des Antiquaires de Picardie, Amiens.

Amann A. H.

1977 : Le matériel archéologique préromain découvert au MontGarou (Sanary, Var), Toulon.

Ambard R.

1955: La villa gallo-romaine de Muscapeù, Tourves, Var, Provence historique, V, 20, p. 103-110.

Amouretti M.-C., Comet G.

1979 : L'olivier en Provence, Aix-en-Provence, Edisud.

Amouretti M.-C., Comet G., Ney C., Paillet J.-L.

1984 : A propos du pressoir à huile : de l'archéologie industrielle à l'histoire, Mélanges de l'École Française de Rome Antiquité, 96,1, p. $379-421$.

Arcelin P.

1979 : La céramique modelée au jer siècle avant J.-C. dans les Bouches-du-Rhône, La vaisselle culinaire autochlone de la conquête à la romanisation (125 avant J.-C. - règne d'Auguste), thèse de $3^{\mathrm{c}}$ cycle, Aix-en-Provence. Dactylographiée.

Arcelin P., Arcelin C.

1973 : La nécropole protohistorique de la Catalane aux Baux de Provence, Revue archéologique de Narbonnaise (RAN), VI, p. 91-195.

1975 : Les sépultures préromaines de Saint-Rèmy de Provence, $R A N$, VIII, p. 67-135.

Arcelin P., Chabot L.

1980 : Les céramiques à vernis noir du village préromain de $\mathrm{La}$ Cloche, Mélanges de l'École Française de Rome Antiquité, 92-1, p. 109-197.

Argoud G.

1973 : Une huilerie à Salamine, in: Anthologie salaminienne, Paris, de Boccard, p. 201-202.

Balland A., Tchernia $\Lambda$., Hallier G.

1966 : Bolsena, scavi della Scuola francese di Roma : pavimento tardo-republicano o proto-augustei, Notizie degli scavi di antichità, p. 52-78.

Barbet A.

1974-1975 : Peintures murales de Mercin et Vaux (Aisne), Étude comparée, Gallia, 32, p. 107-135; - 33, p. 95-115.

Barruol G.

1969 : Les peuples préromains du Sud-Est de la Gaule, $1^{\mathrm{er}}$ suppl. à la $R A N$, Paris, de Boccard.

Becatti G.

1971 : Scavi di Oslia IV. Mosaici e pavimenti marmorei, Rome.
Benoit $\mathbf{J}$.

1985: L'étude des cadastres antiques : à propos d'Olbia de Provence, Documents d'Archéologie méridionale, 8, p. 25-48.

Bérato $\mathbf{J}$.

1984: Évolution de la céramique modelée de la fin de la protohistoire à la période gallo-romaine sur les sites de Taradeau (Var), Annales de la Société des sciences nalurelles et d'archéologie de Toulon et du Var (ASSNATV), p. 217-224.

Bérato J., Borréani M.

1987 : Récentes découvertes archéologiques à La Valette (Var), ASSNATV, p. 41-44.

Bérato J., Borréani M., Brun J.-P., Pasqualini M., Pollino A. 1986 : L'épave des Roches d'Aurelles, in : L'exploitation de la mer, Ve rencontres internationales d'archéologie et d'histoire, Antibes, octobre 1985, Antibes, Association pour la Promotion et la Diffusion des connaissances archéologiques, p. 191-216.

Bérato J. et N., Imbert L., Saliceti P., Tabariès F.

1987 : Les huileries du Ier siècle après J.-C. de la villa de SaintMichel, La Garde, Var, Bulletin archéologique de Provence, p. 11-25.

Bernard P. J.

1788: Mémoire pour servir à l'histoire nalurelle de l'olivier, Marseille.

Blanchet A. (dir), Couissin P., Donnadieu A., Gerin-Ricard H. de.

1932: Forma orbis romani, Carte archéologique de la Gaule romaine, II, Var, Paris, Leroux.

Blanckenhagen P. V., Cotton M. A., Ward-Perkins J. B.

1965: Two roman villas at Francolise, Provincia Caserta, Interim report 1962-1964, Papers of the British School at Rome, 33, p. 237-254.

Bonstetten, Baron de.

1873 : Carte archéologique du Var, Toulon.

Borréani M.

1984 : L'oppidum de Baudouvin-La Bigoye, ASSNATV, p. 8791.

Boyer R., Février P.-A.

1959 : Stations routières de Provence, Revue d'Études ligures, XXV, 3-4, p. 162-183.

1980 : Toulon avant le royaume, in : Agulhon M. (éd.) Histoire de Toulon, Toulouse, Privat.

Braemer F.

1982 : L'ornementation des établissements ruraux en Gaule et dans les régions limitrophes, in: Actes du colloque La villa romaine dans les provinces du Nord-Ouest, Caesarodunum, XVII, p. 53-74.

Brun J.-P.

1982 : Recherches sur les huileries antiques du Var, Thèse de $3^{\mathrm{e}}$ cycle, Aix-en-Provence. Dactylographiée. 
1984 : L'oléiculture antique en Provence d'après les recherches archéologiques récentes, Échos du Monde classique/Classical Views, p. 249-262.

1985 : Recherches récentes sur l'oléiculture antique en Provence : les données archéologiques et leur interprétation in: L'huile d'olive en Méditerranée, colloque du Groupement d'Intèrêt scientifique, 1983, Aix-en-Provence, p. 35-52.

1986 a : L'oléiculture antique en Provence, Les huileries du département du Var, $15^{\mathrm{e}}$ suppl. à la RAN, Paris, Éd. du C.NRS. $1986 \mathrm{~b}$ : La préhistoire et l'antiquité, in: Delplace M. et alii, La Garde en Images-Vingl siècles d'histoire, Ville de La Garde, p. 20-28.

1987: Les huileries, in: Archéologie d'Entremont au Musée Granet, Aix-en-Provence, p. 100-105.

Brun J.-P., Gérard M., Pasqualini M.

1981: La villa gallo-romaine de Saint-Michel à La Garde, Dossiers Histoire el Archéologie, 57, p. 69-70.

Brun J.-P., Congès G., Gébara C., Pasqualini M.

1985 : L'habitat rural dans le Var à l'époque romaine, Provence historique, 141, p. 233-251.

Callot $\mathrm{O}$.

1984 : Huileries antiques de Syrie du Nord, Paris, Geuthner.

Camps-Fabrer $\mathrm{H}$.

1953 : L'olivier el l'huile dans l'Afrique romaine, Alger.

Caprino C.

1944-1945: Guidonia, villa rustica con torcularium, Notizie degli scavi di antichilà, VII, 5-6, p. 39-51.

Carandini A. (dir.) et alii

1986 : Settefinesire, una villa schiavistica nell'Etruria romana, Modène, Panini.

Carandini A., Settis S.

1979: Schiavi e padroni nell'Etruria romana. La villa di Seltefinestre dallo scavo alla mostra, Bari, De Donato.

1981 : Esclaves et maîtres en Elrurie romaine, les fouilles de la villa de Settefinestre, Paris, CNRS/CDSH.

Casanova A.

1978 : Techniques, socièté rurale et idéologie en France à la fin du xvirre siècle, Paris, Les Belles Lettres (coll. Annales de l'Universilé de Besançon).

\section{Caton}

De agricultura, Goujard, R. (éd.), Paris, Les Belles Lettres, 1975.

CDAV 1979 à 1987 : Centre de Documentation archéologique du Var, Travaux du Centre de documentation archéologique du Var, Toulon, ASSNATV, 1979, p. 29-43;-1980, p. 29-41; - 1981, p. $33-54$; - 1982, p. $29-49$; - 1983, p. 190-210; 1984 , p. 197-214; - 1985, p. 203-221;-1986, p. 213-229;1987, p. 193-212.

Chabot L.

1979 : Découverte de fours à pain dans les oppida de La Tène III de la périphérie de l'Étang de Berre, Centre de Coordination des Sociétés archéologiques de Provence, 6, p. 1-17.

Chazelles C.-A. de, Fiches J.-L., Poupet P.

1985 : La Gaule méridionale, p. 61-71, in : Lasfargues J. (dir.), Archilectures de terre el de bois. L'habilat privé des provinces occidentales du monde romain. Antécédents et prolongements : Protohistoire, Moyen Age el quelques expériences contemporaines, Documents d'Archéologie française, (DAF) no 2, Paris, Maison des Sciences de l'Homme.
Christofle $\mathrm{M}$.

1930: Essai de restitution d'un moulin à huile de l'époque romaine à Madaure (Constantine), Alger.

Claustres G.

1958 : Les graffites gallo-romains de Peyrestortes (PyrénéesOrientales), Gallia, p. 41-81.

Columeau P.

1982: Annexe 2, Etude de la faune, in: Arcelin P., ArcelinPradelle C., Gasco Y., Le village protohistorique du Mont Garou, Documents d'Archéologie méridionale, p. 131-137.

Cotton M. A.

1979 : The late republican villa at Posto, Francolise, London, British School at Rome.

Cresswell R.

1965: Un pressoir à olives au Liban, L'Ilomme, livraison de janvier-mars, p. 33-63.

Darton A.

1972 : Sigillée claire B de la Vallée du Rhône, Revue d'Études ligures. XXXVIII, 2, p. 137-189.

De Boe G.

1975: Villa romana in località Posta Crusta, rapporto provisorio sulle campagne di scavo 1972 e 1973, Notizie degli scavi di antichilà, p. 516-530.

Dechelette J.

1904 : Les vases céramiques ornés de la Gaule romaine, Paris.

Deneauve J.

1969 : Lampes de Carthage, Paris, Éd. du CNRS.

Drachmann A. G.

1932 : Ancient oil mills and presses, Kobenhavn.

Dragendorff $\mathrm{H}$.

1895 : Terra sigillata, Bonner Jahrbücher, 96-97, p. 18-155.

Dressel $\mathbf{H}$.

1895: Corpus inscriptionum latinurum, XV, instrumentum domesticum urbis Romae, Berlin.

Faccena D.

1957 : Tivoli, località Granaraccio, resti della parte rustica di una villa, Notizie degli scavi di antichità, p. 206-216.

Fauchier

1805 : Statistique du département du Var, Paris.

Felleti B. M.

1955: Roma, villa rustica, Notizie degli scavi di antichitá, p. 206-216.

Garcin E.

1835 : Dictionnaire hislorique et topographique de la Provence ancienne el moderne, Draguignan, (réed. Nyons, Chantemerle, 1972).

Gascou J., Janon M.

1985: Inscriplions lalines de Narbonnaise, Fréjus, $44^{e}$ suppl. à Gallia, Paris, Éd. du C.NRS.

Gérard M.

1971 : Vestiges d'un établissement gallo-romain à La Garde, ASSNATV, 23, p. 43-69.

Gérard M., Joubert J.

1968: L'antenne toulonnaise du Centre de Documentation archéologique du Var, ASSNATV, 20, p. 22-45.

Ginoux C.

1885 : Notice historique el statistique sur la commune de La 
Garde près de Toulon et sur l'ex-commune de Sainte-Marguerite suivie de promenades archéologiques et artistiques, Toulon, Isnard.

Gnoli R.

1971 : Marmora romana, Roma.

Goudineau C.

1968: La céramique aréline lisse, Paris, de Boccard.

1973 : Informations archéologiques, Gallia, 31, 2, p. 549-570.

1975 : Informations archéologiques, Gallia, 33, 2, p. 559-570.

1977 a : Note sur la céramique commune grise de Vaison-laRomaine, RAN, p. 154-169.

1977 b : Informations archéologiques, Gallia, 35, 2, p. 495-510.

1979 a : Les fouilles de la Maison au Dauphin. Recherches sur la romanisation de Vaison-la-Romaine, $37^{\mathrm{e}}$ suppl. à Gallia, Paris, Éd. du C.NRS.

1979 b : Informations archéologiques, Gallia, 37, 2, p. 553-568.

1981 : Informations archéologiques, Gallia, 39, 2, p. 531-546.

Goujard R. (éd.)

1975 : Caton, De agricullura, Paris, Les Belles Lettres.

Hayes J. W.

1972 : Late roman pottery, Londres.

Hermet F.

1934 : La Graufesenque, Paris, Leroux.

Heron d'Alexandrie

Mécanique, Baron Carra de Vaux (éd.), Journal asiatique, 1893, 9

Héron de Villefosse A.

1899 : Le trésor de Boscoreale. Monuments et mémoires, Fondation E. Piol, V, Paris, Leroux.

Hoffmann B.

1965 : Fssai de datation de la céramique de Banassac, Rei cretariae romanae fautorum acta, VII, p. 39-65.

Humbel X.

1976 : Vieux pressoirs sans frontières, Paris, Guénégaud.

Isings $\mathrm{C}$.

1957 : Roman glass from dated finds, Groningen/Djakarta.

Joncheray J.-P.

1972 : Contribution à l'étude de l'épave du Dramont D, dite des pelvis, Cahiers d'Archéologie subaquatique, 1, p. 11-34.

Jourdan L.

1976 : La faune du sile gallo-romain et paléochrétien de La Bourse à Marseille, Paris, Éd. du CNRS.

Jullian C.

1887: Note de M. Jullian sur les inscriptions latines de Toulon, Bulletin de la Société nationale des Antiquaires de France, p. 163-169.

La Saussaye L. de

1842 : Numismatique de la Gaule Narbonnaise, Paris.

La Tour H. de

1892 : Atlas des monnaies gauloises, Paris.

Lafaye $\mathbf{G}$.

1909 : Inventaire des mosaïques de la Gaule, Paris.

Lamboglia $\mathrm{N}$.

1950 : Gli scavi di Albintimilium e la cronologia della ceramica romana, Bordighera.

1952: Per una classificazione preliminare della ceramica campana, in: Alti del primo congresso di studi liguri, 1950, Bordighera, p. 139-206.

1958, 1963: Nuove osservazioni sulla terra sigillata chiara, Revue d'Études ligures, p. 257-330 et p. 145-212.

Laubenheimer F.

1985 : La production des amphores en Gaule Narbonnaise, Paris, Les Belles Lettres.

Lecacheur P.

1985 : Les dolia de la villa du Grand Loou à La Roquebrussanne, Var, ASSNATV, p. 169-179.

Lequément $\mathbf{R}$.

1985 : L'apport des textes antiques, p. 29-32, in: Lasfargues J. (dir.) Architeclures de terre et de bois. L'habitat privé des provinces occidentales du monde romain. Antécédents el prolongements : Protohistoire, Moyen Age et quelques expériences contemporaines, $D A F, \mathrm{n}^{\circ} 2$, Paris, Maison des Sciences de l'llomme.

Leveau P.

1984: Caesarea de Mauretanie, une ville romaine et ses campagnes, Paris, de Boccard.

Loisel R.

1976 : La végétation de l'ètage méditerranéen dans le Sud-Est continental français, thèse de doctorat d'État, université d'AixMarseille III.

Loussert R., Brousse G.

1978 : L'olivier, Paris, Maisonneuve et Larose.

Lumley H. de, Démians d'Archimbaud G.

1972: L'habitat dans la Grotte de l'Hortus à l'époque paléochrétienne. Fosse à offrandes contenant des restes de deux jeunes marcassins, in: de Lumley II. (dir.), La grotte moustérienne de l'Horlus, Vauflanès, Hérault. Aix-en-Provence, Ed. du CNRS, p. 659-664.

Maillard R.

1981 : L'olivier, Paris, INFULVEC.

Manacorda D.

1981 : Produzione agricola, produzione ceramica e proprietari nell' Ager Cosanus nel I a.C., p. 3-54, in: Giardina A., Schiavone A., Merci, mercali e scambi nel Meditarraneo, Rome/Bari, Laterza.

Marabini-Moeus M. T.

1973: The roman thin walled pollery from Cosa, Rome, American Academy in Rome.

Matijasic R.

1982: Roman Rural Agriculture in the Territory of Colonia Iulia Pola, American Journal of Archaeology, 86, 1, p. 53-64.

Mattingly H. (dir.)

1923... : Coins of the roman empire in the Brilish Museum, London.

Mattingly H., Sydenham E. A. (dir.)

$1923 \ldots$ :.. The roman imperial coinage, London.

\section{Maurin L.}

1964 : Etablissement viticole à Allas les Mines, Dordogne, Gallia, 22, p. 209-221.

Mayet F.

1975 : Les céramiques à parois fines dans la péninsule ibérique, Paris, de Boccard.

Mercando L.

1979: Marche : Rinvenimenti di insediamenti rurali, Notizie degli scavi di anlichilà, p. 89-296. 
Monguilan L.

1981: La douceur de vivre dans le Midi rhodanien, Dossiers Histoire et Archéologie, 58, p. 52-57.

Morel J.-P.

1981: La céramique campanienne: les formes, Rome, École française de Rome.

\section{Oswald F.}

1964a : Index of figures' lypes on terra sigillata, Farnborough (réed).

1964b : Index of potters' stamps on terra sigillata, Farnborough (réed).

\section{Oxé A., Comfort H.}

1968: Corpus vasorum arretinorum, Bonn, R. Habelt Verlag.

Palladius

Opus agricullurae, Martin R. (éd.), Paris, Les Belles Lettres, 1975.

\section{Panella C.}

1973: Le anfore, p. 463-633, in: Carandini A., Panella C., Ostia III, Studi miscellanei, Rome.

\section{Parker A. J.}

1977 : Lusitanian amphorae, p. 35-46, in : Méthodes classiques et méthodes formelles dans l'étude des amphores, Rome, École française de Rome.

Pasqualini M.

1985 : Un atelier de potiers sur la commune de Lorgues (Var), Documents d'Archéologie méridionale, 8, p. 175-180.

Pasqui A.

1897: La villa pompeiana della Pisanella presso Boscoreale, in: Monumenti Antichi, VII, Rome.

Pauly A., Wissowa G.

1893 ... : Real Encyclopädie der Klassischen Altertums Wissenschaft, Stuttgart.

\section{Picon M.}

1973 : Introduction à l'étude lechnique des céramiques sigillées de Lezoux, Dijon, Centre de recherche sur les techniques grécoromaines.

Ponsich M.

1964 : Exploitations agricoles romaines de la région de Tanger, Bulletin d'Archéologie marocaine, 5, p. 235-252.
1974-1979 : Implantation rurale antique sur le Bas-Guadalquivir, Madrid, Casa de Velasquez.

Py $\mathbf{M}$.

1978: L'oppidum des Castels à Nages (Gard), 35e suppl. à Gallia, Paris, Éd. du C.NRS.

\section{Reinach S.}

1892: Peintures murales découvertes dans la nécropole d'Hadrumète, Bullelin du Comité des lravaux historiques et scientifiques, p. 456-460.

\section{Rigoir J.}

1968 : Les sigillées paléochrètiennes grises et orangées, Gallia, p. 177-244.

\section{Ritterling E.}

1913 : Das frührömische Lager bei Hofheim im Taunus Annalen des Vereins f. nassavische Alterlumskunde, XL, Wiesbaden.

\section{Rivet L.}

1980 : Les fouilles du Clos de la Tour à Fréjus (Var): les rues, thèse de $3^{\mathrm{c}}$ cycle, Aix-en-Provence. Dactylographiée.

1982 : La céramique culinaire micacée de la région de Fréjus (Var), $R A N$, p. 243-262.

\section{Soyer J.}

1968: Découverte d'emplacements d'habitats gallo-romains dans la plaine d'Aix, $R A N$, I, p. 201-218.

1973: Les centuriations de Provence (I), RAN, VI, 1973, p. 197-232.

Spinola $\mathrm{O}$.

s.d. : Il museo Marlini di storia dell'enologia, Pessione, Turin.

\section{Tchernia A., Pomey P., Hesnard H.}

1978: L'épave romaine de La Madrague de Giens (Var), $34^{e}$ suppl. à Gallia, Paris, Éd. du C.NRS.

\section{Triat-Laval $\mathbf{H}$.}

1978 : Contribulion polleanalytique a l'histoire tardi- et postglaciaire de la végétalion de la basse vallée du Rhône, thèse de doctorat d'État, université d'Aix-Marseille III.

\section{Vindry G.}

1981 : L'huilerie romaine du Candéou à Peymeinade, Dossiers Histoire el Archéologie, 57, 1981, p. 71-74. 